Identificação de espécies vegetais por meio de análise de imagens microscópicas de folhas

Jarbas Joaci de Mesquita Sá Junior 

SERVIÇO DE PÓS-GRADUAÇÃO DO ICMC-USP

Data de Depósito: 19 de março de 2008

Assinatura:

\title{
Identificação de espécies vegetais por meio de análise de imagens microscópicas de folhas
}

\author{
Jarbas Joaci de Mesquita Sá Junior
}

Orientador: Prof. Dr. Odemir Martinez Bruno

Dissertação apresentada ao Instituto de Ciências Matemáticas e de Computação - ICMC-USP, como parte dos requisitos para obtenção do título de Mestre em Ciências Ciências de Computação e Matemática Computacional. 

Dedico este trabalho aos meus pais Marlene e Mesquita (in memorian), ao meu padastro Hélio e à minha irmã Luciana. 

À Natureza, por ter permitido que um punhado de poeira estelar escrevesse esta dissertação.

À minha mãe Marlene, pela vida, pelas noites de sono perdidas cuidando de mim, pelo amor que muitas vezes não compreendi, e por me incentivar a alcançar os meus sonhos.

Ao meu pai Mesquita (in memorian), pela vida e pelo amor.

Ao meu padrasto Hélio, pelo amor dedicado à minha família, pelos incentivos aos meus projetos e por ser um grande amigo.

À minha irmã Luciana, por ser minha melhor amiga, pelo amor que nos une, e por ter me apoiado de infinitas maneiras para que eu concluísse o mestrado.

Aos meus avós Valderez e Mesquita (in memorian) pelo carinho e presença constante na minha vida.

Aos meus tios e primos, especialmente tias Zulene, Silvana, Doriane e Geovane, pelo carinho e incentivo.

Ao Prof. Dr. Odemir Martinez Bruno, pela orientação, amizade e constante bom humor ao longo deste trabalho.

À Profa. Dra. Rosana Marta Kolb, por fornecer as imagens usadas na elaboração desta dissertação e pela paciência ao responder as minhas dúvidas de biologia vegetal.

Aos meus amigos do INSS de Sobral/CE, especialmente Mano Barreto, Luis Bôto, Assis Fagundes, Jaqueline Mont'Alverne e Wiviane Rocha, por me apoiarem quando resolvi trilhar essa jornada acadêmica.

Aos meus amigos do ICMC-USP, em especial a André Backes, Cláudio Yamamoto, Dalcimar Casanova, Marco Roncatti, João Florindo e Márcio Almeida. Este trabalho foi enriquecido pelo convívio que tive com esses "malucos" que integram o LCAD 2.

Aos funcionários do ICMC-USP, especialmente as funcionárias do serviço de Pós-Graduação, Ana Paula, Elizabeth e Laura, por sempre me tratarem com simpatia e presteza.

Ao CNPq, pelo apoio financeiro. 
Viver é a coisa mais rara do mundo. A maioria das pessoas apenas existe. (Oscar Wilde) 

A taxonomia vegetal atualmente exige um grande esforço dos botânicos, desde o processo de aquisição do espécime até a morosa comparação com as amostras já catalogadas em um herbário. Nesse contexto, o projeto TreeVis surge como uma ferramenta para a identificação de vegetais por meio da análise de atributos foliares. Este trabalho é uma ramificação do projeto TreeVis e tem o objetivo de identificar vegetais por meio da análise do corte transversal de uma folha ampliado por um microscópio. Para tanto, foram extraídas assinaturas da cutícula, epiderme superior, parênquima paliçádico e parênquima lacunoso. Cada assinatura foi avaliada isoladamente por uma rede neural pelo método leave-one-out para verificar a sua capacidade de discriminar as amostras. Uma vez selecionados os vetores de características mais importantes, os mesmos foram combinados de duas maneiras. A primeira abordagem foi a simples concatenação dos vetores selecionados; a segunda, mais elaborada, reduziu a dimensionalidade (três atributos apenas) de algumas das assinaturas componentes antes de fazer a concatenação. Os vetores finais obtidos pelas duas abordagens foram testados com rede neural via leave-one-out para medir a taxa de acertos alcançada pelo sinergismo das assinaturas das diferentes partes da folha. Os experimentos consitiram na identificação de oito espécies diferentes e na identificação da espécie Gochnatia polymorpha nos ambientes Cerrado e Mata Ciliar, nas estações Chuvosa e Seca, e sob condições de Sol e Sombra.

Palavras-chave: taxonomia, cutícula, epiderme superior, parênquima paliçádico, parênquima lacunoso, extração de características, distância de Bhattacharyya e de Jeffrey-Matusita, PCA e redes neurais. 

Currently, taxonomy demands a great effort from the botanists, ranging from the process of acquisition of the sample to the comparison with the species already classified in the herbarium. For this reason, the TreeVis is a project created to identify vegetal species using leaf attributes. This work is a part of the TreeVis project and aims at identifying vegetal species by analysing cross-sections of leaves amplified by a microscope. Signatures were extract from cuticle, adaxial epiderm, palisade parenchyma and sponge parenchyma. Each signature was analysed by a neural network with the leave-one-out method to verify its ability to identify species. Once the most important feature vectors were selected, two different approachs were adopted. The first was a simple concatenation of the selected feature vectors. The second, and more elaborated approach, consisted of reducing the dimensionality (three attributes only) of some component signatures before the feature vector concatenation. The final vectors obtained by these two approaches were tested by a neural network with leave-one-out to measure the correctness rate reached by the synergism of the signatures of different leaf regions. The experiments resulted in the identification of eight different species and the identification of the Gochnatia polymorpha species in Cerradão and Gallery Forest environments, Wet and Dry seasons, and under Sun and Shadow constraints.

Keywords: taxonomy, cuticle, adaxial epiderm, palisade parenchyma, sponge parenchyma, feature extraction, Bhattacharyya and Jeffrey-Matusita distance, PCA e neural networks. 

Resumo vii

$\begin{array}{ll}\text { Abstract } & \text { ix }\end{array}$

1 Introdução 1

1.1 Organização . . . . . . . . . . . . . . . . . . . 3

2 Estrutura Interna de Folhas 5

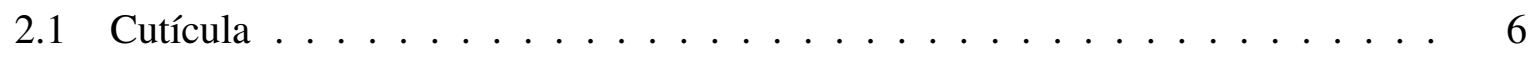

2.2 Epiderme Superior . . . . . . . . . . . . . . . . . 6

2.3 Parênquima Paliçádico . . . . . . . . . . . . . . . 6

2.4 Parênquima Lacunoso . . . . . . . . . . . . . . . . . . . . 7

3 Segmentação de Imagens 9

3.1 Segmentação Baseada em Pixel . . . . . . . . . . . . . . . . . . . . . . . 9

3.2 Segmentação Baseada em Deteç̧ão de Bordas . . . . . . . . . . . . . . . . . . . 10

3.2.1 Detecção de Pontos . . . . . . . . . . . . . . . . . . . . . 10

3.2.2 Detecção de Linhas . . . . . . . . . . . . . . . . . . . . . . . 10

3.2 .3 Detecção de Bordas . . . . . . . . . . . . . . . . . . . . . . 11

3.3 Segmentação Baseada em Regiões . . . . . . . . . . . . . . . . . . . . . . . . . 13

3.3.1 Watershed (Divisor de Águas) . . . . . . . . . . . . . . 13

3.3.2 Algoritmo do Funcional de Mumford-Shah . . . . . . . . . . . . . . 14

4 Extração de Características $\quad 15$

4.1 Coeficientes Tricromáticos . . . . . . . . . . . . . . . . . . 15

4.2 Métodos Estatísticos de Análise de Textura . . . . . . . . . . . . . . . . 16

4.2.1 Características de Primeira Ordem Baseadas em Histograma . . . . . . 16

4.2.2 Características Baseadas em Matrizes de Co-ocorrência . . . . . . . . . 17

4.3 Dimensão Fractal e Complexidade . . . . . . . . . . . . . . . . . . . . . . 19

4.3.1 Métodos para Estimativa da Dimensão Fractal . . . . . . . . . . . . 20

4.3.2 BoxCounting 3D . . . . . . . . . . . . . . 20

4.4 Caminhada Determinística do Turista . . . . . . . . . . . . . . . 23

4.4.1 Caminhada do Turista Modificada . . . . . . . . . . . . . . 24 
5 Pré-processamento dos Dados 27

5.1 Análise de Componentes Principais (PCA) . . . . . . . . . . . . . . . 27

5.2 Distância de Bhattacharyya e de Jeffrey-Matusita . . . . . . . . . . . . . . . . 29

6 Processo de Classificação $\quad 31$

6.1 Redes Neurais Artificiais (RNA) _. . . . . . . . . . . . . . . . . . 31

6.1 .1 Perceptron Multicamadas (MLP) . . . . . . . . . . . . . 33

6.2 Validação Cruzada . . . . . . . . . . . . . . . . . . . . 34

6.2 .1 Hold Out . . . . . . . . . . . . . . . . . . . . 35

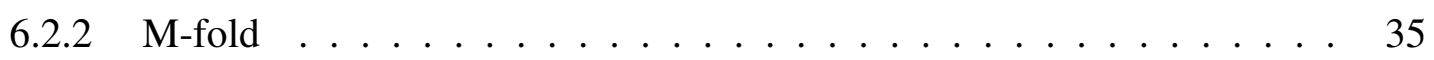

6.2 .3 Leave-one-out . . . . . . . . . . . . . . . 35

7 Procedimentos Experimentais $\quad 37$

7.1 Preparação das Amostras . . . . . . . . . . . . . . . . . . . . . . . 37

7.2 Parâmetros de Rede Neural . . . . . . . . . . . . . . . . . . . . . . . . 38

7.3 Medida de Espessura da Cutícula . . . . . . . . . . . . . . . . . . . 39

7.4 Experimentos na Epiderme Superior . . . . . . . . . . . . . . . . . . . . 40

7.4.1 Medida de Espessura . . . . . . . . . . . . . . . . . 40

7.4.2 Coeficientes Tricromáticos . . . . . . . . . . . . . . 43

7.4.3 Estatísticas de Primeira Ordem . . . . . . . . . . . . . . . 43

7.4.4 Matrizes de Co-ocorrência . . . . . . . . . . . . . . . . . 44

7.4.5 BoxCounting 3D . . . . . . . . . . . . . . . 45

7.5 Experimentos no Parênquima Paliçádico . . . . . . . . . . . . . . 45

7.5.1 Coeficientes Tricromáticos . . . . . . . . . . . . . . . . 46

7.5.2 Estatísticas de Primeira Ordem . . . . . . . . . . . . . . . . 46

7.5.3 Matrizes de Co-ocorrência . . . . . . . . . . . . . . . 46

7.5 .4 BoxCounting 3D . . . . . . . . . . . . . 46

7.5.5 Caminhada Determinística do Turista . . . . . . . . . . . . . 47

7.6 Experimentos no Parênquima Lacunoso . . . . . . . . . . . . . . . . . . 47

7.6.1 Estatísticas de Primeira Ordem . . . . . . . . . . . . . . . . . . . . 48

7.6.2 Matrizes de Co-ocorrência . . . . . . . . . . . . . . . . . . 48

7.6 .3 BoxCounting 3D . . . . . . . . . . . . . . . . . 48

7.6.4 Caminhada Determinística do Turista . . . . . . . . . . . . . . 48

7.7 Medida de Espessura do Corte Transversal . . . . . . . . . . . . . . . . . . . 48

7.8 Montagem do Vetor de Características . . . . . . . . . . . . . . . . . . . . . 49

8 Resultados $\quad 51$

8.1 Espécies Diversas . . . . . . . . . . . . . . . . . 51

8.1.1 Medida de Espessura da Cutícula . . . . . . . . . . . . . . . . . 52

8.1.2 Resultados Experimentais da Epiderme Superior . . . . . . . . . . . . 52

8.1.3 Resultados Experimentais do Parênquima Paliçádico . . . . . . . . . . 54

8.1.4 Resultados Experimentais do Parênquima Lacunoso . . . . . . . . . . 56

8.1.5 Medida de Espessura do Corte Transversal . . . . . . . . . . . . . 58

8.1.6 Montagem do Vetor de Características . . . . . . . . . . . . . . . . . . 58

8.1 .7 Resultados e Discussão . . . . . . . . . . . . . . . . . . . . . . 59

8.2 Espécie Gochnatia polymorpha (Cerrado e Mata Ciliar) . . . . . . . . . . . . 64

8.2.1 Medida de Espessura da Cutícula . . . . . . . . . . . . . . . . . 64

8.2.2 Medida de Espessura da Epiderme Superior . . . . . . . . . . . . . . . . 64

8.2.3 Resultados Experimentais do Parênquima Paliçádico . . . . . . . . . . 65 
8.2.4 Resultados Experimentais do Parênquima Lacunoso . . . . . . . . . . 66

8.2.5 Medida de Espessura do Corte Transversal . . . . . . . . . . . . . . . . 66

8.2.6 Montagem do Vetor de Características . . . . . . . . . . . . . . . . . . . 67

8.2.7 Resultados e Discussão . . . . . . . . . . . . . . . . . . . . . 68

8.3 Espécie Gochnatia polymorpha (Chuva e Seca) . . . . . . . . . . . . . 71

8.3.1 Medida de Espessura da Cutícula . . . . . . . . . . . . . . 71

8.3.2 Medida de Espessura da Epiderme Superior . . . . . . . . . . . . . . 71

8.3.3 Resultados Experimentais do Parênquima Paliçádico . . . . . . . . . . . 72

8.3.4 Resultados Experimentais do Parênquima Lacunoso . . . . . . . . . . 73

8.3.5 Medida de Espessura do Corte Transversal . . . . . . . . . . . . . . 73

8.3.6 Montagem do Vetor de Características . . . . . . . . . . . . . . . . . 74

8.3.7 Resultados e Discussão . . . . . . . . . . . . . . . . . . . . . . . 75

8.4 Espécie Gochnatia polymorpha (Sol e Sombra) . . . . . . . . . . . . . . . 78

8.4.1 Medida de Espessura da Cutícula . . . . . . . . . . . . . . 78

8.4.2 Medida de Espessura da Epiderme Superior . . . . . . . . . . . . . . . 78

8.4.3 Resultados Experimentais do Parênquima Paliçádico . . . . . . . . . . 79

8.4.4 Resultados Experimentais do Parênquima Lacunoso . . . . . . . . . . . . 80

8.4.5 Medida de Espessura do Corte Transversal . . . . . . . . . . . . . . . . . 80

8.4.6 Montagem do Vetor de Características . . . . . . . . . . . . . . . . . . 81

8.4.7 Resultados e Discussão . . . . . . . . . . . . . . . . . 82

9 Conclusão $\quad \mathbf{8 5}$

9.1 Contribuições . . . . . . . . . . . . . . . . . . . 86

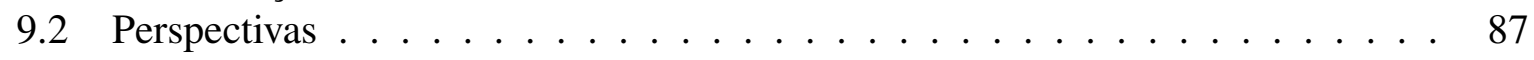



1.1 Ambiente de trabalho do TreeVis, apresentando algumas propriedades extraídas da amostra da folha completa. . . . . . . . . . . . . . . 2

2.1 Corte transversal da folha de Gochnatia polymorpha: a - Cutícula, b - Epiderme Superior, c - Parênquima Paliçádico, d - Parênquima Lacunoso . . . . . . . . . 5

3.1 Máscara usada na detecção de pontos isolados. . . . . . . . . . . . . . . . 10

3.2 Máscara usada na detecção de linhas: (a) - linhas horizontais, (b) - linhas inclinadas em $45^{\circ}$, (c) - linhas verticais, (d) - linhas inclinadas em $-45^{\circ} \ldots \ldots 11$

3.3 Operadores de Sobel: (a) - gradiente na direção $x$, (b) - gradiente na direção $y$. 12

3.4 Máscara usada para computar o Laplaciano. . . . . . . . . . . . . . . . . . 12

4.1 Texturas geradas sinteticamente (Chen et al., 1998) . . . . . . . . . . . . 16

4.2 Divisão de uma imagem pelo método BoxCounting (Backes, 2006) . . . . . . . 20

4.3 Cálculo do coeficiente angular no BoxCounting . . . . . . . . . . . 21

4.4 Cubos de dimensões 3x3x3 sobrepostos a uma imagem (Xu \& Weng, 2006) . . 22

4.5 Gráficos da curva log-log gerada pelo método BoxCounting 3D e respectiva curva de Dimensão Fractal MultiEscala. . . . . . . . . . . . . . . . . . . 22

4.6 Exemplo da caminhada do turista em um mapa randômico bidimensional (Campiteli et al., 2006a). . . . . . . . . . . . . . . . . . 24

4.7 Mapas de distribuição de seis diferentes texturas de Brodatz para o valor de memória $\mu=7$ (Campiteli et al., 2006a). . . . . . . . . . . 25

5.1 Representação gráfica da transformação PCA em duas dimensões. . . . . . . . . 28

6.1 Modelo de neurônio. . . . . . . . . . . . . . . . . . . . . . 32

6.2 Arquitetura gráfica de uma MLP com duas camadas escondidas. . . . . . . . . 33

7.1 Esquema de como as imagens de uma espécie foram adquiridas . . . . . . . . . 38

7.2 Cutícula e respectiva segmentação numa amostra da espécie Byrsonima intermedia. . . . . . . . . . . . . . . . . . 39

7.3 Bordas das cutículas das amostras da espécie Miconia chamissois. . . . . . . . 40

7.4 Imagens de epiderme superior. a - Imagem original; b - Imagem segmentada selecionada na primeira fase de segmentação; c - Imagem segmentada selecionada na segunda fase de segmentação. . . . . . . . . . . . . . . . . . 
7.5 Exemplo de semelhança entre a epiderme superior e o parênquima paliçádico da amostra da espécie Jacaranda caroba. . . . . . . . . . . . . . . . . . . . .

7.6 Imagens de epiderme superior de Vochysia tucanorum. a - Imagem original; b Imagem segmentada selecionada na primeira fase de segmentação. . . . . . . . 42

7.7 Espessuras das epidermes superiores das amostras da espécie Vochysia tucanorum. 43

7.8 Janelas retiradas automaticamente e que contêm a epiderme superior das espécies: a - Byrsonima intermedia, b - Miconia albicans, c - Tibouchina stenocarpa, d - Vochysia tucanorum, e - Xylopia aromatica, $\mathrm{f}$ - Gochnatia polymorpha, g - Miconia chamissois, h - Jacaranda caroba. . . . . . . . . . . . . .

7.9 Exemplos de janelas 300x300 como grid de epiderme superior das amostras: a - espécie Byrsonima intermedia, b - espécie Miconia albicans, c - espécie Tibouchina stenocarpa. . . . . . . . . . . . . . . . . . . . .

7.10 Amostra de Tibouchina stenocarpa e respectiva janela $60 x 60$ do parênquima paliçádico . . . . . . . . . . . . . . . . . .

7.11 Janelas $60 x 60$ retiradas do parênquima paliçádico das espécies: a - Byrsonima intermedia, b - Miconia albicans, c - Tibouchina stenocarpa, d - Vochysia tucanorum, e - Xylopia aromatica.

7.12 Amostra de Byrsonima intermedia e respectivo grid $1 \times 1$ de janela $150 x 150$ do parênquima lacunoso . . . . . . . . . . . . . . . . .

7.13 Exemplos de janelas 150x150 no método BoxCounting 3D: a - grid $1 \times 1$ de janela $150 x 150$ da espécie Vochysia tucanorum, b - grid $2 x 2$ de janelas $75 x 75$ da espécie Xylopia aromatica, c - grid $3 \times 3$ de janelas $50 x 50$ da espécie Jacaranda caroba.

7.14 Imagens do corte transversal da espécie Miconia chamissois. a - Imagem original; b - Imagem segmentada. . . . . . . . . . . . . . . . . . . . . . . . . 49

7.15 Esquema da montagem do vetor de características por concatenação simples. . $\quad 50$

7.16 Esquema da montagem do vetor de características com o auxílio do método PCA. 50

8.1 Cortes transversais das folhas das espécies: A - Byrsonima intermedia, B Miconia albicans, C - Tibouchina stenocarpa, D - Vochysia tucanorum, E Xylopia aromatica, F - Gochnatia polymorpha, G - Miconia chamissois e H Jacaranda caroba.

8.2 Esquema da montagem do vetor de características por concatenação simples. Siglas: Esp - espessura; His - estatística de $1^{a}$ ordem; Cor - coeficientes tricromáticos; Coo - matrizes de co-ocorrência; Box - BoxCounting 3D. . . . . . . .

8.3 Esquema da montagem do vetor de características com o auxílio do método PCA. Siglas: Esp - espessura; His - estatística de $1^{a}$ ordem; Cor - coeficientes tricromáticos; Coo - matrizes de co-ocorrência; Box - BoxCounting 3D. . . . .

8.4 Visualização 2D (PCA - dois primeiros componentes principais) do vetor final obtido por concatenação simples (com seleção por distância de JeffreyMatusita) dos vetores componentes.

8.5 Visualização 2D (PCA - dois primeiros componentes principais) do vetor final obtido por aplicação do método PCA nos vetores componentes cujas dimensionalidades são maiores que três . . . . . . . . . . . . . . . .

8.6 Cortes transversais das folhas da espécie Gochnatia polymorpha nos ambientes: A - Cerrado, B - Mata Ciliar. . . . . . . . . . . . . . . . . . . .

8.7 Esquema da montagem do vetor de características por concatenação simples. Siglas: Esp - espessura; Coo - matrizes de co-ocorrência. . . . . . . . . . . . . 
8.8 Esquema da montagem do vetor de características com o auxílio do método PCA. Siglas: Esp - espessura; Coo - matrizes de co-ocorrência. . . . . . . . . . . 68

8.9 Visualização 2D (PCA - dois primeiros componentes principais) do vetor final obtido por concatenação simples (com seleção por distância de JeffreyMatusita) dos vetores componentes. . . . . . . . . . . . . . .

8.10 Visualização 2D (PCA - dois primeiros componentes principais) do vetor final obtido por aplicação do método PCA nos vetores componentes cujas dimensionalidades são maiores que três . . . . . . . . . . . . . . . .

8.11 Cortes transversais das folhas da espécie Gochnatia polymorpha nas estações: A - Chuvosa, B - Seca . . . . . . . . . . . . . . . . . . .

8.12 Esquema da montagem do vetor de características por concatenação simples. Siglas: Esp - espessura; Cor - coeficientes tricromáticos; His - estatística de $1^{a}$ ordem; Coo - matrizes de co-ocorrência. . . . . . . . . . . . . . . . . .

8.13 Esquema da montagem do vetor de características com o auxílio do método PCA. Siglas: Esp - espessura; Cor - coeficientes tricromáticos; His - estatística de $1^{a}$ ordem; Coo - matrizes de co-ocorrência. . . . . . . . . . . . . . . . .

8.14 Visualização 2D (PCA - dois primeiros componentes principais) do vetor final obtido por concatenação simples (com seleção por distância de JeffreyMatusita) dos vetores componentes. . . . . . . . . . . . . . . . .

8.15 Visualização 2D (PCA - dois primeiros componentes principais) do vetor final obtido por aplicação do método PCA nos vetores componentes cujas dimensionalidades são maiores que três . . . . . . . . . . . . . . . . . .

8.16 Cortes transversais das folhas da espécie Gochnatia polymorpha sob condições de: A - Sol, B - Sombra.

8.17 Esquema da montagem do vetor de características por concatenação simples. Siglas: Esp - espessura; Cor - coeficientes tricromáticos; His - estatística de $1^{a}$ ordem; Coo - matrizes de co-ocorrência. . . . . . . . . . . . . . . . .

8.18 Esquema da montagem do vetor de características com o auxílio do método PCA. Siglas: Esp - espessura; Cor - coeficientes tricromáticos; His - estatística de $1^{a}$ ordem; Coo - matrizes de co-ocorrência. . . . . . . . . . . . . . . .

8.19 Visualização 2D (PCA - dois primeiros componentes principais) do vetor final obtido por concatenação simples (com seleção por distância de JeffreyMatusita) dos vetores componentes.

8.20 Visualização 2D (PCA - dois primeiros componentes principais) do vetor final obtido por aplicação do método PCA nos vetores componentes cujas dimensionalidades são maiores que três . . . . . . . . . . . . . . . . . 



\section{Lista de Tabelas}

8.1 Médias e desvios padrão das espessuras de cutícula. . . . . . . . . . . . . . . 52

8.2 Matriz de confusão média obtida por validação cruzada leave-one-out $(m=80)$ das medidas de espessura de cutícula. . . . . . . . . . . . . . . 52

8.3 Médias e desvios padrão das espessuras de epiderme superior. . . . . . . . . . 52

8.4 Matriz de confusão média obtida por redes neurais via leave-one-out $(m=80)$ das medidas de espessura da epiderme superior. . . . . . . . . . . . . . 53

8.5 Matriz de confusão média obtida por validação cruzada leave-one-out $(m=80)$ dos coeficientes tricromáticos da epiderme superior. . . . . . . . . . . . . 53

8.6 Matriz de confusão média obtida por RNA via leave-one-out $(m=80)$ de estatísticas de primeira ordem aplicadas na janelas formadas pela epiderme superior. 53

8.7 Matriz de confusão média obtida por RNA via leave-one-out $(m=80)$ de matrizes de co-ocorrência aplicadas na janelas formadas pela epiderme superior. $\quad 54$

8.8 Matriz de confusão média obtida por RNA via leave-one-out $(m=80)$ do método BoxCounting 3D aplicado nas janelas formadas pela epiderme superior. $\quad 54$

8.9 Matriz de confusão média obtida por validação cruzada leave-one-out $(m=80)$ dos coeficientes tricromáticos do parênquima paliçádico. . . . . . . . . . . 54

8.10 Matriz de confusão média obtida por RNA via leave-one-out $(m=80)$ das estatísticas de primeira ordem do parênquima paliçádico. . . . . . . . . . . 55

8.11 Matriz de confusão média obtida por RNA via leave-one-out $(m=80)$ das matrizes de co-ocorrência do parênquima paliçádico. . . . . . . . . . . 55

8.12 Matriz de confusão média obtida por RNA via leave-one-out $(m=80)$ do método BoxCounting 3D no parênquima paliçádico. . . . . . . . . . . . . 56

8.13 Matriz de confusão média obtida por validação cruzada leave-one-out ( $m=80)$ da caminhada determinística do turista no parênquima paliçádico. . . . . . . . 56

8.14 Matriz de confusão média obtida por RNA via leave-one-out $(m=80)$ das estatísticas de primeira ordem aplicadas no parênquima lacunoso. . . . . . . . 56

8.15 Matriz de confusão média obtida por RNA via leave-one-out $(m=80)$ das matrizes de co-ocorrência aplicadas no parênquima lacunoso. . . . . . . . . . . 57

8.16 Matriz de confusão média obtida por RNA via leave-one-out $(m=80)$ do método BoxCounting 3D aplicado no parênquima lacunoso. . . . . . . . . .

8.17 Matriz de confusão média obtida por RNA via leave-one-out $(m=80)$ da caminhada determinística do turista no parênquima lacunoso. . . . . . . . . . 58

8.18 Médias e desvios padrão das espessuras de corte transversal de todas as espécies. 58

8.19 Matriz de confusão média obtida por validação cruzada leave-one-out $(m=80)$ das medidas de espessura dos cortes transversais. . . . . . . . . . . . . 58 
8.20 Matriz de confusão média obtida por validação cruzada leave-one-out ( $m=80)$ do vetor final obtido por simples concatenação (com seleção por distância de Jeffrey-Matusita) dos vetores componentes. . . . . . . . . . . . . . . . .

8.21 Matriz de confusão média obtida por validação cruzada leave-one-out $(m=80)$ do vetor final obtido por simples contatenação (sem seleção de características) dos vetores componentes. . . . . . . . . . . . . . . . . . .

8.22 Matriz de confusão média obtida por validação cruzada leave-one-out $(m=80)$ do vetor final obtido por aplicação do método PCA nos vetores componentes cujas dimensionalidades são maiores que três. . . . . . . . . . . . . . .

8.23 Médias e desvios padrão das espessuras de cutícula das amostras de Gochnatia polymorpha nos ambientes Cerrado e Mata Ciliar. . . . . . . . . . . . . . . .

8.24 Performance de identificação por RNA via leave-one-out $(m=30)$ das medidas de espessura de cutícula das amostras de Gochnatia polymorpha nos ambientes Cerrado e Mata Ciliar. . . . . . . . . . . . . . . . . . . . . . . . . . .

8.25 Médias e desvios padrão das espessuras de epiderme superior das amostras de Gochnatia polymorpha nos ambientes Cerrado e Mata Ciliar. . . . . . . . . .

8.26 Performance de identificação por RNA via leave-one-out $(m=30)$ das medidas de espessura de epiderme superior das amostras de Gochnatia polymorpha nos ambientes Cerrado e Mata Ciliar. . . . . . . . . . . . . . . . . . . . .

8.27 Performance de identificação por RNA via leave-one-out $(m=30)$ dos coeficientes tricromáticos das amostras de Gochnatia polymorpha nos ambientes Cerrado e Mata Ciliar. . . . . . . . . . . . . . . . . . . . . . . . . . .

8.28 Performance de identificação por RNA via leave-one-out $(m=30)$ das matrizes de co-ocorrência das amostras de Gochnatia polymorpha nos ambientes Cerrado e Mata Ciliar. . . . . . . . . . . . . . . . . . . . . . . . . . . . . .

8.29 Performance de identificação por RNA via leave-one-out $(m=30)$ de estatísticas de primeira ordem no parênquima lacunoso das amostras de Gochnatia polymorpha nos ambientes Cerrado e Mata Ciliar.

8.30 Performance de identificação por RNA via leave-one-out $(m=30)$ das matrizes de co-ocorrência no parênquima lacunoso das amostras de Gochnatia polymorpha nos ambientes Cerrado e Mata Ciliar. . . . . . . . . . . . . . . .

8.31 Médias e desvios padrão das espessuras do corte transversal das amostras de Gochnatia polymorpha nos ambientes Cerrado e Mata Ciliar. . . . . . . . . .

8.32 Performance de identificação por RNA via leave-one-out $(m=30)$ das medidas de espessura dos cortes transversais das amostras de Gochnatia polymorpha nos ambientes Cerrado e Mata Ciliar. . . . . . . . . . . . . . . . . . . . . .

8.33 Performance de identificação média obtida por validação cruzada leave-oneout ( $m=30)$ do vetor final obtido por simples concatenação (com seleção por distância de Jeffrey-Matusita) dos vetores componentes. . . . . . . . . . . . . .

8.34 Performance de identificação obtida por validação cruzada leave-one-out ( $m=$ 30) do vetor final obtido por aplicação do método PCA nos vetores componentes cujas dimensionalidades são maiores que três. . . . . . . . . . . . . .

8.35 Médias e desvios padrão das espessuras de cutícula das amostras de Gochnatia polymorpha nas estações Chuvosa e Seca. . . . . . . . . . . . . . . .

8.36 Performance de identificação por RNA via leave-one-out $(m=30)$ das medidas de espessura de cutícula das amostras de Gochnatia polymorpha nas estações Chuvosa e Seca. . . . . . . . . . . . . . . . . . . . . 
8.37 Médias e desvios padrão das espessuras de epiderme superior das amostras de Gochnatia polymorpha nas estações Chuvosa e Seca. . . . . . . . . . . . . . .

8.38 Performance de identificação por RNA via leave-one-out $(m=30)$ das medidas de espessura de epiderme superior das amostras de Gochnatia polymorpha nas estações Chuvosa e Seca. . . . . . . . . . . . . . . . . . .

8.39 Performance de identificação por RNA via leave-one-out $(m=30)$ dos coeficientes tricromáticos das amostras de Gochnatia polymorpha nas estações Chuvosa e Seca. . . . . . . . . . . . . . . . . . . . . . . . . . .

8.40 Performance de identificação por RNA via leave-one-out $(m=30)$ das matrizes de co-ocorrência das amostras de Gochnatia polymorpha nas estações Chuvosa e Seca . . . . . . . . . . . . . . . . . . . . . . . .

8.41 Performance de identificação por RNA via leave-one-out $(m=30)$ de estatísticas de primeira ordem no parênquima lacunoso das amostras de Gochnatia polymorpha nas estações Chuvosa e Seca. . . . . . . . . . . . . . . . . . . .

8.42 Performance de identificação por RNA via leave-one-out $(m=30)$ das matrizes de co-ocorrência no parênquima lacunoso das amostras de Gochnatia polymorpha nas estações Chuvosa e Seca.

8.43 Médias e desvios padrão das espessuras do corte transversal das amostras de Gochnatia polymorpha nas estações Chuvosa e Seca.

8.44 Performance de identificação por RNA via leave-one-out $(m=30)$ das medidas de espessura dos cortes transversais das amostras de Gochnatia polymorpha nas estações Chuvosa e Seca. . . . . . . . . . . . . . . . . . . . . .

8.45 Performance de identificação média obtida por validação cruzada leave-oneout $(m=30)$ do vetor final obtido por simples concatenação (com seleção por distância de Jeffrey-Matusita) dos vetores componentes. . . . . . . . . . . . .

8.46 Performance de identificação obtida por validação cruzada leave-one-out ( $m=$ 30) do vetor final obtido por aplicação do método PCA nos vetores componentes cujas dimensionalidades são maiores que três. . . . . . . . . . . . . . . . . . .

8.47 Médias e desvios padrão das espessuras de cutícula das amostras de Gochnatia polymorpha sob condições de Sol e Sombra.

8.48 Performance de identificação por RNA via leave-one-out $(m=30)$ das medidas de espessura de cutícula das amostras de Gochnatia polymorpha sob condições de Sol e Sombra.

8.49 Médias e desvios padrão das espessuras de epiderme superior das amostras de Gochnatia polymorpha sob condições de Sol e Sombra. . . . . . . . . . . . . . .

8.50 Performance de identificação por RNA via leave-one-out $(m=30)$ das medidas de espessura de epiderme superior das amostras de Gochnatia polymorpha sob condições de Sol e Sombra. . . . . . . . . . . . . . . . . . . . . . . . . .

8.51 Performance de identificação por RNA via leave-one-out $(m=30)$ dos coeficientes tricromáticos das amostras de Gochnatia polymorpha sob condições de Sol e Sombra. . . . . . . . . . . . . . . . . . . . . . . . . . .

8.52 Performance de identificação por RNA via leave-one-out $(m=30)$ das matrizes de co-ocorrência das amostras de Gochnatia polymorpha sob condições de Sol e Sombra.

8.53 Performance de identificação por RNA via leave-one-out $(m=30)$ de estatísticas de primeira ordem no parênquima lacunoso das amostras de Gochnatia polymorpha sob condições de Sol e Sombra. 
8.54 Performance de identificação por RNA via leave-one-out $(m=30)$ das matrizes de co-ocorrência no parênquima lacunoso das amostras de Gochnatia polymorpha sob condições de Sol e Sombra. . . . . . . . . . . . . . . . . . . . . 80

8.55 Médias e desvios padrão das espessuras do corte transversal das amostras de Gochnatia polymorpha sob condições de Sol e Sombra. . . . . . . . . . . . . . 81

8.56 Performance de identificação por RNA via leave-one-out $(m=30)$ das medidas de espessura dos cortes transversais das amostras de Gochnatia polymorpha sob condições de Sol e Sombra. . . . . . . . . . . . . . . . . . . . . .

8.57 Performance de identificação média obtida por validação cruzada leave-one-
out $(m=30)$ do vetor final obtido por simples concatenação (com seleção por distância de Jeffrey-Matusita) dos vetores componentes. . . . . . . . . . . . . .

8.58 Performance de identificação obtida por validação cruzada leave-one-out ( $m=$ 30) do vetor final obtido por aplicação do método PCA nos vetores componentes cujas dimensionalidades são maiores que três. . . . . . . . . . . . . . 


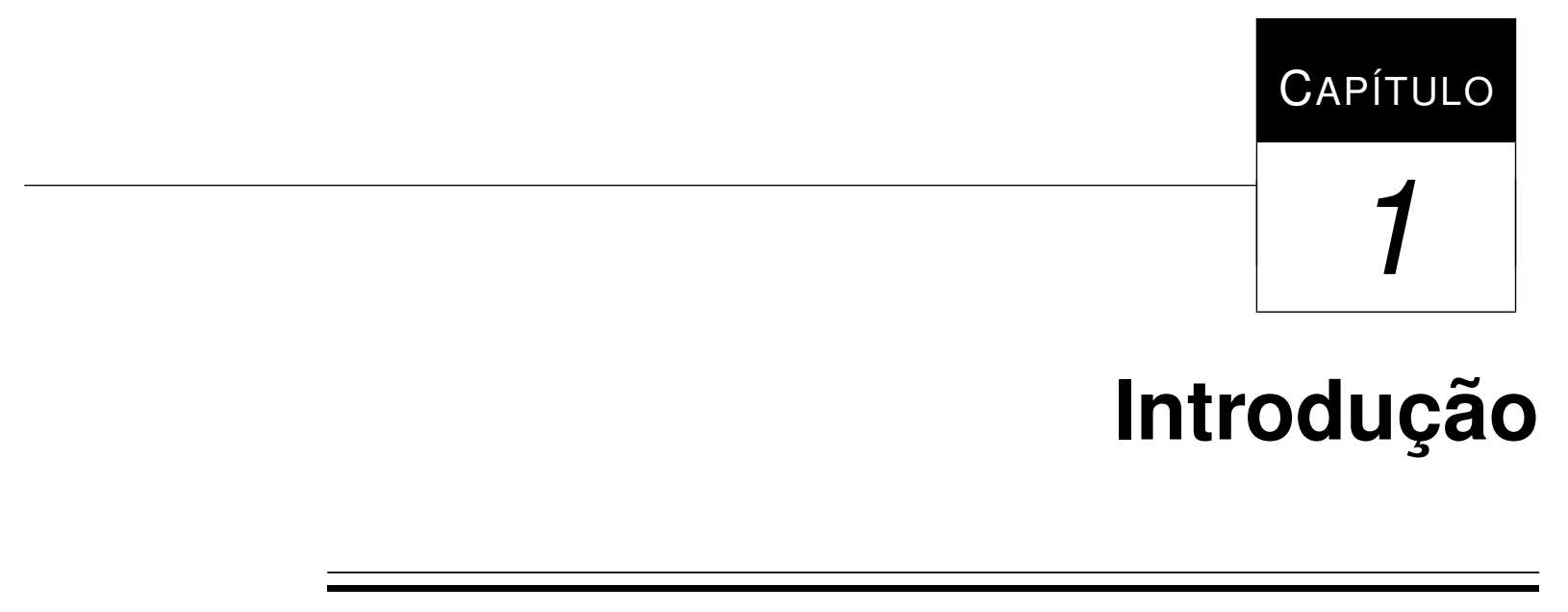

Atualmente, na taxonomia vegetal, a identificação e reconstrução de relações entre as plantas é baseada amplamente em características dos orgãos reprodutivos (Ash et al., 1999). Os ramos férteis (galhos com folhas, podendo possuir flores ou frutos característicos) são coletados na natureza, prensados, dessecados e montados sobre papel cartão. A seguir, eles são comparados com uma coleção científica presente num herbário, por meio da qual é possível estudar espécies procedentes de diferentes locais e ecossistemas (Fidalgo \& Bononi, 1989).

Não obstante os herbários apresentarem bons resultados, alguns problemas ainda permanecem. O primeiro deles é que as flores e os frutos nem sempre estão disponíveis para estudo, o que dificulta a identificação dos materiais coletados (Stace, 1989). Além disso, o processo de identificação das espécies ainda é realizado manualmente e, para realizar tal tarefa, há a necessidade de profissionais com grandes conhecimentos e habilidades na área de taxonomia, o que torna a atividade trabalhosa. Outro ponto desfavorável nessa tarefa ocorre pela perda de propriedades importantes dos materiais após a herborização, tais como: coloração, textura, brilho, geometria, entre outras.

Nesse contexto, surgiu a proposta do projeto TreeVis (Bruno, 2000), nome derivado da junção das palavras (Tree Vision System). Iniciado no Instituto de Ciências Matemáticas e de Computação (ICMC - USP), o projeto tem como objetivo o estudo e desenvolvimento de métodos de sistemas de visão artificial voltados para a extração e análise de medidas biométricas de estruturas foliares. O uso de métodos de visão computacional e modelos matemáticos permite o desenvolvimento de técnicas de aferição e extração de informações, contribuindo para uma análise mais criteriosa da morfologia, anatomia e até mesmo da fisiologia do vegetal. Em 
contrapartida, o estudo dos atributos visuais das folhas é um problema complexo e auxilia no aprimoramento dos métodos matemáticos utilizados no sistema de visão.

O projeto TreeVis propõe o desenvolvimento de herbários digitais inteligentes, sistemas biotecnológicos para controle de pragas ou gerenciamento de nutrientes e laboratórios de análise morfofisiológica, que poderão ser utilizados como ferramentas de pesquisa em botânica, fisiologia e evolução.

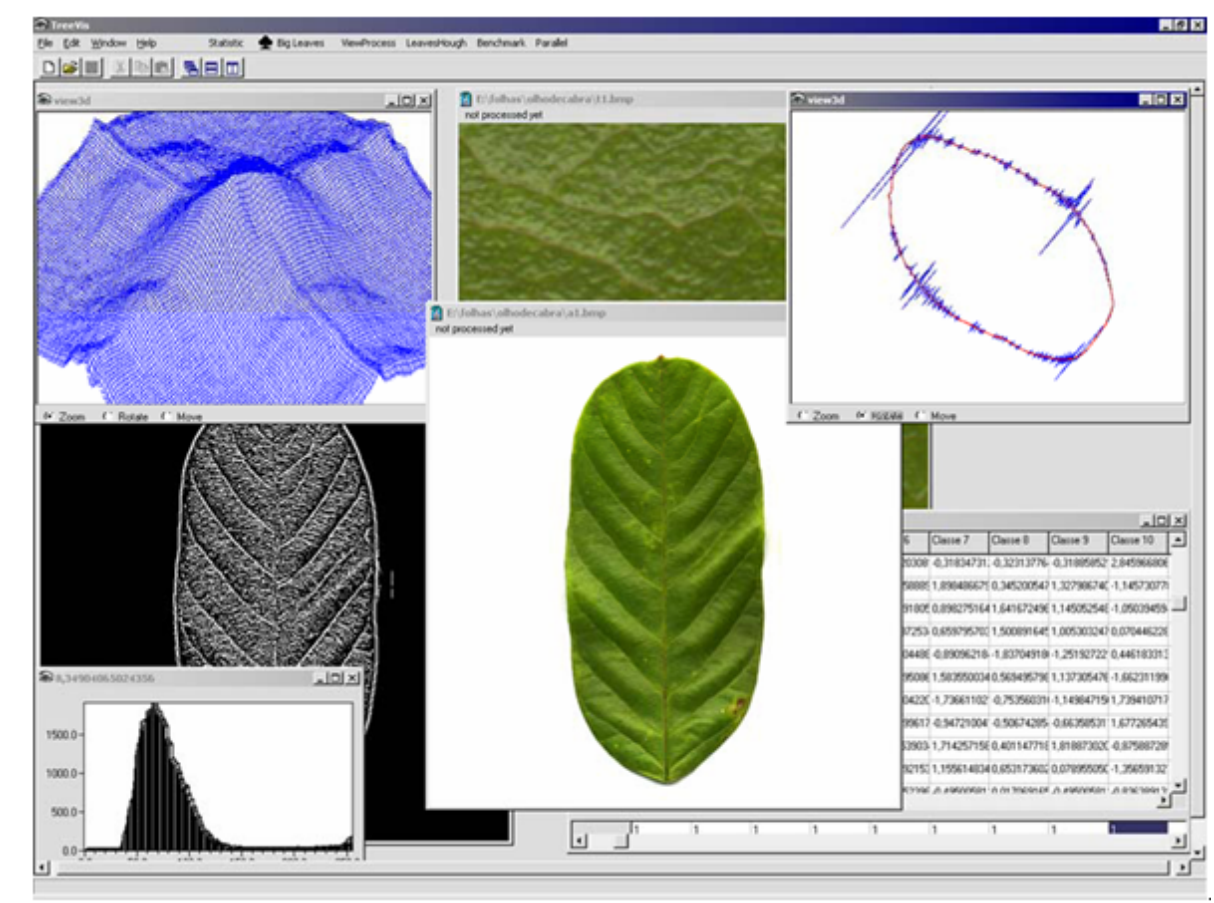

Figura 1.1: Ambiente de trabalho do TreeVis, apresentando algumas propriedades extraídas da amostra da folha completa.

O Projeto TreeVis incorpora atualmente a identificação de vegetais por meio de análise da forma interna dos órgãos foliares e análise de contorno foliar (Plotze, 2004; Falvo, 2005). Essas metodologias baseiam-se na exploração sistemática dos atributos obtidos das folhas e na análise estatística, o que implica que os resultados obtidos são aproximações diretamente relacionadas à sinergia da combinação das características obtidas (Falvo, 2005).

Esta dissertação, com o intuito de contribuir com os trabalhos já incorporados ao projeto TreeVis, e, concomitantemente, estabelecer uma nova abordagem de identificação vegetal, descreve a análise do corte transversal de folhas ampliado microscopicamente. Essa abordagem tem um caráter pioneiro pelo fato de que métodos computacionais ainda não tinham sido usados para extrair assinaturas das estruturas celulares.

Atualmente, há trabalhos na área biológica que utilizam informações morfológicas tanto para fins taxonômicos como para verificação de plasticidade frente a diferentes ambientes - por exemplo, a análise da espécie Alchornea triplinervia sob condições de Sombra e Sol (Rôças \& Scarano, 1997), da espécie Xylopia brasiliensis Sprengel em condições de luminosidade (Justo 
et al., 2005) etc. Esses trabalhos, não obstante efetuarem medidas importantes, não contemplam outras características relevantes, tais como: cor, textura, complexidade etc.

Este trabalho, portanto, para contribuir com a identificação de táxons diferentes e ampliar os estudos já realizados na análise das alterações morfológicas de uma espécie frente a diferentes condições ambientais, desenvolve duas linhas de experimentos. No primeiro experimento, foram utilizadas as espécies Byrsonima intermedia A. Juss., Miconia albicans (Sw.) Triana, Tibouchina stenocarpa (DC.) Cogn., Vochysia tucanorum Mart., Xylopia aromatica (Lam.) Mart., Gochnatia polymorpha (Less.) Cabrera, Miconia chamissois Naudin e Jacaranda caroba (Vell.) A. DC., espécies lenhosas típicas do cerrado do Estado de São Paulo, Brasil. Esse estudo teve o objetivo de averiguar a possibilidade de identificação de vegetais pela extração de características de diferentes regiões do corte transversal de folhas.

A segunda linha de pesquisa consistiu na análise de alterações morfológicas de uma mesma espécie sob diferentes situações, visando verificar a possibilidade de usar ferramentas computacionais em estudos de plasticidade. Nesse sentido, os experimentos foram realizados na espécie Gochnatia polymorpha nos ambientes Cerrado e Mata Ciliar, nas estações Chuvosa e Seca, e sob condições de Sol e Sombra.

\subsection{Organização}

Este trabalho está dividido da seguinte maneira: o Capítulo 2 descreve sucintamente as regiões do corte transversal de uma folha das quais foram extraídas informações. O Capítulo 3 descreve alguns algoritmos estudados para a segmentação das imagens. O Capítulo 4 explica os métodos empregados para a extração de vetores de características das imagens microscópicas. O capítulo 5 explica os métodos empregados para redução e seleção de características. O Capítulo 6 descreve os métodos para identificação dos vetores de características. O Capítulo 7 descreve os experimentos realizados. O Capítulo 8 expõe os resultados obtidos na identificação de diferentes espécies e a análise histológica da espécie Gochnatia polymorpha nos ambientes Cerrado e Mata Ciliar, nas estações Chuvosa e Seca, e sob condições de Sol e Sombra. Finalmente, o Capítulo 9 define algumas conclusões sobre os resultados alcançados, as contribuições do trabalho na literatura, e cita algumas lacunas do sistema desenvolvido, bem como as possibilidades de expansão deste projeto. 



\begin{tabular}{|c|c|}
\hline CAPITULO \\
\hline Estrutura Interna de Folhas \\
\hline
\end{tabular}

Independente do tipo de folha, na sua constituição participam praticamente os mesmos padrões celulares característicos. Via de regra, a folha apresenta epiderme superior e inferior, normalmente acompanhadas por uma cutícula. Abaixo da epiderme superior situa-se o parênquima paliçádico, que recebe esse nome devido à disposição de suas células e, em contato com o parênquima paliçádico está o parênquima lacunoso, caracterizado por apresentar grandes espaços intercelulares (Nultsch, 1996).

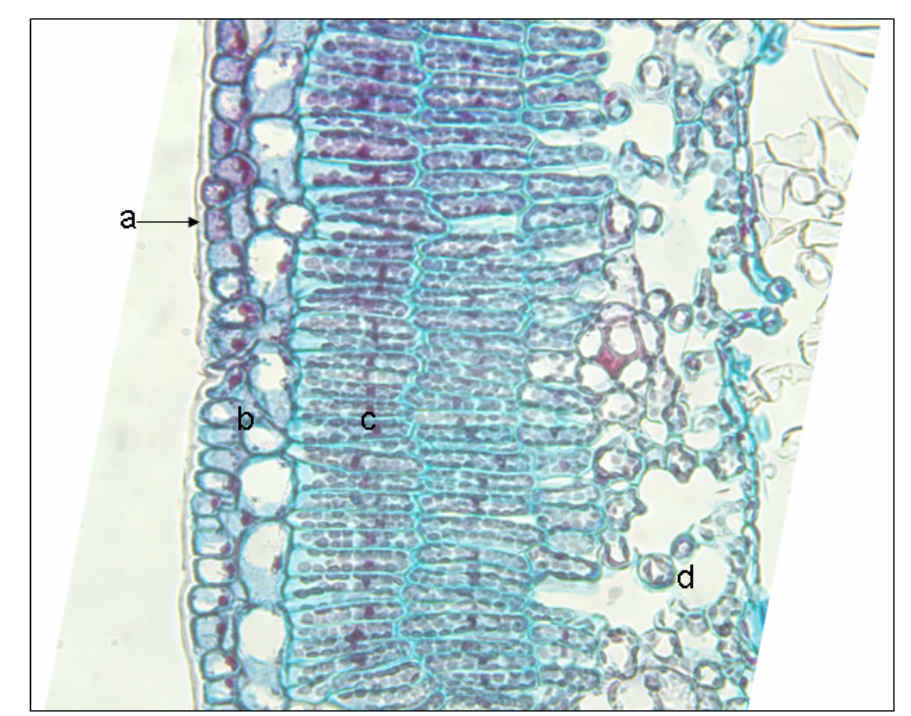

Figura 2.1: Corte transversal da folha de Gochnatia polymorpha: a - Cutícula, b - Epiderme Superior, c - Parênquima Paliçádico, d - Parênquima Lacunoso 
Para os propósitos deste trabalho, nas seções seguintes serão descritos sucintamente apenas os componentes internos da folha dos quais foram retirados vetores de características.

\subsection{Cutícula}

A cutícula é uma delgada camada protetora formada por cutina, espécie de cera que reveste os órgãos mais delicados das plantas, como as folhas, as flores e partes jovens das mesmas (Oliveira, 1996). Por ser constituída de substâncias hidrófobas, a espessura da cutícula determina quanta água é perdida pelas células por evaporação. A cutícula é também excepcionalmente resistente a bactérias e outros organismos causadores de doenças (Stern, 1994). A Figura 2.1(a) mostra a localização da cutícula na espécie Gochnatia polymorpha.

\subsection{Epiderme Superior}

A epiderme superior (ou adaxial) é composta por células que se encontram dispostas de modo compacto e são recobertas por uma cutícula que reduz a perda de água (Raven et al., 1978). Quando vistas de cima, com o auxílio de um microscópio, as células da epiderme superior freqüentemente se assemelham a peças encaixadas de um quebra-cabeças. Com exceção das células-guarda (células dispostas lado a lado e que controlam a abertura do estômato), as células da epiderme superior não contêm cloroplastos, de modo que sua função é primariamente a proteção dos delicados tecidos do interior da folha (Stern, 1994). A Figura 2.1(b) mostra a localização da epiderme superior.

A epiderme geralmente é formada por uma única camada, mas pode ocorrer também epiderme múltipla. Muitas vezes, encontra-se abaixo da epiderme uma ou mais camadas de células que podem ser interpretadas como epiderme múltipla, entretanto, essas células formam um tecido denominado hipoderme. A diferenciação entre hipoderme e epiderme múltipla é difícil, pois se baseia na ontogênese desses tecidos (Alquini et al., 2003). Desse modo, neste trabalho não foi feita distinção entre esses dois tecidos, sendo denominados genericamente de epiderme superior.

\subsection{Parênquima Paliçádico}

As células do tecido paliçádico têm forma cilíndrica, com os eixos maiores orientados perpendicularmente à epiderme superior e podem ter uma ou mais camadas. Embora o parênquima paliçádico pareça mais compacto que o parênquima lacunoso (ver Seção 2.4), as paredes verticais das células de paliçada, em sua maioria, estão expostas aos espaços intercelulares e, em algumas folhas, a superfície da paliçada pode ser duas a quatro vezes maior que a do parênquima lacunoso. Além disso, os cloroplastos também são mais numerosos nas células em paliçada, de 
modo que, aparentemente, a maior parte da fotossíntese ocorre nesse tecido (Raven et al., 1978). A Figura 2.1(c) mostra a localização do parênquima paliçádico.

\subsection{Parênquima Lacunoso}

O parênquima lacunoso (ou esponjoso) consiste de células irregulares organizadas frouxamente, com muitos espaços intercelulares que se comunicam com a atmosfera por meio dos estômatos (Raven et al., 1978). Esses espaços garantem a eficiência das trocas gasosas, fundamentais para função fotossintética da folha. Além disso, essas células também possuem cloroplastos, embora em menor quantidade do que o parênquima paliçádico. A Figura 2.1(d) mostra a localização do parênquima lacunoso. 



픅

\section{Segmentação de Imagens}

Um dos passos mais críticos no processo de reduzir imagens à informação é a segmentação: dividir a imagem em regiões que presumivelmente correspondem a unidades estruturais na cena ou distinguir objetos de interesse (Russ, 2002). Há inúmeras técnicas disponíveis para segmentação, sendo que a natureza do problema define qual delas é a mais adequada.

Neste trabalho, alguns algoritmos de segmentação foram estudados, sendo que o algoritmo do Funcional de Mumford-Shah foi aquele que atendeu melhor às necessidades do problema. Desse modo, ele foi o único empregado em todas as fases de segmentação deste projeto. A seguir, as três classes tradicionais de segmentação são brevemente apresentadas. São elas:

\subsection{Segmentação Baseada em Pixel}

Nas técnicas desse grupo a decisão de segmentação é tomada somente com base no nível de cinza ou características de pixels individuais (Jähne, 1997). O exemplo mais significativo é a técnica thresholding, na qual um limiar é definido e os pixels com intensidade acima desse limite são considerados como pertencentes ao objeto de interesse e os demais como "pano de fundo", ou vice-versa.

A técnica de thresholding está intimamente relacionada ao conceito de histograma, que é um vetor $h(n)$ cujos valores para cada índice $n$ correspondem à quantidade de vezes que o nível de cinza $n$ ocorre na imagem (a Seção 4.2.1 apresenta maiores detalhes sobre histograma).

As informações contidas no histograma podem auxiliar na definição de um limiar (threshold). Por exemplo, picos no histograma freqüentemente identificam várias regiões homogêneas e um limiar pode ser aplicado entre esse picos (Russ, 2002). Quando o histograma não 
apresenta picos que permitem identificar facilmente a localização do limiar, algumas técnicas podem ser aplicadas. Uma delas é encontrar limiares que se adequem a diferentes regiões da imagem por meio de algoritmos de thresholding adaptativo (Cesar, Jr. \& Costa, 2001). Uma outra possibilidade é buscar o limiar automaticamente, por meio de algoritmos que tentam otimizar alguma função critério, como variância (método Otsu), entropia etc.

\subsection{Segmentação Baseada em Detecção de Bordas}

Essas técnicas se baseiam na detecção de descontinuidades em uma imagem, que podem ser um ponto, uma linha ou a borda de um objeto.

\subsubsection{Detecção de Pontos}

\begin{tabular}{|c|c|c|}
\hline-1 & -1 & -1 \\
\hline-1 & 8 & -1 \\
\hline-1 & -1 & -1 \\
\hline
\end{tabular}

Figura 3.1: Máscara usada na detecção de pontos isolados.

A detecção e segmentação de pontos isolados é aplicada principalmente na remoção de ruído e análise de partículas (Gonzalez, 1987). Basicamente, isso consiste na convolução espacial de uma máscara $3 x 3$ (ver Figura 3.1) com a imagem, de modo que a intensidade de pixel resultante é dada pela seguinte soma de produtos

$$
I=-x_{11}-x_{12}-x_{13}-x_{21}+8 x_{22}-x_{23}-x_{31}-x_{32}-x_{33}
$$

onde $\left(x_{11}, x_{12}, \ldots, x_{33}\right)$ representam os níveis de cinza abaixo da máscara.

Como é possível deduzir, numa área de nível de cinza constante o resultado dessa operação será 0 . Por outro lado, se a máscara está centrada num ponto isolado $\left(x_{5}\right)$, cuja intensidade é maior que a intensidade de pano de fundo, o resultado será diferente de 0 .

\subsubsection{Detecção de Linhas}

O processo para detecção de linhas é similar ao processo de detecção de pontos. Usando como exemplo a máscara da Figura 3.2(a), esta responderá de modo mais intenso para linhas horizontais, principalmente quando a linha da imagem coincidir com a linha do meio $(2,2,2)$ da matriz. Para determinar a direção de determinada linha, basta convoluir as quatro máscaras e verificar qual delas ofereceu a maior intensidade em módulo. 


\begin{tabular}{|c|c|c|}
\hline-1 & -1 & -1 \\
\hline 2 & 2 & 2 \\
\hline-1 & -1 & -1 \\
\hline
\end{tabular}

(a)

\begin{tabular}{|c|c|c|}
\hline-1 & -1 & 2 \\
\hline-1 & 2 & -1 \\
\hline 2 & -1 & -1 \\
\hline
\end{tabular}

(b)

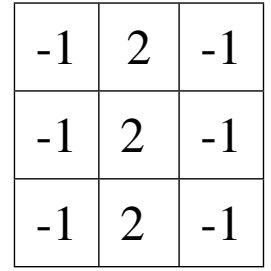

(c)

\begin{tabular}{|c|c|c|}
\hline 2 & -1 & -1 \\
\hline-1 & 2 & -1 \\
\hline-1 & -1 & 2 \\
\hline
\end{tabular}

(d)

Figura 3.2: Máscara usada na detecção de linhas: (a) - linhas horizontais, (b) - linhas inclinadas em $45^{\circ}$, (c) - linhas verticais, (d) - linhas inclinadas em $-45^{\circ}$

\subsubsection{Detecção de Bordas}

Embora a detecção de pontos e linhas sejam elementos de qualquer discussão sobre segmentação, a detecção de bordas é a abordagem mais comum para detectar descontinuidades significativas em nível de cinza. A razão disso é que pontos isolados e linhas finas não são ocorrências freqüentes na maioria das aplicações de interesse prático (Gonzalez, 1987). Basicamente, os métodos de detecção de bordas se baseiam nos conceitos matemáticos de Gradiente e Laplaciano.

\section{Operadores de Gradiente}

Alguns métodos para detectar bordas se apoiam no conceito matemático de gradiente. Dada uma função $g(x, y)$ que seja contínua e admita derivadas parciais em $\left(x_{0}, y_{0}\right)$, o vetor gradiente da função $g$ no ponto citado é dado pela seguinte equação.

$$
\vec{\nabla} g\left(x_{0}, y_{0}\right)=\left(\frac{\partial g}{\partial x}\left(x_{0}, y_{0}\right), \frac{\partial g}{\partial y}\left(x_{0}, y_{0}\right)\right)
$$

O vetor $\vec{\nabla} g\left(x_{0}, y_{0}\right)$ aponta para a direção da taxa máxima de variação da função $g$ no ponto $\left(x_{0}, y_{0}\right)$. Para detecção de bordas, o interesse se concentra na magnitude desse vetor, muitas vezes denotada simplesmente como gradiente, e é dada pela seguinte equação

$$
\left|\vec{\nabla} g\left(x_{0}, y_{0}\right)\right|=\sqrt{\left(\frac{\partial g}{\partial x}\left(x_{0}, y_{0}\right)\right)^{2}+\left(\frac{\partial g}{\partial y}\left(x_{0}, y_{0}\right)\right)^{2}}
$$

A direção do vetor gradiente é também uma quantidade importante. Tal medida pode ser usada para a análise da orientação da borda, um importante problema em textura e análise de movimento (Zucker, 1985 apud Cesar, Jr. \& Costa, 2001). A direção do vetor é obtida pela Equação 3.4.

$$
\alpha\left(x_{0}, y_{0}\right)=\arctan \left(\frac{\frac{\partial g}{\partial y}\left(x_{0}, y_{0}\right)}{\frac{\partial g}{\partial x}\left(x_{0}, y_{0}\right)}\right)
$$


No domínio discreto (imagens), o cômputo do gradiente pode ser feito pelos operadores de Sobel. Basicamente, esse método consiste em duas máscaras de convolução, que calculam o vetor gradiente na direção $x$ e $y$, conforme demonstra a Figura 3.3.

\begin{tabular}{|c|c|c|}
\hline-1 & -2 & -1 \\
\hline 0 & 0 & 0 \\
\hline 1 & 2 & 1 \\
\hline
\end{tabular}

(a)

\begin{tabular}{|l|l|l|}
\hline-1 & 0 & 1 \\
\hline-2 & 0 & 2 \\
\hline-1 & 0 & 1 \\
\hline
\end{tabular}

(b)

Figura 3.3: Operadores de Sobel: (a) - gradiente na direção $x$, (b) - gradiente na direção $y$

Há outros métodos que detectam bordas por gradiente, tais como os operadores de Roberts, Prewitt etc., mas estes seguem basicamente a mesma idéia dos operadores de Sobel, de modo que não serão descritos neste trabalho.

\section{Operador Laplaciano}

O operador Laplaciano é um operador derivativo de segunda ordem definido para a função $g(x, y)$ - função contínua - nos pontos $\left(x_{0}, y_{0}\right)$ pela seguinte equação

$$
\nabla^{2} g\left(x_{0}, y_{0}\right)=\frac{\partial^{2} g}{\partial x^{2}}\left(x_{0}, y_{0}\right)+\frac{\partial^{2} g}{\partial y^{2}}\left(x_{0}, y_{0}\right)
$$

No domínio discreto, o operador Laplaciano pode ser representado pela máscara presente na Figura 3.4. Como é possível perceber, o Laplaciano resulta no valor 0 para áreas de nível de cinza constante.

\begin{tabular}{|c|c|c|}
\hline 0 & 1 & 0 \\
\hline 1 & -4 & 1 \\
\hline 0 & 1 & 0 \\
\hline
\end{tabular}

Figura 3.4: Máscara usada para computar o Laplaciano.

Embora esse operador seja sensível a transições de intensidade, raramente ele é usado na forma supracitada para detecção de bordas. A razão é que, por ser um operador de derivada de segunda ordem, ele é muito sensível a ruídos na imagem. Para contornar esse problema, esse operador pode ser combinado com uma função Gaussiana, que é um filtro de suavização, gerando assim um Laplaciano de Gaussiana ( $L o G)$, conforme definido na equação abaixo.

$$
\nabla^{2} g\left(x_{0}, y_{0}\right)=\left(1-\frac{x_{0}^{2}+y_{0}^{2}}{\sigma^{2}}\right) \exp \left(-\frac{x_{0}^{2}+y_{0}^{2}}{2 \sigma^{2}}\right)
$$




\subsection{Segmentação Baseada em Regiões}

Esse tipo de segmentação divide a imagem procurando por regiões que atendam a algum critério de similaridade. Em geral, uma imagem segmentada é formada por um número $n$ de regiões de pontos na imagem, sendo que a união dessas regiões compõe a imagem completa. Exemplos de algoritmos dessa classe são Watershed e Algoritmo do Funcional de MumfordShah.

\subsubsection{Watershed (Divisor de Águas)}

Nesse método de segmentação, a imagem é tratada como um relevo topográfico e a idéia principal consiste em preencher esse relevo com água, de forma que a superfície seja dividida em regiões, devido aos domínios de atração exercidos em cada região (Vincent \& Soille, 1991 apud Pazoti \& Bruno, 2004). A partir dessa analogia, alguns termos podem ser definidos, como:

- Bacia de captação: são os vales nos quais a água se acumula.

- Linha divisória: à medida que as bacias de captação são preenchidas, as águas de diferentes vales tendem a se encontrar. Quando isso acontece, linhas divisórias ou "diques" são construídos para que as águas não se misturem.

- Mínimos locais: é o conjunto de pontos com a menor altitude (ou nível de cinza) dentro de cada vale.

Uma vez estabelecidos esses conceitos, o algoritmo simula um processo de imersão. $\mathrm{O}$ volume de água de cada bacia de captação vai aumentando até o momento em que a água tende a se misturar com as águas de outras bacias. Nesse momento de transição, um "dique" é construído. Desse modo, as linhas divisórias representam a separação entre regiões e as bacias de captação representam as diferentes regiões na imagem. No que diz respeito aos algoritmos, basicamente existem duas maneiras diferentes de efetuar a inundação de um relevo topográfico: síncrona e uniforme.

- Síncrona: por esse método de inundação, todas as bacias de captação são inundadas ao mesmo tempo, cada uma mantendo um mesmo nível de profundidade. Quando a água de uma determinada bacia atinge um ponto de transição, o volume de água nessa bacia pára de subir até que a água da outra bacia atinja o mesmo nível. A seguir, as águas de ambas as bacias continuam a subir e mantêm o mesmo nível, separadas por uma linha divisória.

- Uniforme: Nesse método, o nível de água começa a crescer a uma velocidade constante a partir do mínimo local de menor altitude. À medida que o nível aumenta, outros mínimos locais (e bacias) começam a ser inundados. Na sequiência, o processo é semelhante à inundação síncrona. 
Uma característica dessa metodologia é a super-segmentação, provocada pela presença da grande quantidade de mínimos locais. Para solucionar esse problema, é possível escolher apenas alguns mínimos locais ou um conjunto de pontos na imagem, denominados marcadores. Nesse caso, a seleção e posicionamento dos marcadores passa a ser um problema de "inteligência" do sistema de segmentação (Carvalho, 2004).

\subsubsection{Algoritmo do Funcional de Mumford-Shah}

O Algoritmo do funcional de Mumford-Shah (Mumford \& Shah, 1989; Chambolle, 1995) é um algoritmo de segmentação por crescimento de regiões que minimiza um funcional com o objetivo de detectar bordas numa imagem. O funcional a ser minimizado é, na sua forma genérica, definido como

$$
E(f, K)=\alpha \int_{\Omega}|f-g|^{2}+\int_{\Omega-K}|\nabla f|^{2}+\lambda \int H^{n-1}(K)
$$

onde $g$ é imagem original, $f$ é imagem segmentada, $H$ é a medida de Hausdorff, $n$ é a dimensão de $f, \Omega$ é o espaço no qual $f$ está imerso, $K$ é um conjunto de descontinuidades e $\alpha$ e $\lambda$ são os parâmetros de ajuste.

Os três termos do funcional de Mumford-Shah possuem o seguinte significado:

- O primeiro termo controla a qualidade da aproximação de $f$ a $g$;

- O segundo termo calcula a variação mínima de $f$ dentro de cada região sem a borda;

- O terceiro termo controla o comprimento, a suavidade e a localização das bordas $K$, e inibe o fenômeno de over-segmentation (segmentação excessiva) (Petitot, 2003).

No algoritmo empregado neste trabalho, entretanto, algumas adaptações foram realizadas. Primeiramente, o $\lambda$ é um conjunto de valores definidos por uma função de passo exponencial da forma $\lambda=2^{l i m}$, de modo que os valores assumem a seguinte forma $\left[2^{1}, 2^{2}, \ldots, 2^{\text {lim }}\right]$. Adicionalmente, a função $f$ é constante dentro de uma região, a qual é a média dos valores de $g$ nessa região e, portanto, um valor constante. Nesse caso, a equação empregada no algoritmo assume a seguinte forma

$$
E(f, K)=\alpha \int_{\Omega}|f-g|^{2}+\lambda \int H^{n-1}(K)
$$




\section{CAPÍTULO}

\section{4}

\section{Extração de Características}

Há vários métodos disponíveis para análise de uma imagem, sendo que a escolha destes é efetuada de acordo com a natureza do problema. No presente trabalho, foram testados os seguintes métodos: Coeficientes Tricromáticos, Estatísticas de Primeira Ordem, Matrizes de Co-ocorrência, BoxCounting 3D e Caminhada Determinística do Turista.

\subsection{Coeficientes Tricromáticos}

As cores são elementos importantes no cotidiano, sendo usadas para distinguir objetos, qualificá-los ou avaliar suas propriedades (Moreira, 1999). Desse modo, para a extração de assinatura de cor, os coeficientes tricromáticos foram medidos. Estes são obtidos a partir de cada uma das três matrizes que representam os componentes cromáticos $(R G B)$ de uma imagem (Gonzalez, 1987). Nas Equações (4.1 - 4.3), $C(r), C(g)$ e $C(b)$ representam os coeficientes; $r$, $g$ e $b$ representam as matrizes Red, Green e Blue, respectivamente, e $n$ é o número de pontos pertencentes à imagem.

$$
\begin{aligned}
& C(r)=\sum_{i=1}^{n} r_{i} /\left(r_{i}+g_{i}+b_{i}\right) \\
& C(g)=\sum_{i=1}^{n} g_{i} /\left(r_{i}+g_{i}+b_{i}\right) \\
& C(b)=\sum_{i=1}^{n} b_{i} /\left(r_{i}+g_{i}+b_{i}\right)
\end{aligned}
$$




\subsection{Métodos Estatísticos de Análise de Textura}

Embora não haja definição concreta sobre o conceito de textura, a mesma é facilmente percebida e é rica em informação visual. Geralmente, texturas são padrões visuais complexos compostos por entidades, ou subpadrões, que têm brilho, cor, inclinação, tamanho característicos (Materka \& Strzelecki, 1998). Desse modo, texturas provêem informações muito úteis para o reconhecimento e a interpretação automática de uma imagem por um computador (Bala, 1990). Como exemplo, a Figura 4.1 mostra um conjunto de texturas geradas sinteticamente.
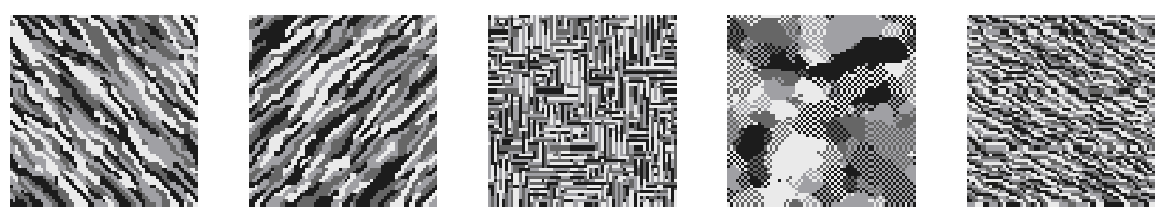

Figura 4.1: Texturas geradas sinteticamente (Chen et al., 1998).

Para os objetivos deste trabalho, as técnicas de extração de características de textura baseadas em histograma e baseadas em matrizes de co-ocorrência foram usadas, tanto por serem amplamente difundidas na literatura como por terem eficácia comprovada.

\subsubsection{Características de Primeira Ordem Baseadas em Histograma}

Assumindo que uma imagem é uma função $f(x, y)$ de duas variáveis espaciais $x$ e $y, x=$ $0,1, \ldots, N-1$ e $y=0,1, \ldots, M-1$ e que só pode assumir os valores discretos $i=$ $0,1, \ldots, G-1$, onde $G$ é o número total de níveis de intensidade de uma imagem, o histograma de níveis de intensidade é uma função que mostra (para cada nível de intensidade) o número de pixels na imagem inteira, conforme a equação abaixo

$$
h(i)=\sum_{x=0}^{N-1} \sum_{y=0}^{M-1} \delta(f(x, y), i)
$$

onde $\delta(j, i)$ é a função delta de Kronecker

$$
\delta(j, i)=\left\{\begin{array}{c}
1, j=i \\
0, j \neq i
\end{array}\right.
$$

O histograma de intensidade é obviamente um simples e conciso sumário da informação estatística contida na imagem. O cálculo do histograma de níveis de cinza envolve apenas pixels simples. O histograma, então, contém informação estatística de primeira ordem sobre a imagem (ou seu fragmento). Dividindo os valores $h(i)$ pelo número total de pixels de uma imagem obtém-se a densidade de probabilidade aproximada de ocorrência dos níveis de intensidade. 


$$
p(i)=h(i) /(N M) \quad i=0,1, \ldots, G-1
$$

A forma do histograma provê muitos indícios das características da imagem. Por exemplo, um histograma de distribuição concentrada num certo intervalo indica uma imagem de pouco contraste. Por outro lado, um histograma bimodal freqüentemente sugere que a imagem contém um objeto com um estreito intervalo de níveis de cinza contra um "pano de fundo" de intensidade diferente.

Diferentes parâmetros úteis podem ser adquiridos do histograma para quantitativamente descrever as propriedades estatísticas de primeira ordem de uma imagem. Algumas delas são definidas pelas Equações (4.7 - 4.12), que representam média, energia, variância, entropia, obliqüidade e curtose, respectivamente.

$$
\begin{aligned}
\mu & =\sum_{i=0}^{G-1} i p(i) \\
E & =\sum_{i=0}^{G-1} p(i)^{2} \\
\sigma^{2} & =\sum_{i=0}^{G-1}(i-\mu)^{2} p(i) \\
H & =-\sum_{i=0}^{G-1} p(i) \log _{2} p(i) \\
\mu_{3} & =\sigma^{-3} \sum_{i=0}^{G-1}(i-\mu)^{3} p(i) \\
\mu_{4} & =\sigma^{-4} \sum_{i=0}^{G-1}(i-\mu)^{4} p(i)-3
\end{aligned}
$$

\subsubsection{Características Baseadas em Matrizes de Co-ocorrência}

Segundo os experimentos de Julesz sobre percepção visual humana de texturas, para uma ampla classe das mesmas, "nenhum par de texturas pode ser discriminado se elas concordam em suas estatísticas de segunda ordem" (Julezs, 1975 apud Chen et al., 1998). Desse modo, pode-se depreender que a estatística de segunda ordem é uma ferramenta poderosa para extrair assinaturas.

Com o preâmbulo exposto, podemos definir uma matriz de co-ocorrência. Formalmente, dada uma imagem $f(x, y)$ com um conjunto de $G$ níveis discretos de intensidade, a matriz $h_{d \theta}(i, j)$ é definida tal que cada entrada na posição $(i, j)$ seja igual ao número de vezes que as condições das Equações (4.13 - 4.14) sejam satisfeitas. Isso resulta em uma matriz quadrada 
de dimensão igual ao número de níveis de intensidade da imagem, para cada distância $d$ e orientação $\theta$. Se essa matriz é dividida pelo total de vizinhos $R(d, \theta)$, torna-se uma matriz de probabilidades $p_{d \theta}(i, j)$ de dois pixels a uma distância $d$ e orientação $\theta$ serem $i$ e $j$.

$$
\begin{gathered}
f\left(x_{1}, y_{1}\right)=i \text { e } f\left(x_{2}, y_{2}\right)=j \\
\left(x_{2}, y_{2}\right)=\left(x_{1}, y_{1}\right)+(d \cos (\theta), d \sin (\theta))
\end{gathered}
$$

Duas formas de matriz de co-ocorrência existem: uma simétrica onde os pares separados por $d$ e $-d$ para uma certa direção são contados; e outra não simétrica onde somente os pares separados pela distância $d$ são contados. Devido à natureza intensa das computações envolvidas, freqüentemente somente as distâncias $d=1$ e 2 pixels com ângulos de $\theta=\left(0^{\circ}, 45^{\circ}, 90^{\circ}, 135^{\circ}\right)$ são considerados. Se cada par de pixels na imagem está altamente correlacionado, as entradas em $h_{d \theta}(i, j)$ serão agrupadas ao longo da diagonal da matriz. A classificação de texturas finas requer valores pequenos para $d$, enquanto que para texturas mais grosseiras são necessários valores mais altos. A redução do número de níveis de intensidade (pela quantização da imagem para níveis de intensidade menores) ajuda no aumento de velocidade de computação, mas com alguma perda de informação textural.

Haralick (1979) propôs algumas características úteis que podem ser extraídas a partir das matrizes de co-ocorrência. Algumas delas são definidas pelas Equações (4.15 - 4.20), que representam energia, homogeneidade, valor absoluto, contraste, entropia e correlação, respectivamente. As variáveis $\mu_{x}, \mu_{y}$ e $\sigma_{x}, \sigma_{y}$ denotam as médias e os desvios padrão da soma dos elementos de cada linha e coluna da matriz.

$$
\begin{aligned}
& \sum_{i=0}^{G-1} \sum_{j=0}^{G-1} p(i, j)^{2} \\
& \sum_{i=0}^{G-1} \sum_{j=0}^{G-1} \frac{p(i, j)}{1+|i-j|} \\
& \sum_{i=0}^{G-1} \sum_{j=0}^{G-1}|i-j| p(i, j) \\
& \sum_{i=0}^{G-1} \sum_{j=0}^{G-1}(i-j)^{2} p(i, j) \\
& \sum_{i=0}^{G-1} \sum_{j=0}^{G-1}-p(i, j) \log p(i, j) \\
& \sum_{i=0}^{G-1} \sum_{j=0}^{G-1} \frac{i j p(i, j)-\mu_{x} \mu_{y}}{\sigma_{x} \sigma_{y}}
\end{aligned}
$$




\subsection{Dimensão Fractal e Complexidade}

Os fractais reais são objetos teóricos que ocorrem exclusivamente no mundo matemático. Algumas formas encontradas na natureza apresentam algumas características fractais e se aproximam do conceito em alguns aspectos (auto-similaridade e complexidade), mas ferem o conceito teórico em relação ao infinito (Backes, 2006). Os objetos manufaturados, entretanto, bem como as imagens, não possuem auto-similaridade em escala nem complexidade infinita, tornando questionável relacionar a eles o termo fractal ou estimar sua Dimensão Fractal (Carlin, 2000). Não obstante, em análise de imagens a estimativa de Dimensão Fractal tem sido utilizada como uma metodologia para aferir a complexidade de uma imagem (Bruno et al., 2008).

Para tanto, a técnica de estimativa da Dimensão Fractal é adaptada para trabalhar com as limitações físicas de escala e auto-similaridade dos objetos, tornando a técnica útil para objetos não-fractais, tais como as imagens.

Para o cálculo da Dimensão Fractal, considere uma linha de comprimento $L$ e outra de comprimento $u$, de modo que $L>u$. Sobrepondo a linha $u$ sobre a linha $L$ até cobri-la completamente, encontra-se um valor $N=L / u$, que nada mais é do que uma medida da linha.

Do mesmo modo que foi feito para a linha, pode-se medir um quadrado de lado $L$ sobrepondoo com pequenos quadrados de lado $u$, obtendo-se a relação $N=(L / u)^{2}$.

De uma maneira mais geral, esse processo leva a uma relação do tipo

$$
N=(L / u)^{D}
$$

A aplicação de logaritmos em ambos os lados da Equação 4.21 resulta na equação a seguir, onde $D$ é a Dimensão Fractal.

$$
D=\frac{\ln N}{\ln (L / u)}
$$

Para objetos não fractais, no entanto, essa relação varia conforme a variação de $u$. Faz-se necessário, então, obter um valor para o qual a equação acima convirja. Esse valor pode ser estimado como

$$
D=\lim _{u \rightarrow 0} \frac{\ln N}{\ln (L / u)}
$$

O cálculo da Equação 4.23 resolve o problema de se estimar a Dimensão Fractal em objetos não-fractais, mas adiciona o problema do cálculo de um limite. Esse problema é resolvido pela adaptação desse cálculo para um espaço discreto, como é o caso das imagens. Em vez de se estimar o limite supracitado, o que se faz é desenhar o gráfico

$$
\ln N x \ln (L / u)
$$


e calcular a inclinação $\alpha$ da curva gerada. A Dimensão Fractal $D$ é então estimada como

$$
D=\alpha
$$

Essa adaptação permite estimar com precisão a Dimensão Fractal de objetos não-fractais. O resultado obtido passa a ser uma estimativa do nível de complexidade que um dado objeto apresenta (Carlin, 2000).

\subsubsection{Métodos para Estimativa da Dimensão Fractal}

Existem diversos métodos para calcular a Dimensão Fractal (Chaudhuri \& Sarkar, 1995), tais como: Massa Raio, Análise Intersecção Acumulativa, BoxCounting, Dividers (Compass), Boulingand-Minkowski etc. Contudo, esses métodos ainda estão no estado da arte para imagens em níveis de cinza (os métodos trabalham com imagens binárias), o que, por conseguinte, restringiu a análise de complexidade nas imagens microscópicas ao método BoxCounting 3D, posto que já há estudos demonstrando sua eficácia na análise de imagens.

\subsubsection{BoxCounting 3D}

Dentre os métodos utilizados para calcular a Dimensão Fractal de uma forma ou imagem, o método BoxCounting é um dos mais fáceis de apreender e aplicar. A idéia básica desse método é particionar a imagem em quadrados de tamanho $r$ x $r$ e contar o número $N(r)$ de quadrados contendo uma porção (por menor que seja) da imagem (Cesar, Jr. \& Costa, 2001). A Figura 4.2 mostra um exemplo de uma imagem sobreposta por duas malhas de tamanho de quadrados diferentes.
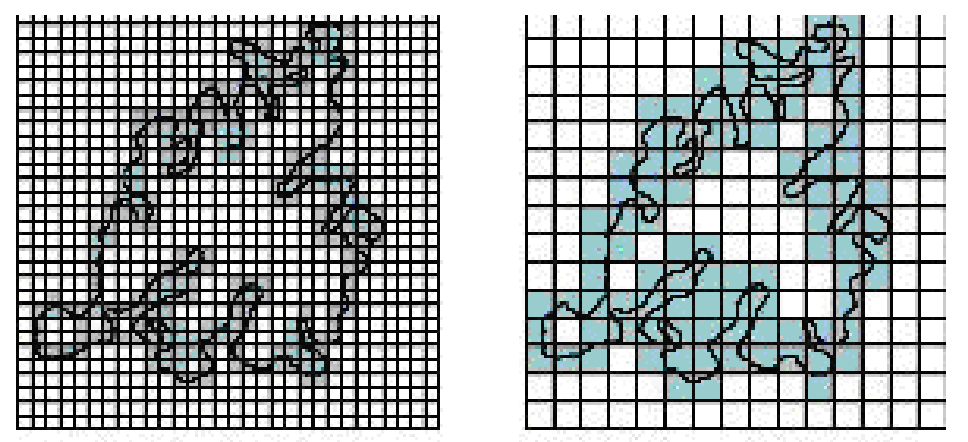

Figura 4.2: Divisão de uma imagem pelo método BoxCounting (Backes, 2006)

Para a execução desse método, é necessário definir um conjunto $B$ de cubos de medidas de lados $r$ a ser utilizados nas diversas iterações do método. Apesar de $B$ poder ser definido inicialmente pelo usuário, é padrão calculá-lo com base nas dimensões da imagem, conforme a relação abaixo, onde $a$ e $l$ representam a altura e a largura da imagem, respectivamente. 


$$
\forall r_{i} \in B\left\{\begin{array}{l}
r_{0}, \max (a, l), \\
r_{i+1}, r_{i} / 2 .
\end{array}\right.
$$

Após a definição do conjunto de lados $r$, é possível criar um gráfico $\ln N x \ln (L / u)$, ou seja, que represente os pontos que relacionam os logaritmos dos lados $r$ pelos correspondentes logaritmos das quantidades de caixas, e calcular a inclinação $-\alpha$ da reta gerada através dos pontos desse gráfico. Vale salientar que essa reta possui coeficiente angular negativo, o que implica que o mesmo terá de ser considerado em módulo para representar a Dimensão Fractal. A Figura 4.3 representa um exemplo de gráfico log-log do método supracitado.

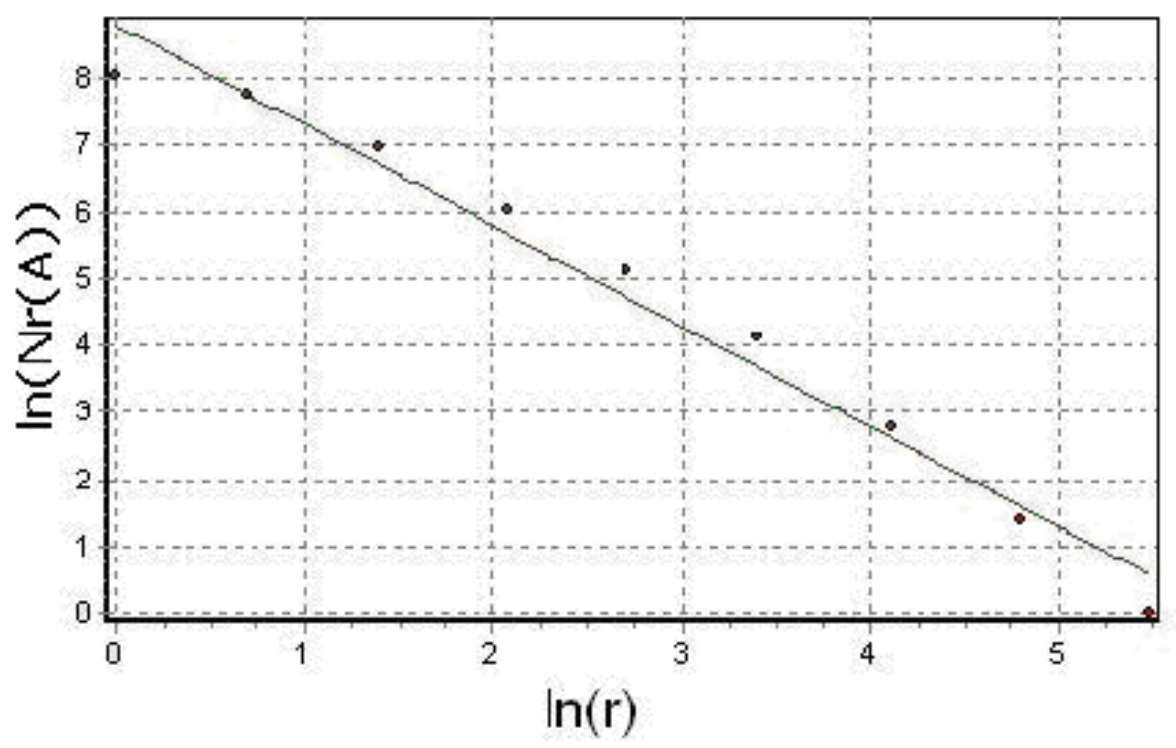

Figura 4.3: Cálculo do coeficiente angular no BoxCounting

O método acima descrito, no entanto, possui a limitação de somente ter aplicação em imagens binárias, posto que leva em consideração apenas a localização dos pixels - coordenadas $x$ e $y$. Para que o método possa ter aplicabilidade neste projeto, é necessário estendê-lo para sua versão $3 D$, que leva em consideração a coordenada $z$, ou seja, a intensidade do pixel em questão.

Para tanto, foi desenvolvido o método BoxCounting 3D, que divide a imagem em cubos de lado $r$ e empilha os mesmos na quantidade mínima necessária para cobrir toda a superfície gerada pelos níveis de cinza. Uma idéia intuitiva seria imaginar a imagem como um relevo topográfico com montanhas, vales, planaltos etc. Nesse caso, haverá a necessidade de mais blocos empilhados na região do cume das montanhas, de menos cubos nas depressões e assim por diante. A Figura 4.4 demonstra como os cubos interceptam a superfície de níveis de cinza.

O método BoxCounting 3D segue exatamente as mesmas regras do BoxCounting para imagens binárias, ou seja, os cubos são contados para cada valor de lado $r$, de modo a obter um gráfico $\ln N x \ln (L / u)$, como exemplificado na Figura 4.3, e extrair o coeficiente angular da reta obtida $-\alpha$, ou seja, a Dimensão Fractal da imagem (Xu \& Weng, 2006). 


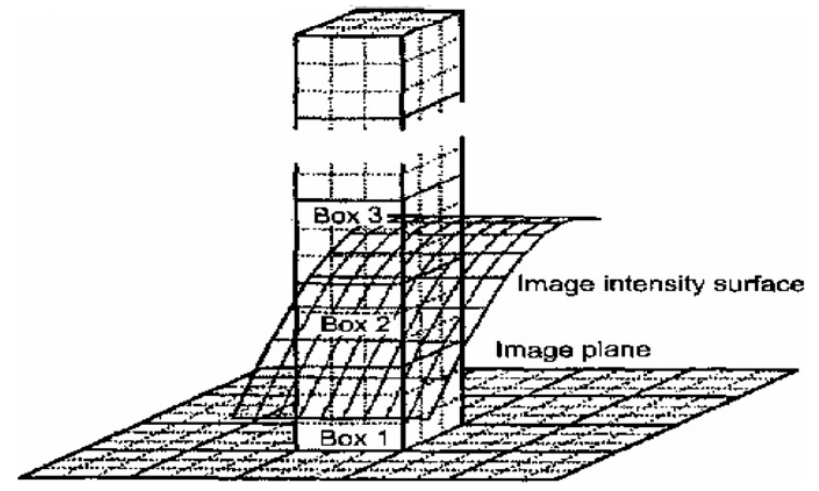

Figura 4.4: Cubos de dimensões 3x3x3 sobrepostos a uma imagem (Xu \& Weng, 2006)

\section{Dimensão Fractal MultiEscala}

Apesar de sua freqüente utilização em análise de imagens e reconhecimento de padrões, a medida de Dimensão Fractal possui limitações para essas aplicações: objetos e padrões com naturezas geométricas distintas podem ter Dimensões Fractais equivalentes ou aproximadas (Plotze et al., 2005). Para a solução desse problema, portanto, há a necessidade de uma nova abordagem denominada Dimensão Fractal MultiEscala.

Tal método consiste na derivação da curva log-log obtida pelo método de estimativa de Dimensão Fractal - no contexto deste projeto, o BoxCounting 3D. Esse procedimento permite a obtenção de uma função que representa os diferentes níveis de fractalidade da imagem para diferentes escalas espaciais, o que propicia uma assinatura característica da mesma. A Figura 4.5 mostra um gráfico de curva log-log gerada pelo método BoxCounting 3D e a respectiva curva de Dimensão Fractal MultiEscala.
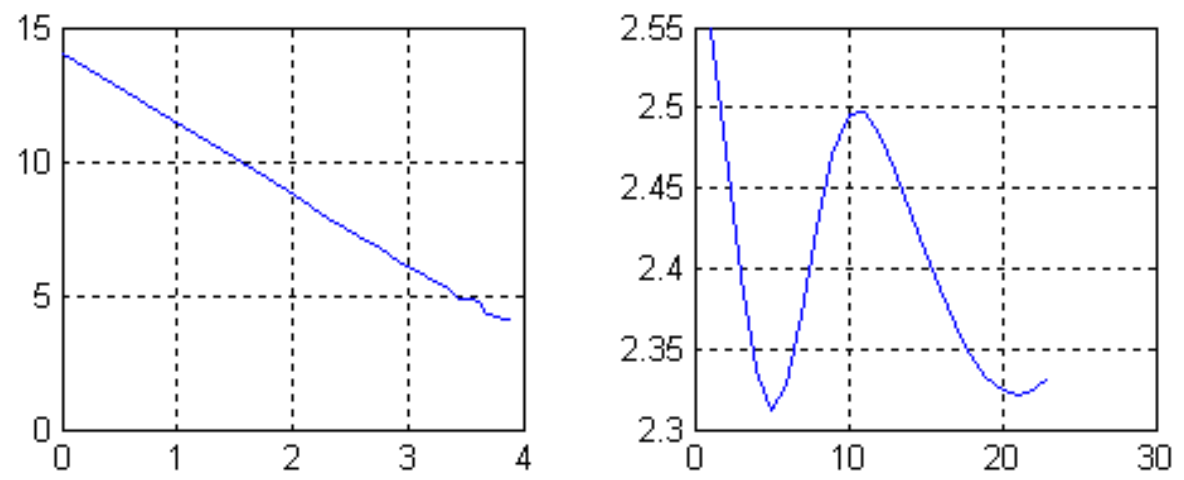

Figura 4.5: Gráficos da curva log-log gerada pelo método BoxCounting 3D e respectiva curva de Dimensão Fractal MultiEscala.

A derivada da curva $\log -\log u(t)$ pode ser obtida através de Diferenciação MultiEscala Baseada em Fourier e Diferenciação MultiEscala por Diferenças Finitas, mas neste projeto apenas o primeiro método foi utilizado. Este consiste na utilização da propriedade derivativa da Transformada de Fourier e, diferentemente do método baseado em Diferenças Finitas, que considera 
apenas a vizinhança do sinal analisado, leva em conta todo o sinal para diferenciação. Os passos necessários para esse procedimento estão resumidos na Equação 4.27, onde $t$ e $u(t)$ são, respectivamente, o logaritmo dos lados $r$ e da quantidade de cubos para cada lado $r$ no Método BoxCounting 3D, $F$ é a Transformada de Fourier, $F^{-1}$ é a Transformada Inversa de Fourier, $f$ é a freqüência e $j$ é o número imaginário.

$$
\frac{d u(t)}{d t}=F^{-1}\{F\{u(t)(j 2 \pi f)\}\}
$$

Neste momento, é oportuno fazer algumas considerações para que o método possa ter um bom resultado. Primeiramente, deve se garantir que o sinal analisado possua um espaçamento uniforme e uma boa amostragem. Para garantir uma boa amostragem, é necessário desconsiderar os primeiros pontos do sinal, uma vez que a amostragem nesses pontos é muito baixa. Já para garantir um espaçamento uniforme, uma interpolação pode ser utilizada para preencher espaços entre cada dois lados $r$ exatos, colocando entre esses lados uma média deles (Backes, 2006).

Um outro detalhe importante é que a derivada de Fourier se torna descontínua nas extremidades do sinal (fenômeno de Gibbs), o que torna necessário um esquema de replicação e reflexão do sinal, de modo a fazê-lo contínuo para a Transformada Discreta de Fourier. Além disso, os métodos de diferenciação tendem a enfatizar ruídos das altas freqüências, o que torna necessário a utilização de filtros de suavização. Com essas ressalvas, a Dimensão Fractal MultiEscala para o método BoxCounting 3D pode ser encontrada através da Equação 4.28. O sinal negativo da equação é uma característica do BoxCounting, visto que a curva na qual a derivação é feita possui coeficiente angular negativo.

$$
D F M=-\frac{d u(t)}{d t}
$$

\subsection{Caminhada Determinística do Turista}

Embora não tão amplamente estudadas como as caminhadas randômicas, as caminhadas determinísticas têm obtido o interesse dos pesquisadores (Backes et al., 2006). No escopo deste projeto, o interesse concentra-se na exploração de um algoritmo de caminhada determinística que evita a si mesma parcialmente, conhecido como caminhada do turista (TW).

O algoritmo TW pode ser visualizado como um turista que deseja visitar $N$ cidades randomicamente distribuídas em um mapa de $d$ dimensões. O turista começa sua rota numa determinada cidade do mapa e se move de acordo com a seguinte regra determinística: seguir para a cidade mais próxima que não tenha sido visitada nos $\mu$ passos de tempo (Campiteli et al., 2006a). Cada trajetória do turista consiste em um tempo de transição $t$ (novas cidades são visitadas) e um ciclo final de período $p$ (novas cidades não são mais visitadas). Desse modo, as trajetórias são complexas e dependem estritamente do ponto de partida e da configuração dos 
dados. A única relação conhecida que persiste é $p \geq \mu+1$. Os movimentos do turista são baseados em graus de vizinhança. Tais graus são convenientemente representados por uma tabela de vizinhança que não leva em conta a distância entre as cidades. Essa característica conduz a uma invariância de transformações de escala.

Vale salientar alguns aspectos importantes das caminhadas determinísticas. São eles:

1. A cada intervalo de tempo o turista se move de uma cidade para outra, não importando as distâncias entre elas.

2. Começando por diferentes cidades no mapa, o turista realiza diferentes trajetórias com tempos de transição variáveis (os quais podem ser nulos) e finaliza em ciclos de período $p \geq \mu+1$.

3. As trajetórias são diferentes para diferentes condições iniciais, mas inúmeras trajetórias podem terminar no mesmo ciclo com um dado período $p$.

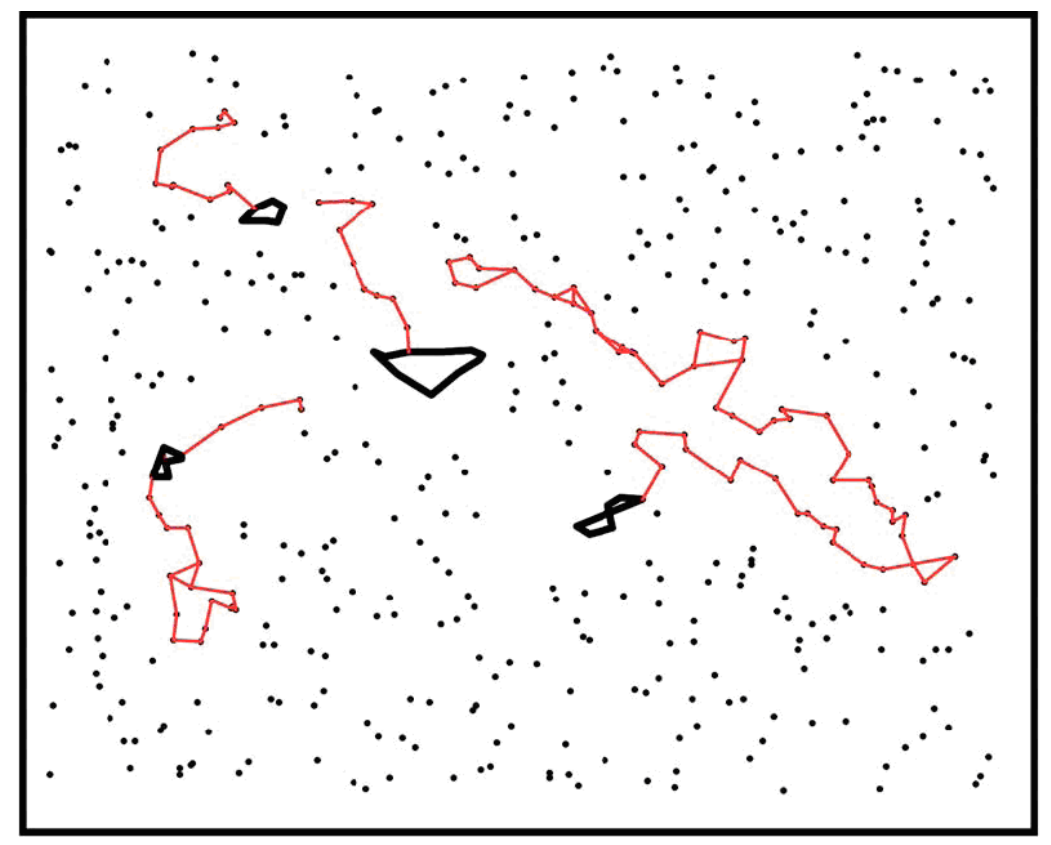

Figura 4.6: Exemplo da caminhada do turista em um mapa randômico bidimensional (Campiteli et al., 2006a).

\subsubsection{Caminhada do Turista Modificada}

No contexto de imagens $(d=2)$, é possível considerar cada pixel como um ponto (ou cidade). No algoritmo original a tabela de vizinhança tem o tamanho de $N^{2}$, onde é estabecido o grau de vizinhança de cada ponto em relação aos demais $N-1$ outros pontos. Vale enfatizar que a memória $\mu$ varia de 0 a $N-1$, onde todas as cidades são visitadas (o circuito não contém ciclos) (Backes et al., 2006). 
Para imagens, o algoritmo foi modificado, visto que cada pixel interage somente com os pixels de sua vizinhança-de-8 e o turista segue sempre na direção da diferença mínima de intensidade (gradiente). Desse modo, a tabela de vizinhança tem o tamanho máximo de $N x 8$ como as imagens são limitadas, os pixels pertencentes às bordas e aos cantos terão cinco e três vizinhos, respectivamente (Campiteli et al., 2006b).

Assim como no modelo original de caminhada determinística, o turista se move de acordo com a regra de ir em direção ao pixel de menor intensidade comparada ao pixel (cidade) no qual o turista está localizado, de tal modo que tal diferença de intensidade não esteja relacionada aos $\mu$ passos precedentes, ou seja, as $\mu$ cidades visitadas. Dessas caminhadas, o tempo de transição (quantidade de pixels novos visitados antes de se formar um ciclo) e o período de ciclo (quantidade de pixels no ciclo do qual o turista não consegue sair) são calculados e um mapa de distribuição é construído. Exemplos de mapas de distribuição são mostrados na Figura 4.7 .

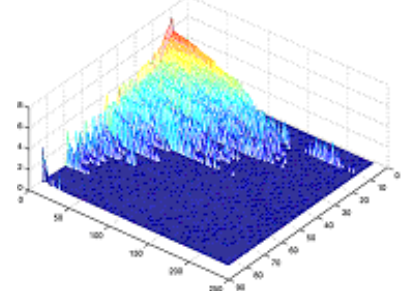

(a)

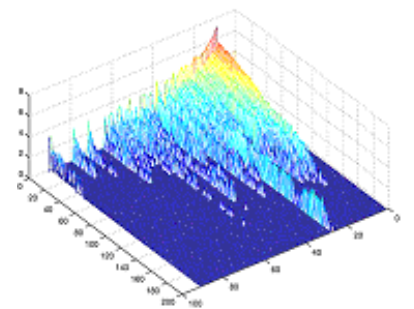

(c)

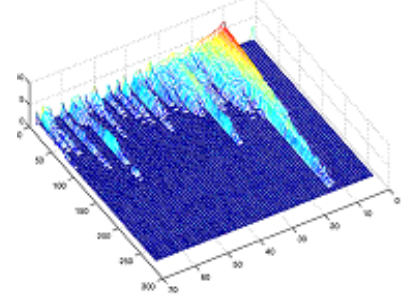

(e)

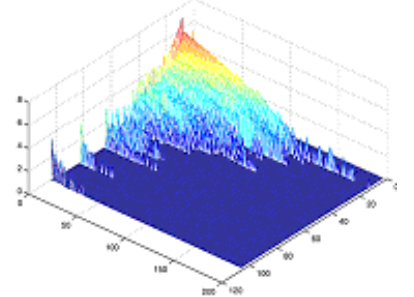

(b)

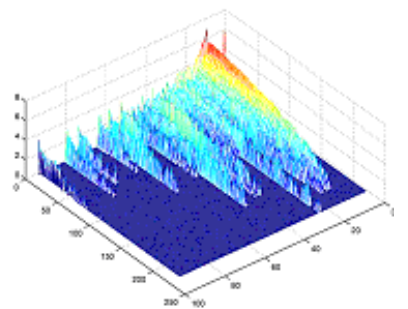

(d)

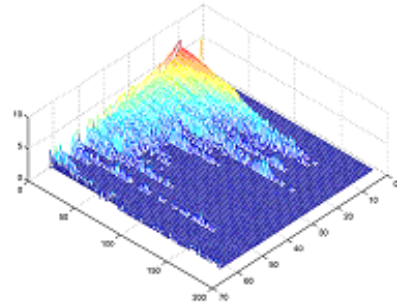

(f)

Figura 4.7: Mapas de distribuição de seis diferentes texturas de Brodatz para o valor de memória $\mu=7$ (Campiteli et al., 2006a).

A ocorrência de indecisão sobre para qual pixel prosseguir (presença de mais de um vizinho com a menor diferença de intensidade) é resolvida pela escolha do primeiro pixel no sentido anti-horário, preservando a natureza determinística do algoritmo (Backes et al., 2006). Para uma dada imagem e a mesma imagem rotacionada $90^{\circ}$, são obtidos mapas de distribuição 
distintos. Tal fato se deve ao modo determinístico de o algoritmo resolver empates de vizinhos que possuem o menor nível de intensidade.

Operacionalmente, o mapa de distribuição consiste em uma matriz tridimensional cujos eixos representam o tempo de transição $t$, o período de ciclo $p$ e a memória $\mu$. A Figura 4.7 representa uma fatia dessa matriz na coordenada de valor sete no eixo de memória $\mu$ para seis diferentes texturas de Brodatz. Desse modo, fica evidente que para cada valor de memória $\mu$ há um grande número de informações que podem ser obtidas. Surge, portanto, a necessidade de estabelecer regras para a retirada das informações realmente relevantes para caracterizar a textura na qual o método foi aplicado.

Para tal intento, são retiradas assinaturas dos mapas de distribuição. Essas assinaturas são vetores de características que podem ser obtidos de duas maneiras. Na primeira abordagem, o vetor de características $\psi$ é construído a partir de um valor específico $\mu$ de um mapa de distribuição, conforme mostrado na Equação 4.29, onde os valores de $t$ e $a$ indicam o número máximo de tempos de transição e de períodos de ciclo, respectivamente.

$$
\psi_{\mu}(t, a)=\left[S_{2, \mu}^{N}(0: t, \mu+1) S_{2, \mu}^{N}(0: t, \mu+2) \ldots S_{2, \mu}^{N}(0: t, \mu+a)\right]
$$

Dependendo do tipo de problema a ser resolvido, talvez haja a necessidade de empregar uma segunda abordagem, na qual uma seqüência de valores de memória $\mu$ são utilizados para a montagem de um vetor composto por outros vetores, sendo que cada vetor componente pertence a uma determinada memória $\mu$ e é obtido conforme a Equação 4.29. A Equação 4.30 descreve a fórmula do vetor concatenado, onde $\mu_{i}, \mu_{f}, t$ e $a$ representam a memória inicial, a memória final, número máximo de tempos de transição e de períodos de ciclos, respectivamente.

$$
\varphi\left(\mu_{i}, \mu_{f}\right)=\left[\psi_{\mu_{i}}(t, a) \ldots \psi_{\mu_{f}}(t, a)\right]
$$




\section{CAPÍTULO \\ 5 \\ Pré-processamento dos Dados}

Uma vez adquiridos os vetores de características, nem sempre é possível utilizá-los sem antes os mesmos passarem por um pré-processamento. Basicamente, há dois tipos de problemas a serem sanados. O primeiro se refere à dimensionalidade do vetor original, conhecido na literatura como maldição da dimensionalidade. A dificuldade mais evidente de se trabalhar com um espaço de características de dimensionalidade muito alta é o custo computacional, mais precisamente memória e processamento (Santos, 2007).

O segundo problema se refere ao fato de que muitas vezes há características presentes num vetor que não contribuem (ou contribuem muito pouco) para representar determinado objeto de uma classe. Nesse caso, há a necessidade de selecionar as medidas mais representativas para reduzir a dimensionalidade e, ao mesmo tempo, aumentar a performance de classificação.

Para resolver esses problemas, os métodos Análise de Componentes Principais e Distância de Battacharyya e de Jeffrey-Matusita, pertencentes aos paradigmas não-supervisionado e supervisionado, respectivamente, foram empregados neste trabalho.

\subsection{Análise de Componentes Principais (PCA)}

A análise de componentes principais (PCA, do inglês Principal Components Analysis) tem o propósito de derivar novas variáveis (em ordem decrescente de importância) que são combinações lineares das variáveis originais e que são descorrelacionadas (Webb, 2002). Essas combinações lineares são denominadas componentes principais. Geometricamente, o método PCA pode ser entendido como a rotação dos eixos do sistema de coordenadas original para um 
novo conjunto de eixos ortogonais que são ordenados em termos da quantidade de variação dos dados originais que eles encerram em si, conforme exemplo da Figura 5.1.

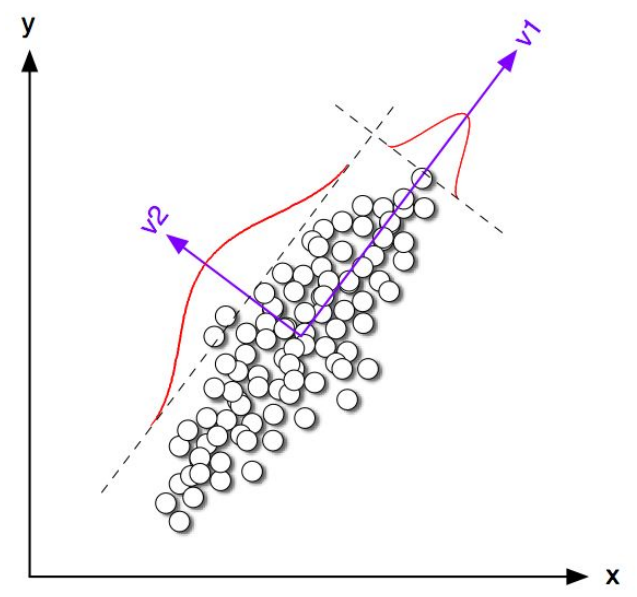

Figura 5.1: Representação gráfica da transformação PCA em duas dimensões.

Se há $p$-variáveis originais, é possível obter-se $p$ componentes principais. No entanto, como o objetivo é a redução do número de variáveis a serem avaliadas, a informação contida nas $p$ variáveis originais é substituída pela informação contida em $k(k<p)$ componentes principais. Dessa forma, o sistema de variabilidade do vetor aleatório composto de $p$-variáveis originais é aproximado pelo sistema de variabilidade do vetor aleatório que contém as $k$ componentes principais (Mingoti, 2005). A qualidade de aproximação depende da quantidade $k$ escolhida e pode ser medida pela proporção de variância de cada componente principal.

Para demonstrar como os componentes principais são obtidos, seja $X=\left(X_{1}, X_{2}, \ldots, X_{n}\right)^{\prime}$, um vetor aleatório com vetor de médias $\mu=\left(\mu_{1},, \mu_{2}, \ldots, \mu_{n}\right)^{\prime}$ e matriz de covariâncias $\Sigma_{p x p}$. Sejam $\lambda_{1} \geq \lambda_{2} \geq \ldots \geq \lambda_{p}$ os autovalores da matriz $\Sigma_{p x p}$, com os respectivos autovetores normalizados $e_{1}, e_{2}, \ldots, e_{p}$, isto é, os autovetores $e_{i}$ satisfazem às seguintes condições

(i) $\quad e_{i}^{\prime} e_{j}=0$ para todo $i \neq j$

(ii) $e_{i}^{\prime} e_{i}=1$ para todo $i=1,2, \ldots, p$

(iii) $\Sigma_{p x p} e_{i}=\lambda_{i} e_{i}$ para todo $i=1,2, \ldots, p$

Considerando o vetor aleatório $Y=O^{\prime} X$, onde $O_{p x p}$ é a matriz ortogonal de dimensão $p x p$, constituída dos autovetores normalizados da matriz $\Sigma_{p x p}$, isto é,

$$
O_{p x p}=\left(\begin{array}{cccc}
e_{11} & e_{21} & \cdots & e_{p 1} \\
e_{12} & e_{22} & \cdots & e_{p 2} \\
\vdots & \vdots & \ddots & \vdots \\
e_{1 p} & e_{2 p} & \cdots & e_{p p}
\end{array}\right)=\left(e_{1},, e_{2}, \ldots, e_{p}\right)
$$


o vetor $Y$ é composto de $p$ combinações lineares das variáveis aleatórias do vetor $X$, tem vetor de médias igual a $O^{\prime} \mu$ e matriz de covariâncias $\Lambda_{p x p}$, que é uma matriz diagonal cujos elementos são iguais a $a_{i i}=\lambda_{i}, i=1,2, \ldots, p$, ou seja,

$$
\Lambda_{p x p}=\left(\begin{array}{cccc}
\lambda_{1} & 0 & \cdots & 0 \\
0 & \lambda_{2} & \cdots & 0 \\
\vdots & \vdots & \ddots & \vdots \\
0 & 0 & \cdots & \lambda_{p}
\end{array}\right)
$$

A matriz de covariância $\Lambda_{p x p}$ demonstra que as variáveis aleatórias que constituem o vetor $Y$ são descorrelacionadas. Cada autovalor $\lambda_{j}$ representa a variância de um componente principal $Y_{j}$. Como os autovalores estão ordenados em ordem decrescente, o primeiro componente principal é o de maior variabilidade e o $p$-ésimo o menor. Sendo assim, é possível estabelecer as seguintes definições

$$
\begin{aligned}
& Y_{j}=e_{j}^{\prime} X=e_{j 1} X_{1}+e_{j 2} X_{2}+\ldots+e_{j p} X_{p} \\
& \operatorname{Var}\left[Y_{j}\right]=e_{j}^{\prime} \Sigma_{p x p} e_{j}=\lambda_{j}
\end{aligned}
$$

onde a Equação 5.3 define como obter o componente principal $Y_{j}$ e a Equação 5.4 define a respectiva variância deste.

\subsection{Distância de Bhattacharyya e de Jeffrey-Matusita}

Uma medida amplamente usada para medir a separabilidade de duas classes ( $h$ e $k$ nas fórmulas abaixo) é a distância de Jeffrey-Matusita $\left(J M_{h, k}\right)$ (Huber \& Dutra, 1998), que depende da distância de Bhattacharyya $\left(B_{h, k}\right)$ (Fukunaga, 1990)

$$
\begin{gathered}
J M_{h, k}=\sqrt{2\left(1-\exp \left(-B_{h, k}\right)\right)} \\
B_{h, k}=\frac{1}{8}\left(M_{h}-M_{k}\right)^{T}\left(\frac{C_{h}+C_{k}}{2}\right)^{-1}\left(M_{h}-M_{k}\right)+\frac{1}{2} \ln \left(\frac{\left|\frac{C_{h}+C_{k}}{2}\right|}{\sqrt{\left|C_{h}\right|\left|C_{k}\right|}}\right)
\end{gathered}
$$

onde $h, k$ são as classes que estão sendo comparadas e $M$ e $C$ são o vetor médio dos padrões e a matriz de covariância da classe, respectivamente.

Uma peculiaridade dessas distâncias é que elas crescem monotonicamente com o aumento da dimensionalidade, o que implica que a distância entre duas classes, dado um conjunto de atributos, sempre é maior do que a distância obtida por qualquer subconjunto desse conjunto original. Tal característica é o que permite a viabilidade de métodos ótimos, mas não exaustivos, 
como o branch and bound (Roncatti \& Batista Neto, 2007), por exemplo, que faz a comparação entre subconjuntos de dados de tamanhos iguais.

Para os objetivos deste trabalho, entretanto, é necessária a comparação de separabilidade entre classes com vetores de características de dimensões diferentes. Para chegar a esse objetivo, em todos os vetores de características foi aplicado o método PCA e somente os três componentes com maior variância foram considerados como o vetor representativo do vetor original. Desse modo, foi possível utilizar a distância de Jeffrey-Matusita para medir quão bem os clusters estão separados uns dos outros, não importando a dimensionalidade do vetor utilizado.

Como este projeto não envolve apenas a separação entre duas classes, foi adotado o procedimento usual de somar as distâncias de todos os pares de classes. Para fins de normalização no intervalo entre $[01]$, a soma obtida foi dividida pela quantidade de pares de classes e por $\sqrt{2}$, conforme Equação 5.7, onde $n$ é a quantidade de classes.

$$
J M=\sum_{h, k} \frac{J M_{h, k}}{\left(\begin{array}{l}
n \\
2
\end{array}\right) \sqrt{2}}
$$




$+\frac{1}{2}$

Na última etapa deste projeto, que consiste no reconhecimento de padrões dos vetores de características adquiridos na etapa precedente, foi utilizada uma rede neural artificial (RNA) denominada perceptron multicamadas, ou MLP (multilayer perceptron). Em virtude de haver poucas amostras para identificação, o método leave-one-out foi empregado para garantir a acurácia dos resultados de identificação adquiridos.

\subsection{Redes Neurais Artificiais (RNA)}

Redes neurais podem ser vistas como sistemas computacionais massivamente paralelos consistindo de um grande número de unidades de processamento simples (neurônios) (Jain et al., 2000). Tais unidades são dispostas em uma ou mais camadas e interligadas por um grande número de conexões, geralmente unidirecionais. Na maioria dos modelos essas conexões estão associadas a pesos, os quais armazenam o conhecimento representado no modelo e servem para ponderar a entrada recebida por cada neurônio da rede. O funcionamento dessas redes é inspirado em uma estrutura física concebida pela natureza: o cérebro humano (Braga et al., 2000).

Nesse sentido, a RNA, assim como o cérebro humano, passa inicialmente por uma fase de aprendizagem, em que um conjunto de exemplos é apresentado para a rede, dos quais extrai as características necessárias para representar a informação fornecida. Esse aprendizado propicia a capacidade de generalização, ou seja, de a rede reconhecer padrões que não foram apresentados previamente, o que a torna uma boa classificadora de padrões. 
Há diversos tipos de redes neurais, que variam de acordo com a quantidade de camadas de neurônios, tipos de função de ativação, ligações entre os neurônios etc., mas a unidade fundamental de todas elas - o neurônio - possui os mesmos elementos básicos. São eles:

1. Um conjunto de sinapses, sendo que cada qual é caracterizada por um peso. Especificamente, um sinal $x_{j}$ como entrada na sinapse $j$ conectada ao neurônio $k$ é multiplicado pelo peso sináptico $w_{k j}$.

2. Um adicionador para somar os sinais de entrada multiplicados pelos respectivos pesos sinápticos. As operações descritas aqui constituem um combinador linear.

3. Uma função de ativação para limitar a amplitude da saída do neurônio a uma faixa de valores finitos. Normalmente, a faixa de amplitude normalizada da saída de um neurônio está no intervalo de $[0,1]$ ou $[-1,1]$.

Adicionalmente, um valor externo denominado bias $b_{k}$ pode ser empregado para incrementar ou diminuir o cômputo do combinador linear na função de ativação, dependendo se o mesmo é positivo ou negativo, respectivamente. A Figura 6.1 exemplifica o modelo de um neurônio.

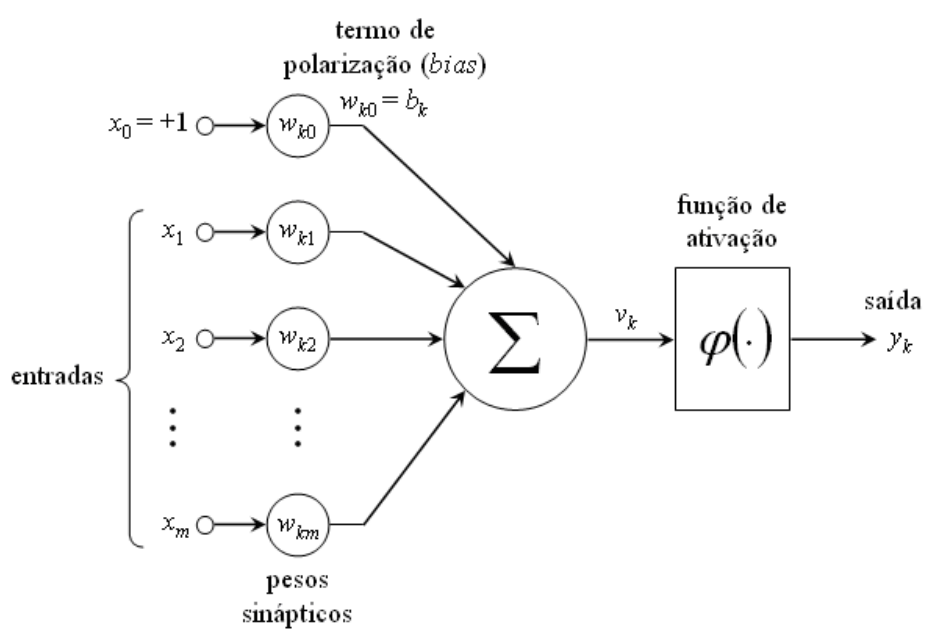

Figura 6.1: Modelo de neurônio.

Em termos matemáticos, o neurônio $K$ pode ser descrito pelo seguinte par de equações

$$
\begin{gathered}
u_{k}=\sum_{j=1}^{m} w_{k j} x_{j} \\
y_{k}=\varphi\left(u_{k}+b_{k}\right)
\end{gathered}
$$

onde $x_{1}, x_{2}, \ldots, x_{n}$ são os sinais de entrada; $w_{k 1}, w_{k 2}, \ldots, w_{k m}$ são os pesos sinápticos do neurônio $K ; u_{k}$ é o resultado do combinador linear devido aos sinais de entrada; $b_{k}$ é o bias; $\varphi($.$) é a função de ativação; e y_{k}$ é o sinal de saída do neurônio (Haykin, 1999). 
Essa descrição sucinta sobre as características mais gerais de uma RNA teve o objetivo de fornecer os subsídios básicos para a compreensão da RNA do tipo Perceptron Multicamadas (MLP). A escolha desse tipo de RNA para os propósitos deste projeto se deve à sua simplicidade em relação aos demais tipos existentes, bem como à sua capacidade de separar padrões não-linearmente separáveis, característica esta indispensável para um classificador realmente efetivo.

\subsubsection{Perceptron Multicamadas (MLP)}

Basicamente, esse tipo de RNA consiste em um conjunto de unidades sensoras que constituem uma camada de entrada, uma ou mais camadas intermediárias (escondidas) de neurônios (nodos computacionais), e uma camada de saída, também composta por nodos computacionais. A explicação desse arranjo é que as camadas intermediárias permitem que a rede aprenda tarefas complexas por extrair progressivamente características significativas dos padrões de entrada (Haykin, 1999). Como uma rede de uma única camada resolve apenas problemas linearmente separáveis e os problemas que as RNAs se propõem a resolver não apresentam geralmente essa disposição espacial ideal, ou seja, os elementos não são separáveis por hiperplanos, faz-se necessária a inclusão de novas camadas. A Figura 6.2 mostra um exemplo de uma MLP.

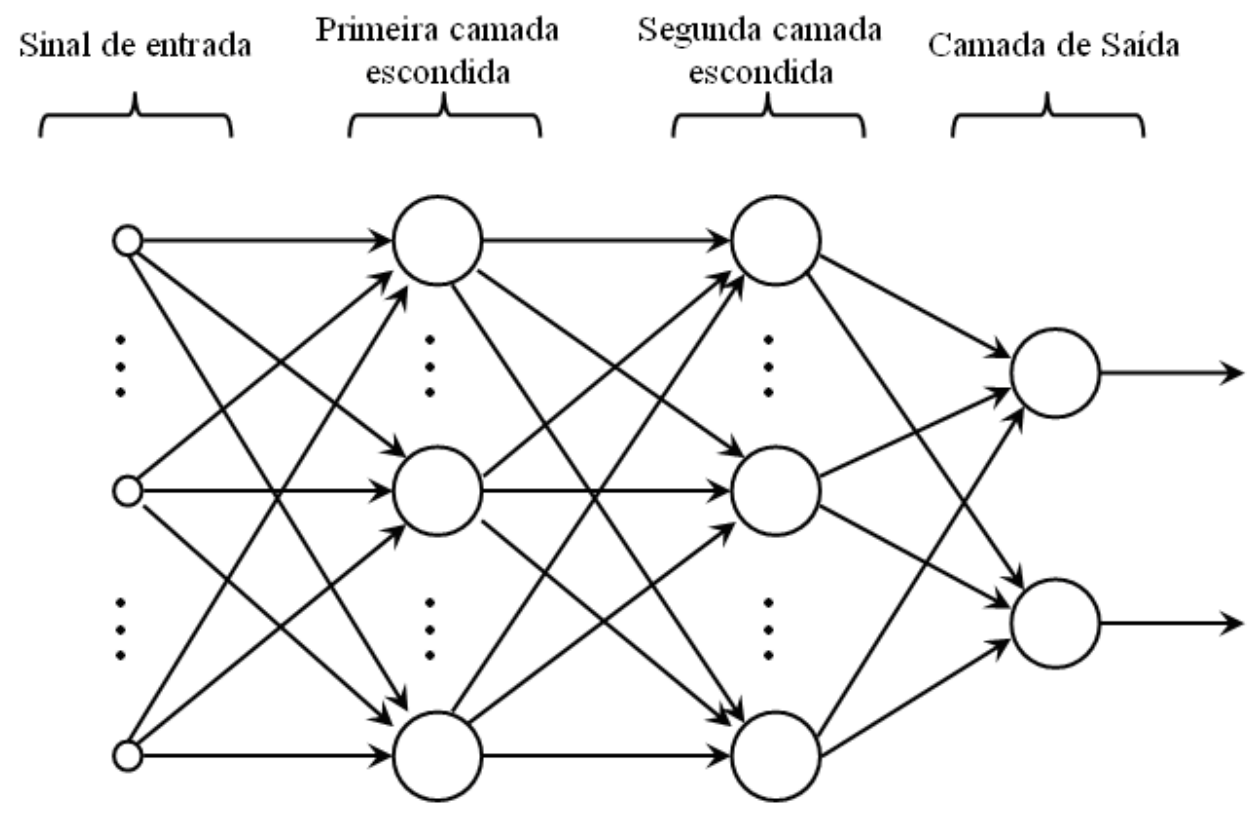

Figura 6.2: Arquitetura gráfica de uma MLP com duas camadas escondidas.

Para que uma rede MLP possa realmente tratar com dados que não são linearmente separáveis, além de possuir a arquitetura supracitada, os neurônios da mesma devem ter uma função de ativação não-linear e diferenciável. Ambas as exigências são relacionadas ao modo de treinamento da rede, que consiste na propagação dos erros obtidos entre as respostas esperadas e as oferecidas pela rede desde a camada de saída até a primeira camada escondida, de modo a 
ajustar os pesos sinápticos. Em relação à primeira exigência, se a função de ativação for do tipo limiar (threshold), a avaliação do erro será bastante complexa, uma vez que os nodos das camadas intermediárias e de saída não saberão quão distantes as respostas de seus nodos estão dos valores desejados. Tal afirmação poderia sugerir o uso de funções de ativação lineares, mas uma rede com mais de uma camada cujos nodos utilizam funções de ativação lineares é equivalente a uma rede de uma só camada, o que resolve apenas os problemas linearmente separáveis (Braga et al., 2000). Desse modo, só as funções de ativação não-lineares atendem às necessidades do algoritmo de treinamento. Quanto à segunda exigência, as funções precisam ser diferenciáveis para que o gradiente possa ser calculado, permitindo assim que os pesos sinápticos convirjam para valores ideais.

Quanto ao treinamento da rede MLP, há vários algoritmos disponíveis, porém o mais conhecido é o algoritmo back-propagation. Este é um algoritmo supervisionado que utiliza pares (entrada - saída desejada) para, por meio de um mecanismo de correção de erros, ajustar os pesos da rede. O treinamento ocorre em duas fases, em que cada fase percorre a rede em um sentido. Essas duas fases são chamadas de fase forward e fase backward. A fase forward é utilizada para definir a saída da rede para um dado padrão de entrada. A fase backward utiliza a saída desejada e a saída fornecida pela rede para atualizar os pesos de suas conexões.

$\mathrm{O}$ algoritmo back-propagation procura minimizar o erro obtido pela rede ajustando pesos e limiares para que eles correspondam às coordenadas dos pontos mais baixos de uma superfície de erro. Para isso, ele utiliza um método denominado gradiente descendente.

O gradiente de uma função está na direção e sentido em que a função tem taxa de variação máxima. Isso garante que a rede caminha na superfície que vai reduzir mais o erro obtido. Para superfícies simples, esse método certamente encontra a solução com erro mínimo. Para superfícies mais complexas, no entanto, o algoritmo, além de se tornar lento, pode convergir para mínimos locais, que são soluções estáveis, mas que não correspondem à melhor solução esperada.

Para superar esses problemas, algumas técnicas são utilizadas tanto para acelerar o processo de ajuste de pesos como quanto para reduzir a incidência de mínimos locais. São elas:

- utilizar taxa de aprendizado decrescente;

- adicionar nós intermediários;

- utilizar um termo momentum;

- adicionar ruído aos dados.

\subsection{Validação Cruzada}

$\mathrm{Na}$ validação simples, as amostras de treinamento rotuladas são particionadas randomicamente em duas partes: uma é usada como conjunto de treinamento tradicional de modo a ajustar 
os parâmetros do classificador. O outro conjunto - denominado conjunto de validação - é usado para estimar o erro de generalização. Como o objetivo principal é o menor erro de generalização, o classificador é treinado até alcançar um erro de validação mínimo. Para tanto, é essencial que o conjunto de validação (ou de teste) não inclua pontos usados para treinar os parâmetros no classificador (Duda et al., 2001).

A seguir, são descritas as variantes de validação cruzada (cross-validation).

\subsubsection{Hold Out}

O conjunto de dados disponíveis é dividido em dois subconjuntos, um para treinamento e o outro para teste. A maior desvantagem dessa técnica é que ela reduz o tamanho do conjunto de treinamento e do conjunto de validação. Um outro problema é decidir quantos dos $N$ dados disponíveis serão alocados para o conjunto de treinamento e para o conjunto de teste (Theodoridis \& Koutroumbas, 1999).

\subsubsection{M-fold}

Nesse método, muitas vezes empregado quando há escassez de exemplos rotulados, o conjunto disponível de $N$ exemplos é dividido em $K$ subconjuntos, $K>1$, onde $K$ é divisor de $N$. O modelo é treinado com todos os subconjuntos exceto por um, que será usado como conjunto de validação. O processo é repetido $K$ vezes, cada vez com um subconjunto diferente como conjunto de validação. A performance do modelo é obtida pela média do erro quadrático de todas as $K$ classificações realizadas. Há uma desvantagem na validação cruzada $m$-fold: ela pode requerer um excessivo custo computacional, posto que o modelo tem de ser treinado $K$ vezes, onde $1<K \leq N$ (Haykin, 1999).

\subsubsection{Leave-one-out}

Quando o número de exemplos rotulados disponíveis, $N$, é severamente limitado, há a necessidade de usar a forma extrema de validação cruzada conhecida como método leave-one-out. Nesse caso, $N-1$ exemplos são usados para treinamento e um exemplo é usado para validação. O experimento é repetido $N$ vezes, cada vez um exemplo diferente sendo usado como validação. $\mathrm{O}$ erro quadrático médio é então a média dos $N$ erros quadráticos do experimento. 



\section{Procedimentos Experimentais}

\subsection{Preparação das Amostras}

Para cada espécie estudada, foram obtidos segmentos medianos do semilimbo de folhas completamente expandidas de cinco indivíduos adultos diferentes, escolhidos ao acaso, localizados na Estação Ecológica de Assis, Assis, Estado de São Paulo, Brasil (22³3'65” $22^{\circ} 36^{\prime} 68^{\prime \prime}$ e $50^{\circ} 22^{\prime} 29^{\prime \prime}$ - 50²3'00”W). As amostras foram fixadas em FAA70, desidratadas em uma série etanólica, embebidas em parafina e cortadas em secções de $8 \mu m$. As secções transversais foram coradas com azul de astra e fucsina básica e montadas em entellan. As imagens foram obtidas com microscópio trinocular Leica, modelo DM-1000, acoplado a uma câmera de vídeo Leica, DFC-280 com uma ampliação $200 x$ (experimento com espécies diversas) e de $400 x$ (experimento com Gochnatia polymorpha em diferentes ambientes, estações e condições de luminosidade)

Nos experimentos para espécies vegetais diversas, 80 imagens foram utilizadas, sendo dez imagens por espécie. Para a composição das imagens de uma única espécie, foram utilizadas cinco folhas distintas e retiradas duas imagens de regiões diferentes do mesmo corte transversal de cada uma delas. Cada folha foi nomeada com uma letra (a, b, c, d, e) e as duas imagens retiradas de cada folha mantiveram essa nomeação, conforme ilustra o exemplo da Figura 7.1. Desse modo, nos experimentos é possível distinguir imagens oriundas de uma mesma folha ou de folhas distintas. A seguir, as imagens foram rotacionadas para que o corte transversal ficasse o mais próximo possível da posição vertical.

Nos experimentos para a análise morfológica de uma mesma espécie em diferentes situações (espécie Gochnatia polymorpha), 30 imagens foram utilizadas e divididas igualmente em 


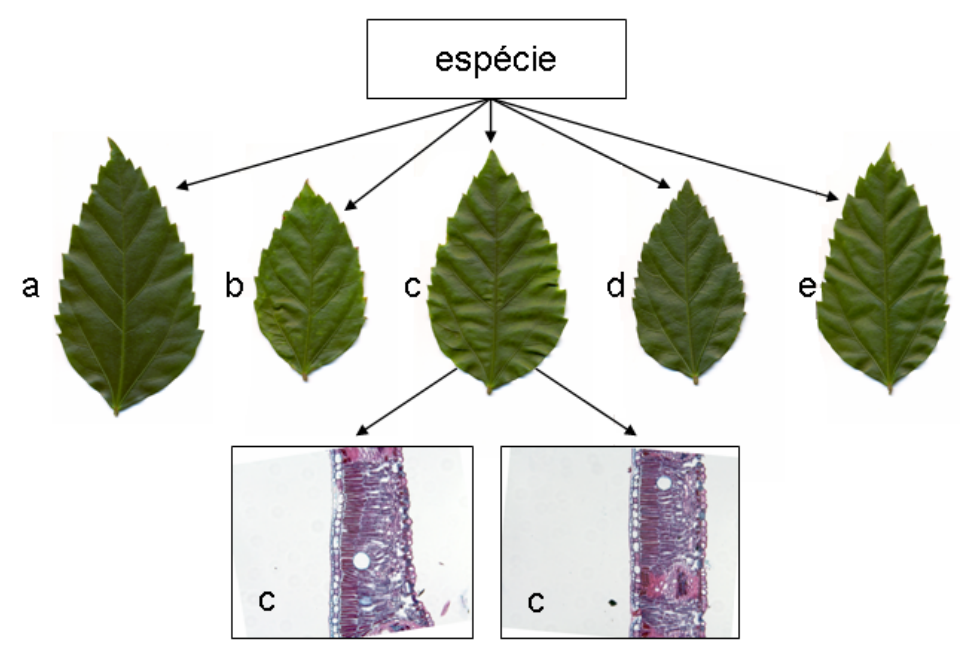

Figura 7.1: Esquema de como as imagens de uma espécie foram adquiridas

dois grupos (ambientes Cerrado e Mata Ciliar; estações Chuvosa e Seca e condições de Sol e Sombra). A composição das imagens seguiu basicamente as regras aplicadas no experimento com espécies diversas: cinco folhas distintas de cada ambiente, estação ou condição e retirada de três imagens de regiões diferentes do corte transversal de cada uma delas. Cada folha foi nomeada com uma letra ( $a, b, c, d, e)$ e as três imagens retiradas de cada folha mantiveram essa nomeação.

Esses procedimentos foram adotados para aumentar a quantidade de imagens por espécie (ou de uma espécie em determinado ambiente, por exemplo), posto que o processo de preparo das folhas torna difícil a obtenção de muitas amostras distintas. Além disso, esse procedimento serviu para verificar as variações entre indivíduos diferentes bem como variações dentro de uma mesma folha.

\subsection{Parâmetros de Rede Neural}

A identificação das amostras foi efetuada por meio de uma rede neural artificial perceptron multicamadas composta por cinco camadas - camada de entrada, camadas intermediárias de 30, 100, 60 neurônios e camada de saída de 8 (experimento com espécies diversas) ou 2 (experimento com a mesma espécie em ambientes, estações ou condições diferentes de luminosidade) neurônios. Os neurônios das camadas intermediárias utilizam a função de ativação do tipo tangencial sigmoidal hiperbólica e os neurônios da camada de saída utilizam a função de ativação do tipo sigmoidal logarítmica. $\mathrm{O}$ algoritmo de treinamento escolhido foi uma variação do algoritmo back-propagation conhecida como algoritmo de Fletcher-Reeves, que é um algoritmo de gradiente conjugado cuja velocidade de convergência é bem mais alta do que o back-propagation básico. Cada treinamento da rede neural possui 500 ciclos de apresentação dos dados e tem o objetivo de atingir o erro quadrático médio de $10^{-4}$. 


\subsection{Medida de Espessura da Cutícula}

Para a medição da cutícula, que é a camada mostrada pela Figura 2.1(a), três janelas $20 x 60$ foram retiradas manualmente de cada amostra, de modo que a média das espessuras foi adotada como a espessura da cutícula da amostra. Devido ao fato de o processo de aquisição de imagens nem sempre preservar a cutícula com boa qualidade, a escolha do posicionamento das janelas teve de ser feito de forma criteriosa. Além disso, para algumas poucas imagens houve a necessidade de retirar manualmente eventuais sujeiras.

O cálculo das espessuras foi feito a partir de um conjunto de regras para a escolha da imagem segmentada que melhor representasse a imagem original. Primeiramente, o conjunto de valores $\alpha=[0.45,0.46 \ldots, 0.65]$ e $\lim =[8,9,10]$ foi adotado para que um conjunto de imagens segmentadas fosse obtido (no caso, 21 x $3=63$ imagens de cutícula/amostra) a partir do algoritmo do funcional de Mumford-Shah. Do conjunto de imagens segmentadas, foram selecionadas aquelas que obedeceram à seguinte regra: possuir ao menos uma zona plana zona plana, no presente caso, é um conjunto de pixels que possuam o mesmo nível de cinza e que estejam conectados entre si por uma vizinhança- 8 - que não seja a zona predominante nos primeiros $20 \%$ da área esquerda da imagem segmentada e que não possua nenhum pixel que toque a lateral direita da imagem (ver Figura 7.2). Uma vez que a imagem segmentada atenda a essas exigências, uma das zonas planas que se enquadram nas regras acima tem de ser escolhida como a representante da cutícula. Para tanto, aquela cuja média de intensidade é maior é a selecionada. Na Figura 7.2(b), é possível verificar que a mesma possui três zonas planas que se enquadram nas regras supracitadas. A zona representada por $Z P$ foi a escolhida por apresentar a média de intensidades mais alta.

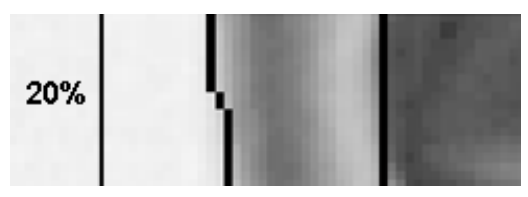

(a)

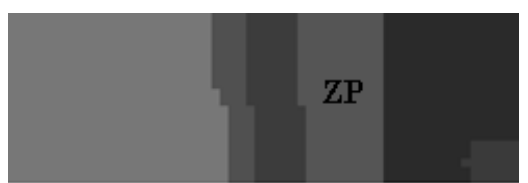

(b)

Figura 7.2: Cutícula e respectiva segmentação numa amostra da espécie Byrsonima intermedia.

Após a obtenção desse subconjunto de imagens segmentadas e respectivas zonas planas, há a necessidade de escolha da imagem segmentada que representa a imagem original. Para tanto, a zona plana escolhida $Z P$ de cada uma é utilizada para maximizar a seguinte função de custo

$$
F(A z p, A i)=\frac{A z p}{A i}
$$

onde $A z p$ é área da zona plana e $A i$ é a área da imagem original. Essa função tem o objetivo de selecionar a imagem com a maior zona plana, de modo a representar a cutícula o mais fielmente possível. 
Uma vez cumpridas as fases precedentes, o próximo passo é detectar as bordas à direita da zona plana predominante nos primeiros $20 \%$ da imagem (Figura 7.2(a)) e a borda à direita da zona plana selecionada como representante da cutícula. Finalmente, uma simples média das medidas de distâncias entre os pontos das bordas fornece a espessura média da cutícula. A Figura 7.3 mostra as bordas das cutículas das amostras da espécie Miconia chamissois.
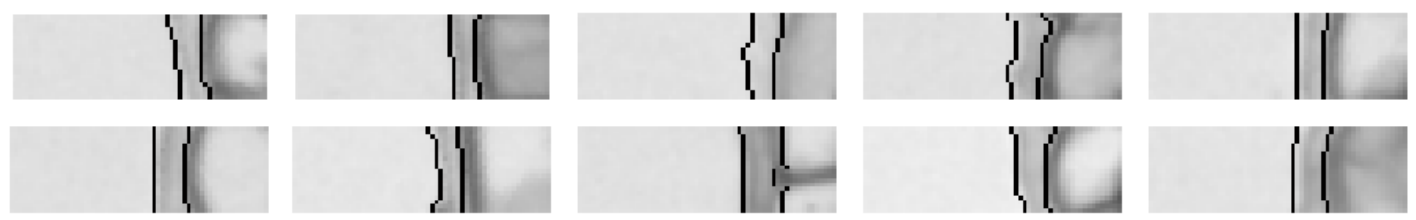

Figura 7.3: Bordas das cutículas das amostras da espécie Miconia chamissois.

\subsection{Experimentos na Epiderme Superior}

Para a análise da epiderme superior, foram retiradas manualmente três janelas $150 x 300$ de cada amostra, de modo que a média das assinaturas (espessura, cromaticidade e medidas de textura) da epiderme superior de cada janela foi considerada como a assinatura da epiderme superior da amostra.

\subsubsection{Medida de Espessura}

Para a obtenção dessa medida, foram necessárias duas fases de segmentação. A primeira foi responsável por encontrar a imagem segmentada que melhor representasse a borda direita da epiderme (ao lado do parênquima paliçádico). A segunda fase ficou com a tarefa de encontrar a borda entre a cutícula e o pano de fundo da imagem. A Figura 7.4 mostra a imagem original e as duas imagens segmentadas necessárias para encontrar as bordas da epiderme superior.

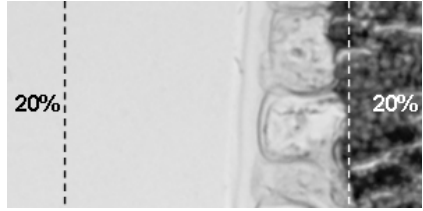

(a)

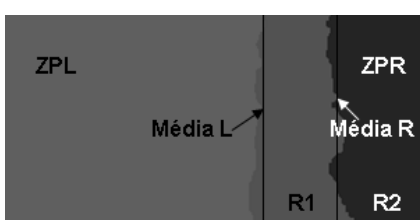

(b)

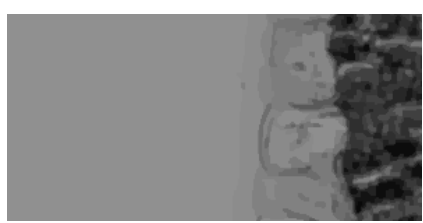

(c)

Figura 7.4: Imagens de epiderme superior. a - Imagem original; b - Imagem segmentada selecionada na primeira fase de segmentação; c - Imagem segmentada selecionada na segunda fase de segmentação.

A primeira fase de segmentação tem o objetivo de segmentar o parênquima paliçádico da melhor forma possível, de modo que a borda entre este e a epiderme superior seja detectada. Para tanto, um conjunto de valores $\alpha=[0.30,0.31 \ldots, 0.65]$ e $\mathrm{lim}=[10,11,12]$ foi adotado para que um conjunto de imagens segmentadas fosse obtido ( 36 x 3=108 imagens). De 
cada imagem segmentada, foi encontrada a zona plana dominante nos primeiros $20 \%$ do lado esquerdo da imagem, denominada $Z P L$, e a zona plana dominante nos últimos $20 \%$ do lado direito da imagem, denominada $Z P R$ (ver Figura 7.4(a) e 7.4(b)). Uma vez descobertas essas zonas planas, a borda direita da zona plana $Z P L$ e a borda esquerda da zona plana $Z P R$ foram extraídas. A partir desses dados, foi possível descobrir as médias Média L e Média R, que foram usadas para o traçado de dois retângulos: o primeiro entre as médias Média L e Média $R$, denominado $R 1$ e o segundo entre a média Média $R$ e a lateral direita da imagem, denominado $R 2$. A partir de então, cada imagem segmentada foi utilizada para maximizar a seguinte função de custo

$$
F(A E S, A R 1, A P P, A R 2)=\frac{A E S}{A R 1}+\frac{A P P}{A R 2}
$$

onde $A E S$ é a quantidade total de pixels que estão entre a borda direita da zona plana $Z P L \mathrm{e}$ a borda esquerda da zona plana $Z P R$ e que estão dentro do retângulo $R 1$ (considerada assim a área da epiderme superior), $A R 1$ é a área total do retângulo $R 1, A P P$ é a quantidade de pixels pertencentes à zona plana $Z P R$ que estão dentro do retângulo $R 2$ (considerada como a área do parênquima paliçádico), $A R 2$ é a área total do retângulo $R 2$.

$\mathrm{O}$ intuito desses procedimentos é encontrar a imagem segmentada que maximize a área pertencente ao parênquima paliçádico dentro do retângulo $R 2$ e, concomitantemente, maximize a área ocupada pela epiderme superior dentro do retângulo $R 1$. Vale salientar também que, pelo fato de a epiderme superior ter uma estrutura cheia de células irregulares de vários formatos e cores, não é possível segmentá-la pelo método mais intuitivo, ou seja, encarando-a como uma zona plana. Desse modo, houve a necessidade do artifício de encará-la como os pixels entre as bordas da zona plana $Z P L$ (que representa o pano de fundo) e $Z P R$, que representa o parênquima paliçádico.

Um outro problema relacionado à epiderme superior é o fato de que muitas vezes esta tem uma estrutura extremamente difícil de diferenciar do parênquima paliçádico (ver Figura 7.5), o que muitas vezes ocasiona a escolha pela função de custo de uma imagem segmentada com a epiderme superior totalmente suprimida. Para contornar esse problema, foi adotado que imagens que tivessem áreas de epiderme superior menores que 3\% (espécies diversas), 30\% (caso da espécie Gochnatia polymorpha nos ambientes Cerrado e Mata Ciliar e nas estações Chuvosa e Seca) e $25 \%$ (caso da espécie Gochnatia polymorpha sob condições de Sol e Sombra) da área total da imagem não partipariam da seleção para a escolha da imagem segmentada representante da epiderme superior. No último caso citado, para três amostras sob condição de Sombra, foi necessário diminuir esse limiar para $7 \%$ devido ao fato de que estas possuem uma epiderme superior muito fina e extremamente destoante das demais amostras do seu grupo.

A segunda fase de segmentação foi necessária em virtude de que, na primeira fase de segmentação, algumas imagens mantêm a cutícula e outras não, dependendo de quão tênue esta se apresente. Para solucionar esse problema, um conjunto de valores $\alpha=[0.65,0.64 \ldots, 0.30]$ 


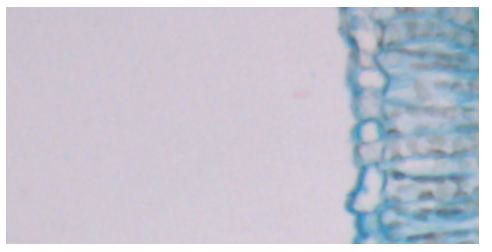

Figura 7.5: Exemplo de semelhança entre a epiderme superior e o parênquima paliçádico da amostra da espécie Jacaranda caroba.

e $\lim =[7,8, \ldots, 12]$ foi adotado para a obtenção de um conjunto de imagens segmentadas. Diferentemente do método anterior, que analisa todas as imagens segmentadas para descobrir a melhor, o processo aqui descrito analisa as imagens segmentadas até encontrar a primeira que satisfaça à seguinte condição: que o vetor que representa a diferença entre a borda esquerda da epiderme superior encontrada na segunda fase de segmentação e a borda esquerda da epiderme superior da imagem selecionada na primeira fase de segmentação tenha pelo menos $70 \%$ de seus elementos menores ou iguais a 25 pixels. É oportuno salientar que pela ordem decrescente dos valores de $\alpha$, as primeiras imagens segmentadas analisadas são aquelas que detêm os maiores detalhes da imagem original.

Essa abordagem foi adotada com o intuito de que a imagem selecionada tivesse uma certa tolerância em relação ao ruído de pano de fundo (30\% ou menos dos elementos do vetor maiores que 25 pixels) que pudesse ser confundido com a cutícula - em muitas imagens, o ruído do pano de fundo é tão ou mais intenso do que a cutícula, de modo que a tentativa de sua eliminação também elimina esta. $\mathrm{O}$ valor de 25 pixels na condição anterior foi determinado empiricamente, baseado nas medidas das cutículas apresentada na Seção 7.3.

Uma vez que a imagem segmentada da segunda fase de segmentação foi escolhida, um vetor que representa as distâncias entre as bordas direitas da primeira fase de segmentação e as bordas esquerdas encontradas na segunda fase de segmentação é construído. Contudo, ainda resta um último desafio a ser enfrentado, que é a escolha de quais distâncias serão usadas para a retirada da média de distância da epiderme superior. Tal desafio se deve ao fato de que, em muitas imagens selecionadas na primeira fase de segmentação, a zona plana $Z P R$ invade áreas que pertencem à epiderme superior, o que acarreta a coleta de medidas de distâncias errôneas, conforme exemplo da Figura 7.6.

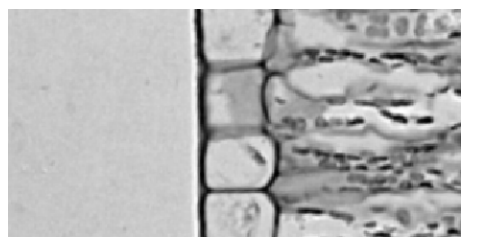

(a)

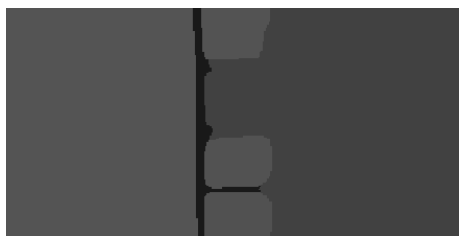

(b)

Figura 7.6: Imagens de epiderme superior de Vochysia tucanorum. a - Imagem original; b Imagem segmentada selecionada na primeira fase de segmentação. 
A resolução desse problema foi feita mediante a ordenação do vetor de distâncias (ou espessuras) e escolha de uma fatia desse vetor conforme a seguinte regra

$$
V D=\left\{\begin{array}{l}
V D(0.90 * \text { length }(V D): 0.97 * \text { length }(V D)), \frac{\sigma(V D)}{\mu(V D)}>0.10 \\
V D(0.20 * \text { length }(V D): 0.80 * \text { length }(V D)), \frac{\sigma(V D)}{\mu(V D)} \leq 0.10
\end{array}\right.
$$

onde $V D$ é o vetor de distâncias ordenado de forma crescente, $\sigma$ é o desvio padrão, $\mu$ é a média e length é o comprimento do vetor. Basicamente, a Equação 7.3 expressa que se o vetor de distâncias tem desvio padrão $10 \%$ maior que sua média, então é extremamente provável que parte da epiderme superior tenha sido suprimida (ver Figura 7.6), de modo que o melhor a fazer é selecionar as maiores distâncias (no caso, empiricamente, foi adotado entre as $90 \%$ e 97\%) maiores distâncias. Caso contrário, é provável que a epiderme superior tenha sido bem segmentada, bastando, portanto, selecionar entre as $20 \%$ e $80 \%$ maiores distâncias. Finalmente, o valor final da epiderme superior é a média desse novo vetor obtido pela Equação 7.3 menos o valor da espessura da cutícula previamente encontrada, conforme a Seção 7.3. A Figura 7.7 mostra a medida de espessura (barras em negrito horizontais) das amostras da espécie Vochysia tucanorum.
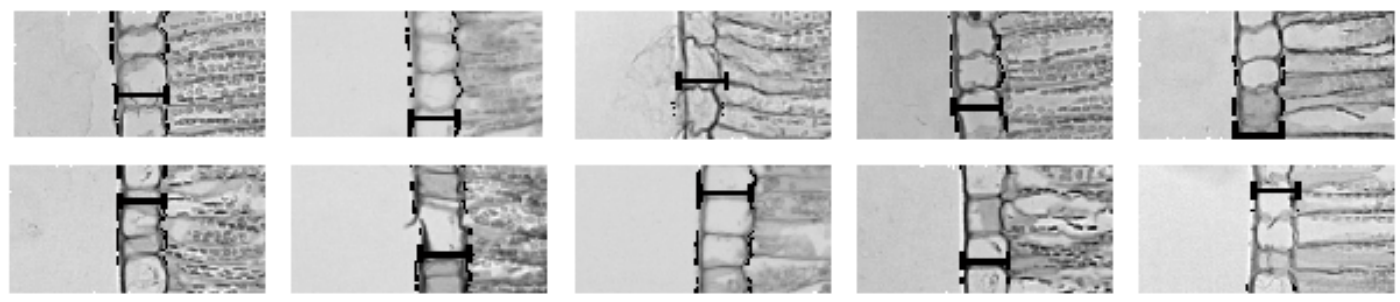

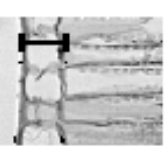

Figura 7.7: Espessuras das epidermes superiores das amostras da espécie Vochysia tucanorum.

\subsubsection{Coeficientes Tricromáticos}

Como as espécies reagem de formas diferentes ao corante aplicado na fase de preparação das amostras, estas apresentam uma coloração específica na epiderme superior. Essas informações, por conseguinte, são úteis para identificar uma determinada espécie. Desse modo, com as medidas de espessura extraídas da epiderme superior, conforme a Seção 7.4.1, foi possível separar automaticamente a mesma do restante da imagem e analisar seus coeficientes tricromáticos.

De cada amostra foram retiradas três janelas de tamanho $150 x$ (medida da epiderme superior), conforme exemplo na Figura 7.8, de modo que a média de cada coeficiente $R, G, B$ foi adotada como o coeficiente tricromático da amostra.

\subsubsection{Estatísticas de Primeira Ordem}

Como o objetivo deste trabalho é extrair diversos vetores de características que possam contribuir de forma sinérgica para a identificação das espécies, uma das formas de análise desenvol- 


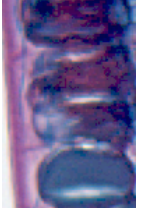

(a)

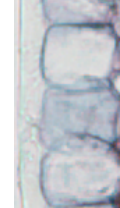

(b)

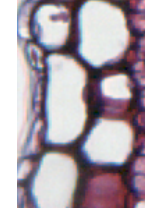

(c)

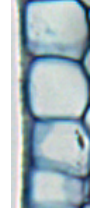

(d)

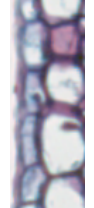

(e)

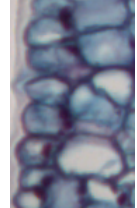

(f)

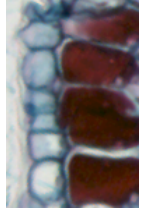

(g)

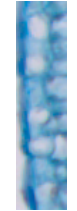

(h)

Figura 7.8: Janelas retiradas automaticamente e que contêm a epiderme superior das espécies: a - Byrsonima intermedia, b - Miconia albicans, c - Tibouchina stenocarpa, d - Vochysia tucanorum, e - Xylopia aromatica, f - Gochnatia polymorpha, g - Miconia chamissois, h Jacaranda caroba.

vida foi a avaliação de dados de textura da epiderme superior. Para tanto, houve a necessidade de contornar o fato de que as diversas espécies apresentam espessuras diferentes de epiderme superior, tornando inviável a análise direta das janelas automaticamente obtidas, assim como foi feito para a análise dos coeficientes tricromáticos, conforme Seção 7.4.2. Para solucionar o problema, foi estabelecido uma janela padrão $300 x 300$ como grid para abrigar as janelas $150 x$ (medida da epiderme superior), conforme exemplo na Figura 7.9.

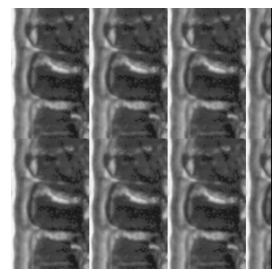

(a)

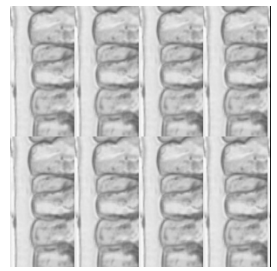

(b)

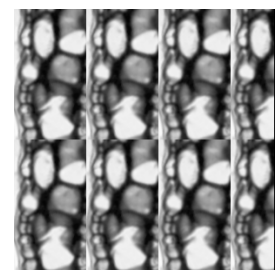

(c)

Figura 7.9: Exemplos de janelas $300 x 300$ como grid de epiderme superior das amostras: a espécie Byrsonima intermedia, b - espécie Miconia albicans, c - espécie Tibouchina stenocarpa.

Uma vez solucionado o problema das janelas, para a realização deste experimento a média aritmética dos vetores de características de três janelas 300x300 em nível de cinza de cada amostra foi adotada como o vetor representativo desta.

Para a seleção do grupo de medidas que melhor identificam as amostras pela epiderme superior, foram feitas combinações ( 3 a 3), (4 a 4), (5 a 5) e com todas as características reunidas das medidas de média, variância, obliqüidade, curtose, energia e entropia. De cada combinação foi extraída a soma das distâncias de Jeffrey-Matusita $(J M)$ entre cada par de classes (ver Seção 5) e do grupo com a maior distância as respectivas medidas foram selecionadas para identificação por rede neural. Para tanto, foi necessário averiguar 42 combinações $\left(\sum_{i=3}^{6} C_{6, i}\right)$.

\subsubsection{Matrizes de Co-ocorrência}

Nos experimentos realizados, assim como na seção precedente, foram adotadas três janelas $300 x 300$ em nível de cinza por amostra, sendo que a média dos vetores foi adotada como o vetor 
representativo. Os parâmetros fixos desse método foram matrizes simétricas (pares $d \mathrm{e}-d$ ) e ângulos de $\left(0^{\circ}, 45^{\circ}, 90^{\circ}, 135^{\circ}\right)$. As medidas testadas foram energia, entropia, correlação, homogeneidade, contraste e valor absoluto.

Para a seleção de características o ideal seria fazer combinações dos 24 atributos (cada medida possui 4 matrizes de co-ocorrência, ou seja, é representada por 4 valores), mas computacionalmente esse procedimento é inviável. A solução desse problema foi dividir os 24 atributos em 12 grupos de 2 atributos - por exemplo, energia (matrizes de $0^{\circ}$ e $90^{\circ}$ ), entropia (matrizes de $45^{\circ}$ e $135^{\circ}$ ) etc. Desse modo, para as distâncias $d=[1,2, \ldots, 5]$, foram feitas combinações dos 12 grupos na forma ( 3 a 3), ( 4 a 4), .., (11 a 11) e com todos os atributos reunidos. A seguir, a soma das distâncias $J M$ entre as classes foi utilizada para selecionar o melhor conjunto. O total de buscas realizadas foi de 20.085 , ou seja, $\left(5 \sum_{i=3}^{12} C_{12, i}\right)$.

\subsubsection{BoxCounting 3D}

A escolha de alguns parâmetros nesse método foi efetuada por busca exaustiva usando como critério a distância de Jeffrey-Matusita. Como parâmetros fixos, foram adotados um cubo inicial de lado 1 e um cubo final de lado 300 (dimensão da janela). Quanto ao processo de busca, o mesmo foi efetuado por três varreduras. A primeira corresponde ao intervalo de valores $\sigma=[2,2.1,2.2, \ldots, 8]$ da função gaussiana usada para suavização da curva de Dimensão Fractal MultiEscala. A segunda se refere ao incremento adotado para o tamanho dos cubos e a busca foi feita no intervalo $[1,2,3, \ldots, 30]$. A terceira varredura é realizada no vetor obtido para a determinação de qual percentagem inicial do mesmo é relevante no processo de identificação. É importante salientar que, dependendo do incremento de cubo averiguado, o vetor resultante possui um comprimento diferente, o que implica um número diferente de buscas por vetor.

\subsection{Experimentos no Parênquima Paliçádico}

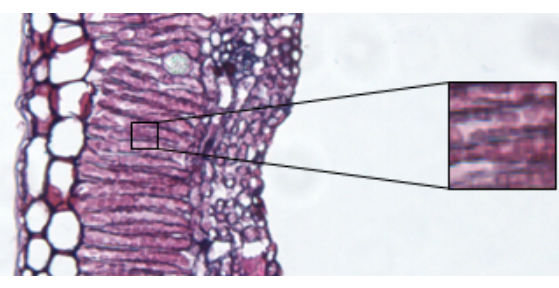

Figura 7.10: Amostra de Tibouchina stenocarpa e respectiva janela $60 x 60$ do parênquima paliçádico

No parênquima paliçádico foram retiradas manualmente quatro janelas $60 x 60$ pixels (ver exemplos na Figura 7.11) de cada amostra na camada de células mais próxima à epiderme superior, sendo que a média das assinaturas das janelas foi adotada como a assinatura da amostra. 
Em cada janela foram calculados os coeficientes tricromáticos, estatísticas de primeira ordem, matrizes de co-ocorrência e caminhada determinística do turista.

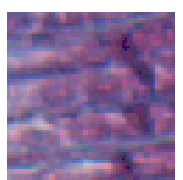

(a)

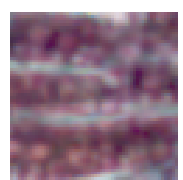

(b)

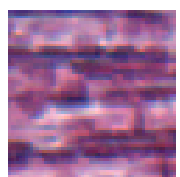

(c)

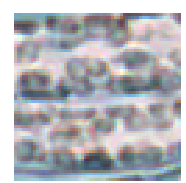

(d)

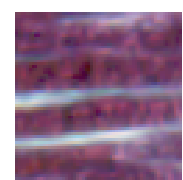

(e)

Figura 7.11: Janelas $60 x 60$ retiradas do parênquima paliçádico das espécies: a - Byrsonima intermedia, b - Miconia albicans, c - Tibouchina stenocarpa, d - Vochysia tucanorum, e Xylopia aromatica.

\subsubsection{Coeficientes Tricromáticos}

Assim como o conjunto epiderme superior-cutícula, o parênquima paliçádico também reagiu de formas diferentes ao corante aplicado no preparo das imagens, de modo que algumas espécies apresentaram uma coloração específica, que pôde ser usada como assinatura da espécie.

Para a extração de características, as imagens das janelas $60 x 60$ do parênquima paliçádico foram armazenadas no formato $R G B$. Desse modo, conforme especifica a Seção 4.1, foram obtidos vetores de características de três atributos.

\subsubsection{Estatísticas de Primeira Ordem}

Esse experimento foi realizado nas janelas $60 x 60$ em nível de cinza. As medidas averiguadas foram média, variância, obliqüidade, curtose, energia e entropia. O processo de busca exaustiva seguiu exatamente as mesmas regras descritas na Seção 7.4.3.

\subsubsection{Matrizes de Co-ocorrência}

Esse experimento foi realizado nas janelas $60 x 60$ em nível de cinza. As medidas utilizadas para verificação de desempenho e os detalhes da busca exaustiva para seleção das melhores características seguem as regras descritas na Seção 7.4.4.

\subsubsection{BoxCounting 3D}

Esse experimento foi realizado nas janelas $60 x 60$ em nível de cinza. A aplicação desse método no parênquima paliçádico segue basicamente as mesmas regras descritas na Seção 7.4.5. A única diferença é o intervalo de incrementos de tamanho de cubo que foi avaliado, que, no presente caso, é $[1,2, \ldots, 12]$. 


\subsubsection{Caminhada Determinística do Turista}

Entre as várias formas de obter um vetor de características pela caminhada determinística do turista, conforme foi explicado na Seção 4.4.1, neste trabalho foram utilizados três tempos de transição $(t=0,1$ e 2$)$ e dois períodos de ciclo $(a=2)$ de cada uma das seguintes memórias $\mu=2,3,5,7$ e 11 e posterior concatenação dos vetores obtidos. Essa abordagem foi a escolhida por ter apresentado uma excelente performance de classificação, com taxa de erro de 0.0500 (ver trabalho (Backes et al., 2006)). Desse modo, o vetor possui 30 atributos e assume a seguinte forma

$$
\varphi\left(\mu_{i}, \mu_{f}\right)=\left[\psi_{\mu_{i}}(3,2), \ldots \psi_{\mu_{f}}(3,2)\right]
$$

\subsection{Experimentos no Parênquima Lacunoso}

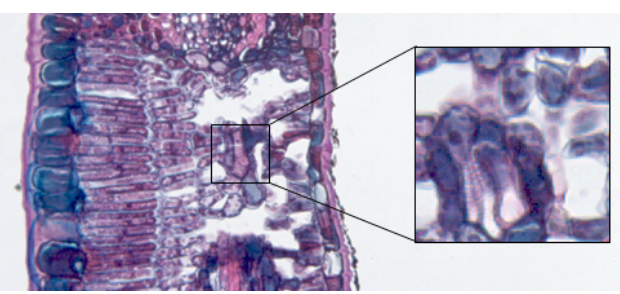

Figura 7.12: Amostra de Byrsonima intermedia e respectivo grid $1 x 1$ de janela $150 x 150$ do parênquima lacunoso

Da região do parênquima lacunoso foram montadas três janelas de $150 x 150$ pixels de cada amostra (a média dos vetores de características das três janelas foi adotado como o vetor da amostra), sendo que essas janelas seguem uma das três seguintes regras: um grid $3 x 3$ de janelas $50 x 50$ pixels (método aplicado nas espécies Miconia albicans, Tibouchina stenocarpa e Jacaranda caroba); um grid $2 \times 2$ de janelas $75 \times 75$ (método aplicado nas espécies Miconia chamissois, Xylopia aromatica, Gochnatia polymorpha); ou um grid $1 \times 1$ de janela $150 x 150$ (método aplicado nas espécies Byrsonima intermedia, Vochysia tucanorum). No caso dos experimentos da espécie Gochnatia polymorpha em diferentes ambientes, estações ou condições, como a ampliação das imagens foi de 400x, foi utilizado um grid $1 x 1$ de janela $150 x 150$.

Esse procedimento foi adotado em virtude de as amostras possuírem parênquimas lacunosos de tamanhos variados e pelo fato de que a adoção de uma janela de dimensões reduzidas para todas as amostras resultaria em perda de informação, visto que o parênquima lacunoso possui células dispostas frouxamente, com muitos espaços intercelulares. Como não foi aferida a cromaticidade nessa região foliar, todos os experimentos foram realizados com as imagens em nível de cinza. A Figura 7.13 mostra exemplos de janelas $150 x 150$ obtidas. 


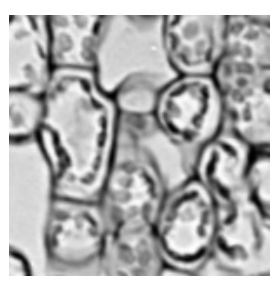

(a)

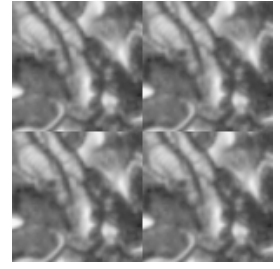

(b)

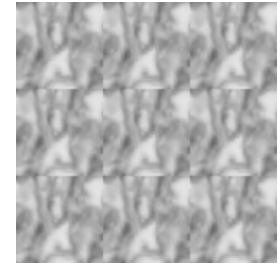

(c)

Figura 7.13: Exemplos de janelas $150 x 150$ no método BoxCounting 3D: a - grid $1 x 1$ de janela $150 x 150$ da espécie Vochysia tucanorum, b - grid $2 \times 2$ de janelas $75 x 75$ da espécie Xylopia aromatica, c - grid $3 \times 3$ de janelas $50 x 50$ da espécie Jacaranda caroba.

\subsubsection{Estatísticas de Primeira Ordem}

Nesse experimento foram averiguadas as medidas de média, variância, obliqüidade, curtose, energia e entropia. A busca exaustiva pelo critério de distância de Jeffrey-Matusita segue as regras descritas na Seção 7.4.3.

\subsubsection{Matrizes de Co-ocorrência}

Nesse experimento, os parâmetros das matrizes de co-ocorrência, as medidas verificadas e o processo de busca exaustiva seguem a descrição na Seção 7.4.4.

\subsubsection{BoxCounting 3D}

Como nos demais experimentos com esse método, foi estabelecido como parâmetros constantes o cubo inicial de lado 1 e cubo final de lado igual à dimensão da janela, ou seja, 150. O processo de varredura segue as regras constantes na Seção 7.4.5, exceto pelo intervalo de incremento dos cubos - $[1,2, \ldots, 15]$.

\subsubsection{Caminhada Determinística do Turista}

Para a análise das janelas $150 x 150$ do parênquima lacunoso, foram utilizados os mesmos parâmetros usados na análise das janelas $60 x 60$ do parênquima paliçádico, ou seja, três tempos de transição $(t=0,1$ e 2$)$ e dois períodos de ciclo $(a=2)$ das memórias $\mu=2,3,5,7$ e 11 (ver Seção 7.5.5).

\subsection{Medida de Espessura do Corte Transversal}

Para extração de medida de espessura, primeiramente foram retiradas manualmente uma janela por amostra, de altura padrão de 200 pixels e de comprimento variável, conforme Figura 7.14 , de modo que esta fosse suficiente para abranger a espessura da imagem. Nessas janelas 
foi aplicado o algoritmo do funcional de Mumford-Shah para segmentação com parâmetros de ajuste $\alpha=0.45$ e $\mathrm{lim}=11$. A seguir, foram calculadas 200 medidas de espessura (uma por cada linha da janela).

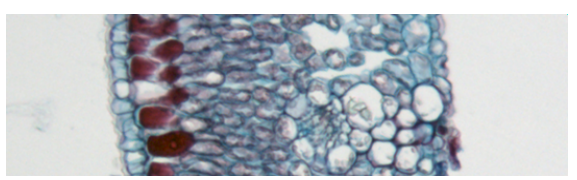

(a)

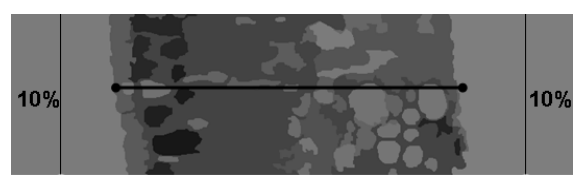

(b)

Figura 7.14: Imagens do corte transversal da espécie Miconia chamissois. a - Imagem original; b - Imagem segmentada.

Diferentemente dos procedimentos aplicados para o cálculo da espessura da cutícula e da epiderme superior, não houve a necessidade de encontrar todas as zonas planas presentes na segmentação da imagem, o que teria um considerável custo computacional devido às dimensões das janelas. No presente caso, como o pano de fundo é muito destoante da imagem, para a descoberta da borda à esquerda do corte transversal, bastou simplesmente descobrir a intensidade de pixel predominante nos primeiros $10 \%$ de área da imagem segmentada e fazer uma varredura para a direita até encontrar um vizinho com intensidade diferente. Para a descoberta da borda à direita, o procedimento foi semelhante: descobrir a intensidade de pixel predominante nos últimos $10 \%$ de área da imagem segmentada e fazer uma varredura para a esquerda até encontrar um vizinho com intensidade diferente. Ao final, a extração da média das espessuras foi usada para definir a espessura do corte transversal.

\subsection{Montagem do Vetor de Características}

Uma vez adquiridos os vetores de características das diferentes regiões do corte transversal da folha, houve a necessidade de escolher quais seriam utilizados para a identificação das espécies vegetais. Nos experimentos para a identificação de espécies diversas, foi adotado que um vetor de características que não obtivesse uma taxa média de acertos pelo método leaveone-out maior que $30 \%$ (exceto as medidas de espessura, cuja tolerância foi de $20 \%$ de acertos) seria desconsiderado. Nos experimentos de identificação de uma mesma espécie em ambientes, estações ou condições de luminosidade diferentes, foi adotado que o vetor deveria ter uma percentagem de acertos maior ou igual a $70 \%$ (exceto as medidas de espessura, cuja tolerância foi de $60 \%$ de acertos). Essas percentagens foram estabelecidas levando em consideração que a probabilidade de que uma amostra seja corretamente identificada ao acaso é de $12,5 \%$ e de $50 \%$ nas duas linhas de experimentos supracitadas, respectivamente.

Após a seleção dos vetores que participariam da identificação, surgiu o problema de como combiná-los para a obtenção de um vetor único que representasse uma amostra. Para solucionar esse problema, a idéia mais simples foi concatenar todos os vetores e normalizar todos os 
atributos entre 0 e 1 . A Figura 7.15 demonstra como seria a montagem desse vetor final, onde os retângulos em branco correspondem aos métodos de extração de características, as setas simples que apontam para o vetor final indicam um único atributo fornecido pelo método e as setas espessas indicam que este contribui com um vetor de mais de três atributos. As letras (X), (Y), (Z) e (W) indicam a quantidade de atributos que o método contém.

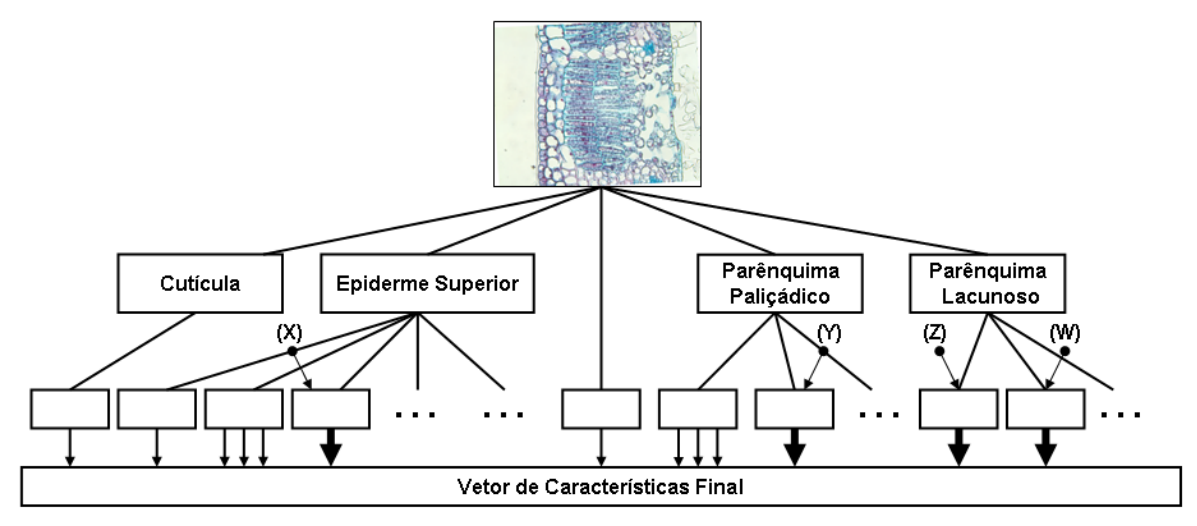

Figura 7.15: Esquema da montagem do vetor de características por concatenação simples.

O método acima descrito, entretanto, possui o problema de montar um vetor final de alta dimensionalidade. Além disso, os vetores de características componentes possuem número de dimensões diferentes (três atributos dos coeficientes tricromáticos, 16 atributos nas matrizes de co-ocorrência etc.), de modo que alguns podem ter maior influência do que outros nos resultados de identificação.

Para solucionar esse problema, uma segunda abordagem foi empregada neste trabalho. Nela, todos os vetores de características que tinham mais de três dimensões foram substituídos pelos seus três componentes principais após a aplicação do método PCA. A seguir, os vetores foram concatenados e seus atributos normalizados entre 0 e 1 . Desse modo, todos os vetores de características (com exceção das medidas de espessura) tiveram a mesma quantidade de atributos no vetor final. A Figura 7.16 demonstra o esquema de montagem desse vetor final, onde as setas com o nome PCA indicam quais métodos sofreram redução de dimensionalidade.

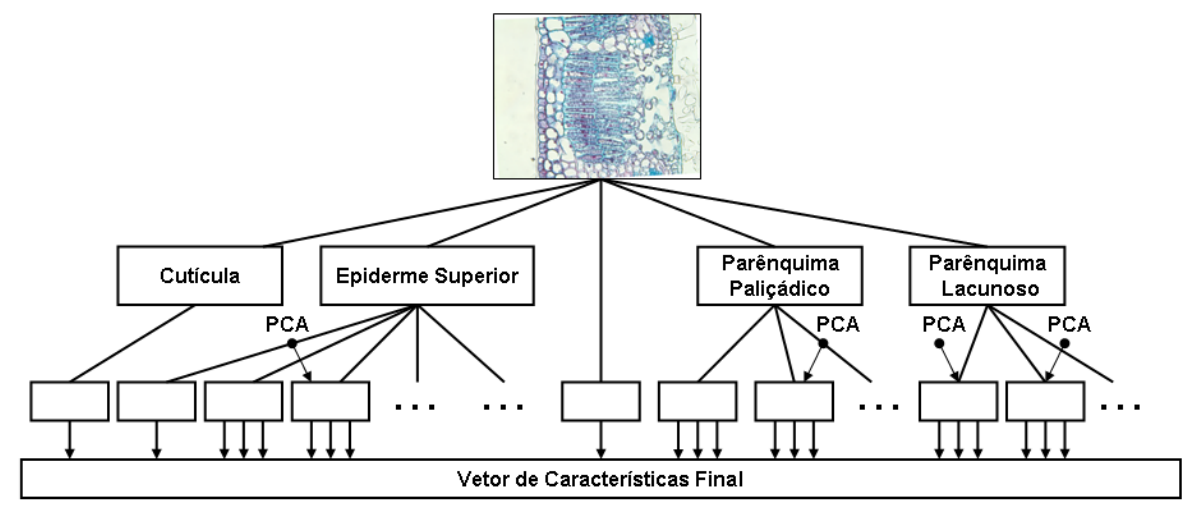

Figura 7.16: Esquema da montagem do vetor de características com o auxílio do método PCA. 


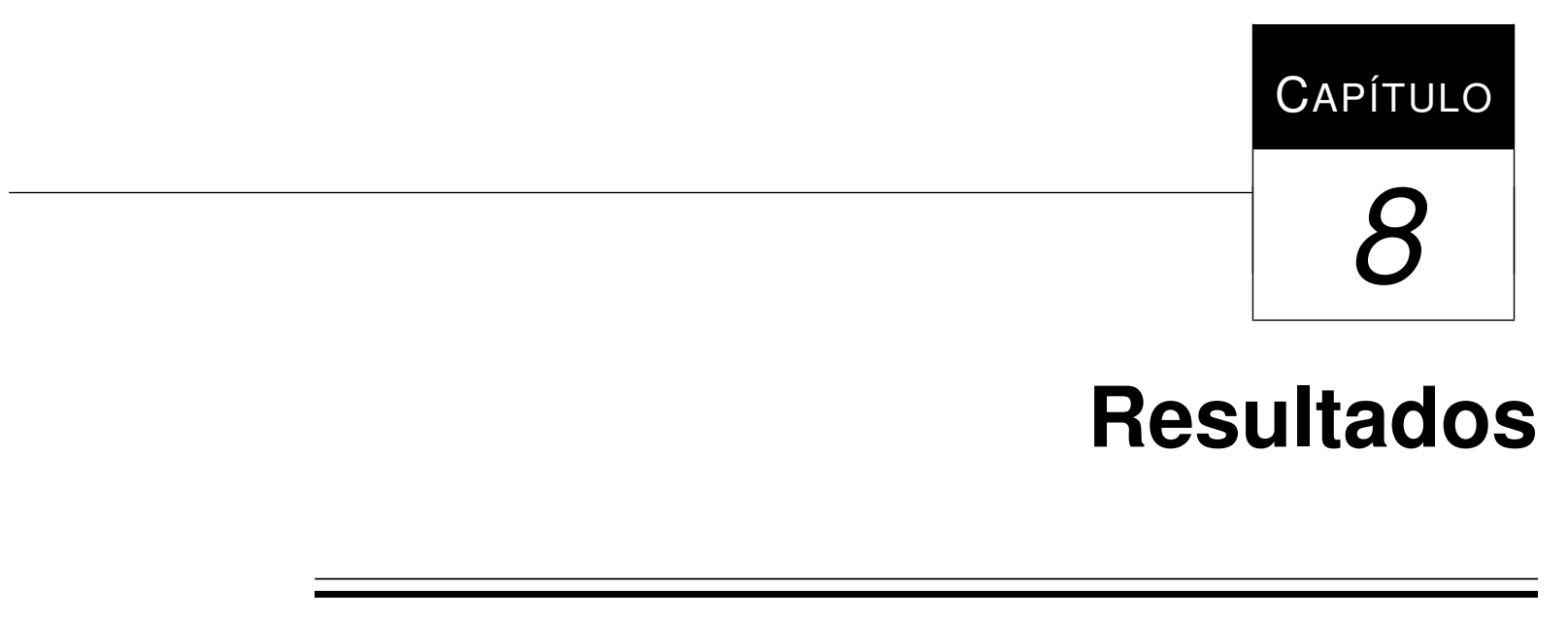

Este capítulo detalha os resultados obtidos na identificação de oito diferentes espécies vegetais, bem como a análise das alterações morfológicas da espécie Gochnatia polymorpha nos ambientes Cerrado e Mata Ciliar, nas estações Chuvosa e Seca, e sob condições de Sol e Sombra.

\subsection{Espécies Diversas}

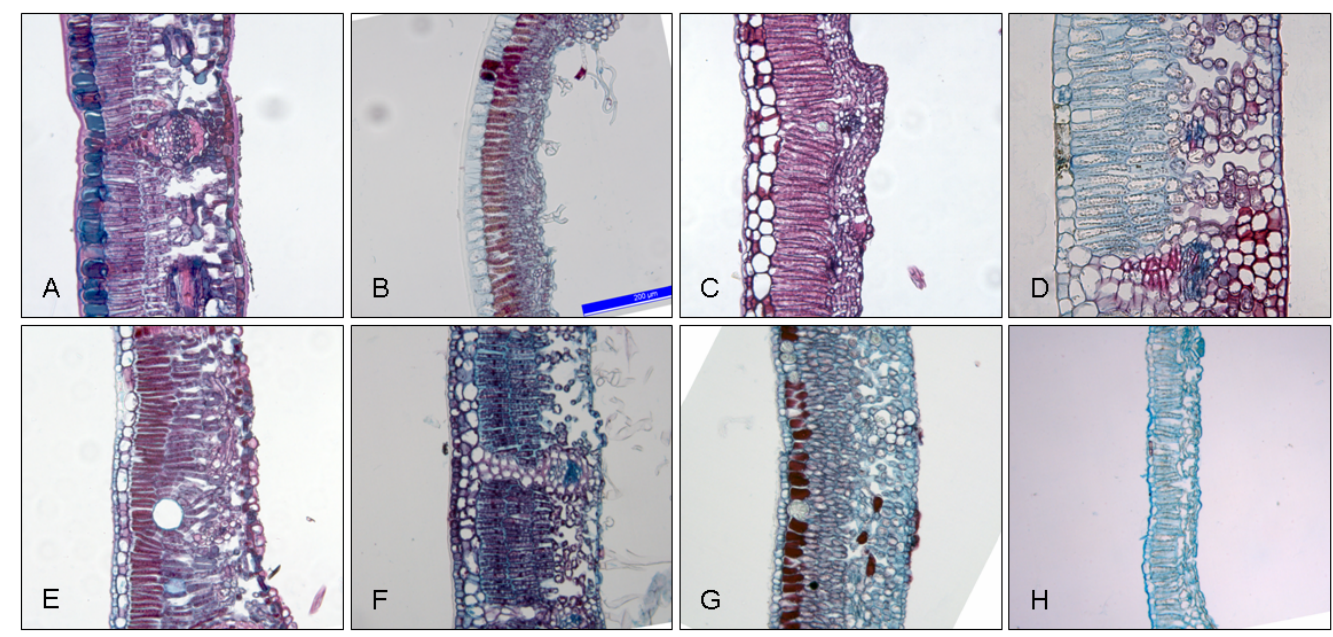

Figura 8.1: Cortes transversais das folhas das espécies: A - Byrsonima intermedia, B Miconia albicans, C - Tibouchina stenocarpa, D - Vochysia tucanorum, E - Xylopia aromatica, F - Gochnatia polymorpha, G - Miconia chamissois e H - Jacaranda caroba. 


\subsubsection{Medida de Espessura da Cutícula}

Na Tabela 8.1 constam as médias e os desvios padrão das espessuras da cutícula de todas as amostras.

\begin{tabular}{|l|c|c|c|c|c|c|c|c|}
\hline & B. intermedia & M. albicans & T. stenocarpa & V. tucanotum & X. aromatica & G. polymorpha & M. chamissois & J. caroba \\
\hline Média (pixels) & 14,920 & 15,960 & 4,745 & 7,512 & 5,839 & 9,622 & 6,845 & 6,050 \\
\hline Desvio Padrão (pixels) & 2,002 & 2,693 & 0,966 & 1,828 & 1,695 & 0,957 & 1,072 & 2,118 \\
\hline
\end{tabular}

Tabela 8.1: Médias e desvios padrão das espessuras de cutícula.

Para avaliar a capacidade de discriminação das assinaturas obtidas, a rede neural descrita na Seção 7.2 foi aplicada por meio do método leave-one-out. Pelos resultados alcançados, presentes na Tabela 8.2, as medidas de espessura da cutícula só têm a capacidade de discriminar corretamente $31,25 \%$ das amostras, em média.

\begin{tabular}{|l|c|c|c|c|c|c|c|c|}
\hline B. intermedia & $40 \%$ & $30 \%$ & 0 & 0 & $10 \%$ & $20 \%$ & 0 & 0 \\
\hline M. albicans & $30 \%$ & $60 \%$ & 0 & 0 & 0 & $10 \%$ & 0 & 0 \\
\hline T. stenocarpa & 0 & 0 & $30 \%$ & 0 & $40 \%$ & 0 & $10 \%$ & $20 \%$ \\
\hline V. tucanotum & 0 & 0 & 0 & $20 \%$ & 0 & $30 \%$ & $40 \%$ & $10 \%$ \\
\hline X. aromatica & 0 & 0 & $30 \%$ & 0 & $10 \%$ & $10 \%$ & $30 \%$ & $20 \%$ \\
\hline G. polymorpha & $10 \%$ & $10 \%$ & $0 \%$ & $30 \%$ & $10 \%$ & $40 \%$ & 0 & 0 \\
\hline M. chamissois & 0 & 0 & $10 \%$ & $10 \%$ & 0 & $10 \%$ & $50 \%$ & $20 \%$ \\
\hline J. caroba & 0 & 0 & $40 \%$ & $30 \%$ & $20 \%$ & $10 \%$ & 0 & 0 \\
\hline & B. intermedia & M. albicans & T. stenocarpa & V. tucanotum & X. aromatica & G. polymorpha & M. chamissois & J. caroba \\
\hline
\end{tabular}

Tabela 8.2: Matriz de confusão média obtida por validação cruzada leave-one-out $(m=80)$ das medidas de espessura de cutícula.

\subsubsection{Resultados Experimentais da Epiderme Superior}

\section{Medida de Espessura}

Na Tabela 8.3 constam as médias e os desvios padrão das espessuras da epiderme superior de todas as amostras.

\begin{tabular}{|l|c|c|c|c|c|c|c|c|}
\hline & B. intermedia & M. albicans & T. stenocarpa & V. tucanotum & X. aromatica & G. polymorpha & M. chamissois & J. caroba \\
\hline Média (em pixels) & 68,37 & 52,58 & 89,57 & 52,49 & 56,37 & 77,95 & 91,26 & 29,16 \\
\hline Desvio Padrão $($ em pixels $)$ & 10,03 & 7,213 & 16,65 & 3,369 & 7,136 & 16,43 & 12,69 & 8,4 \\
\hline
\end{tabular}

Tabela 8.3: Médias e desvios padrão das espessuras de epiderme superior.

Na Tabela 8.4 consta a matriz de confusão obtida por RNA via validação cruzada leaveone-out. Como resultado geral, a performance de acertos de identificação foi de $28,75 \%$, em média. 


\begin{tabular}{|l|c|c|c|c|c|c|c|c|}
\hline B. intermedia & 0 & 0 & $20 \%$ & $10 \%$ & $30 \%$ & $20 \%$ & $20 \%$ & 0 \\
\hline M. albicans & 0 & $20 \%$ & 0 & $30 \%$ & $40 \%$ & 0 & 0 & $10 \%$ \\
\hline T. stenocarpa & $10 \%$ & 0 & $40 \%$ & 0 & 0 & $20 \%$ & $30 \%$ & 0 \\
\hline V. tucanotum & 0 & $10 \%$ & $10 \%$ & $50 \%$ & $30 \%$ & 0 & 0 & 0 \\
\hline X. aromatica & 0 & $10 \%$ & 0 & $30 \%$ & $40 \%$ & $10 \%$ & 0 & $10 \%$ \\
\hline G. polymorpha & $40 \%$ & 0 & $30 \%$ & 0 & $10 \%$ & 0 & $20 \%$ & 0 \\
\hline M. chamissois & $40 \%$ & 0 & $50 \%$ & 0 & 0 & $10 \%$ & 0 & 0 \\
\hline J. caroba & 0 & $20 \%$ & 0 & 0 & 0 & 0 & 0 & $80 \%$ \\
\hline & B. intermedia & M. albicans & T. stenocarpa & V. tucanotum & X. aromatica & G. polymorpha & M. chamissois & J. caroba \\
\hline
\end{tabular}

Tabela 8.4: Matriz de confusão média obtida por redes neurais via leave-one-out ( $m=80)$ das medidas de espessura da epiderme superior.

\section{Coeficientes Tricromáticos}

Na Tabela 8.5 consta a matriz de confusão obtida por RNA via validação cruzada leave-oneout. A performance de acertos de identificação foi de $47,50 \%$, em média.

\begin{tabular}{|l|c|c|c|c|c|c|c|c|}
\hline B. intermedia & $40 \%$ & 0 & 0 & 0 & 0 & $40 \%$ & $20 \%$ & 0 \\
\hline M. albicans & 0 & $40 \%$ & 0 & $40 \%$ & $20 \%$ & 0 & 0 & 0 \\
\hline T. stenocarpa & 0 & 0 & $20 \%$ & $10 \%$ & $10 \%$ & $10 \%$ & $50 \%$ & 0 \\
\hline V. tucanotum & 0 & $40 \%$ & 0 & $30 \%$ & $20 \%$ & $10 \%$ & 0 & 0 \\
\hline X. aromatica & 0 & $20 \%$ & $20 \%$ & $10 \%$ & $30 \%$ & $10 \%$ & $10 \%$ & 0 \\
\hline G. polymorpha & $10 \%$ & 0 & 0 & 0 & $10 \%$ & $80 \%$ & 0 & 0 \\
\hline M. chamissois & $10 \%$ & 0 & $30 \%$ & 0 & $10 \%$ & 0 & $50 \%$ & 0 \\
\hline J. caroba & $10 \%$ & 0 & 0 & 0 & 0 & 0 & 0 & $90 \%$ \\
\hline & B. intermedia & M. albicans & T. stenocarpa & V. tucanotum & X. aromatica & G. polymorpha & M. chamissois & J. caroba \\
\hline
\end{tabular}

Tabela 8.5: Matriz de confusão média obtida por validação cruzada leave-one-out $(m=80)$ dos coeficientes tricromáticos da epiderme superior.

\section{Estatísticas de Primeira Ordem}

Pela busca exaustiva usando como critério a distância de Jeffrey-Matusita, as medidas selecionadas foram média, variância e obliqüidade. A maior distância encontrada foi de 0,97943.

A matriz de confusão obtida por RNA via leave-one-out está presente na Tabela 8.6. A performance de acertos de identificação foi de $85,00 \%$, em média.

\begin{tabular}{|l|c|c|c|c|c|c|c|c|}
\hline B. intermedia & $100 \%$ & 0 & 0 & 0 & 0 & 0 & 0 & 0 \\
\hline M. albicans & 0 & $80 \%$ & 0 & $20 \%$ & 0 & 0 & 0 & 0 \\
\hline T. stenocarpa & 0 & 0 & $90 \%$ & 0 & $10 \%$ & 0 & 0 & 0 \\
\hline V. tucanotum & 0 & $20 \%$ & 0 & $60 \%$ & $10 \%$ & 0 & 0 & $10 \%$ \\
\hline X. aromatica & 0 & 0 & $30 \%$ & 0 & $70 \%$ & 0 & 0 & 0 \\
\hline G. polymorpha & $10 \%$ & 0 & 0 & 0 & 0 & $90 \%$ & 0 & 0 \\
\hline M. chamissois & 0 & 0 & 0 & 0 & 0 & 0 & $100 \%$ & 0 \\
\hline J. caroba & 0 & 0 & 0 & $10 \%$ & 0 & 0 & 0 & $90 \%$ \\
\hline & B. intermedia & M. albicans & T. stenocarpa & V. tucanotum & X. aromatica & G. polymorpha & M. chamissois & J. caroba \\
\hline
\end{tabular}

Tabela 8.6: Matriz de confusão média obtida por RNA via leave-one-out $(m=80)$ de estatísticas de primeira ordem aplicadas na janelas formadas pela epiderme superior.

\section{Matrizes de Co-ocorrência}

A busca exaustiva com critério de distância de Jeffrey-Matusita encontrou como máxima distância $J M$ o valor 0,96148 para matrizes de distância $d=5$. As medidas selecionadas e respectivas matrizes foram as seguintes: entropia (ângulos de $0^{\circ}, 90^{\circ}, 45^{\circ}$ e $135^{\circ}$ ), correlação (ângulos de $0^{\circ}$ e $90^{\circ}$ ), homogeneidade (ângulos de $0^{\circ}, 90^{\circ}, 45^{\circ}$ e $135^{\circ}$ ) e valor absoluto (ângulos de $0^{\circ}$ e $90^{\circ}$ ). 
Na Tabela 8.7 consta a matriz de confusão da identificação das amostras por redes neurais. Em média, 80,00\% das amostras foram classificadas corretamente.

\begin{tabular}{|l|c|c|c|c|c|c|c|c|}
\hline B. intermedia & $80 \%$ & 0 & 0 & 0 & $10 \%$ & 0 & $10 \%$ & 0 \\
\hline M. albicans & 0 & $90 \%$ & 0 & 0 & 0 & 0 & $10 \%$ & 0 \\
\hline T. stenocarpa & 0 & 0 & $80 \%$ & $10 \%$ & 0 & $10 \%$ & 0 & 0 \\
\hline V. tucanotum & 0 & $20 \%$ & 0 & $50 \%$ & $30 \%$ & 0 & 0 & 0 \\
\hline X. aromatica & 0 & 0 & $20 \%$ & 0 & $80 \%$ & 0 & 0 & 0 \\
\hline G. polymorpha & 0 & 0 & 0 & 0 & 0 & $90 \%$ & 0 & $10 \%$ \\
\hline M. chamissois & $10 \%$ & $10 \%$ & 0 & 0 & $10 \%$ & 0 & $70 \%$ & 0 \\
\hline J. caroba & 0 & 0 & 0 & 0 & 0 & 0 & 0 & $100 \%$ \\
\hline & B. intermedia & M. albicans & T. stenocarpa & V. tucanotum & X. aromatica & G. polymorpha & M. chamissois & J. caroba \\
\hline
\end{tabular}

Tabela 8.7: Matriz de confusão média obtida por RNA via leave-one-out ( $m=80)$ de matrizes de co-ocorrência aplicadas na janelas formadas pela epiderme superior.

\section{BoxCounting 3D}

A busca exaustiva em busca da máxima distância de Jeffrey-Matusita resultou na escolha dos seguintes parâmetros: cubos com incremento de quatro unidades, $\sigma=3,3$ e vetor de características com 23 atributos (vetor com tamanho original de 28 atributos). A maior distância encontrada foi $J M=0,96878$.

Na Tabela 8.8 consta a matriz de confusão obtida por RNA via leave-one-out. Em média, $68,75 \%$ das amostras foram classificadas corretamente.

\begin{tabular}{|c|c|c|c|c|c|c|c|c|}
\hline B. intermedia & $70 \%$ & 0 & 0 & $10 \%$ & 0 & 0 & $20 \%$ & 0 \\
\hline M. albicans & 0 & $50 \%$ & 0 & $50 \%$ & 0 & 0 & 0 & 0 \\
\hline T. stenocarpa & 0 & 0 & $60 \%$ & 0 & $40 \%$ & 0 & 0 & 0 \\
\hline V. tucanotum & 0 & $30 \%$ & 0 & $40 \%$ & $20 \%$ & 0 & 0 & $10 \%$ \\
\hline$X$. aromatica & 0 & 0 & $30 \%$ & $20 \%$ & $50 \%$ & 0 & 0 & 0 \\
\hline G. polymorpha & 0 & 0 & 0 & 0 & 0 & $90 \%$ & $10 \%$ & 0 \\
\hline M. chamissois & 0 & 0 & 0 & 0 & 0 & 0 & $100 \%$ & 0 \\
\hline J. caroba & 0 & 0 & 0 & $10 \%$ & 0 & 0 & 0 & $90 \%$ \\
\hline & B. intermedia & M. albicans & T. stenocarpa & V. tucanotum & X. aromatica & G. polymorpha & M. chamissois & J. carobc \\
\hline
\end{tabular}

Tabela 8.8: Matriz de confusão média obtida por RNA via leave-one-out $(m=80)$ do método BoxCounting 3D aplicado nas janelas formadas pela epiderme superior.

\subsubsection{Resultados Experimentais do Parênquima Paliçádico}

\section{Coeficientes Tricromáticos}

A Tabela 8.9 consta a matriz de confusão obtida por RNA via leave-one-out. A performance média de acertos foi de $53,75 \%$.

\begin{tabular}{|l|c|c|c|c|c|c|c|c|}
\hline B. intermedia & $60 \%$ & 0 & $20 \%$ & 0 & $10 \%$ & 0 & 0 & $10 \%$ \\
\hline M. albicans & $10 \%$ & $90 \%$ & 0 & 0 & 0 & 0 & 0 \\
\hline T. stenocarpa & $20 \%$ & $10 \%$ & $10 \%$ & $10 \%$ & $20 \%$ & 0 & $30 \%$ & 0 \\
\hline V. tucanotum & 0 & 0 & 0 & $70 \%$ & 0 & 0 & 0 & $30 \%$ \\
\hline X. aromatica & $20 \%$ & 0 & $40 \%$ & 0 & $20 \%$ & $20 \%$ & 0 & 0 \\
\hline G. polymorpha & 0 & 0 & 0 & 0 & $20 \%$ & $50 \%$ & $20 \%$ & $10 \%$ \\
\hline M. chamissois & 0 & 0 & $20 \%$ & 0 & $10 \%$ & $10 \%$ & $60 \%$ & 0 \\
\hline J. caroba & 0 & 0 & 0 & $20 \%$ & $10 \%$ & 0 & 0 & $70 \%$ \\
\hline & B. intermedia & M. albicans & T. stenocarpa & V. tucanotum & X. aromatica & G. polymorpha & M. chamissois & J. caroba \\
\hline
\end{tabular}

Tabela 8.9: Matriz de confusão média obtida por validação cruzada leave-one-out $(m=80)$ dos coeficientes tricromáticos do parênquima paliçádico. 


\section{Estatísticas de Primeira Ordem}

Pela busca exaustiva realizada com critério de distância de Jeffrey-Matusita, as seguintes medidas foram selecionadas: média, variância e entropia. A maior distância encontrada foi $J M=0,91942$.

A aplicação do redes neurais via leave-one-out resultou na seguinte matriz de confusão constante na Tabela 8.10. O percentagem média de acertos foi de $38,75 \%$.

\begin{tabular}{|l|c|c|c|c|c|c|c|c|}
\hline B. intermedia & $40 \%$ & 0 & $20 \%$ & 0 & 0 & $20 \%$ & $20 \%$ & 0 \\
\hline M. albicans & 0 & $30 \%$ & $30 \%$ & 0 & $20 \%$ & $10 \%$ & $10 \%$ & 0 \\
\hline T. stenocarpa & 0 & 0 & $20 \%$ & $10 \%$ & $10 \%$ & 0 & $50 \%$ & $10 \%$ \\
\hline V. tucanotum & 0 & 0 & $20 \%$ & $50 \%$ & 0 & 0 & $10 \%$ & $20 \%$ \\
\hline X. aromatica & 0 & $20 \%$ & 0 & 0 & $50 \%$ & $30 \%$ & 0 & 0 \\
\hline G. polymorpha & $20 \%$ & $20 \%$ & 0 & 0 & $10 \%$ & $50 \%$ & 0 & 0 \\
\hline M. chamissois & $10 \%$ & 0 & $30 \%$ & $20 \%$ & 0 & 0 & $30 \%$ & $10 \%$ \\
\hline J. caroba & $10 \%$ & $10 \%$ & $20 \%$ & $10 \%$ & 0 & 0 & $10 \%$ & $40 \%$ \\
\hline & B. intermedia & M. albicans & T. stenocarpa & V. tucanotum & X. aromatica & G. polymorpha & M. chamissois & J. caroba \\
\hline
\end{tabular}

Tabela 8.10: Matriz de confusão média obtida por RNA via leave-one-out $(m=80)$ das estatísticas de primeira ordem do parênquima paliçádico.

\section{Matrizes de Co-ocorrência}

A busca exaustiva com critério de distância de Jeffrey-Matusita encontrou como máxima distância $J M$ o valor 0,94747 para matrizes de distância $d=3$. As medidas selecionadas e respectivas matrizes foram as seguintes: energia (ângulos de $45^{\circ}$ e $135^{\circ}$ ), correlação (ângulos de $45^{\circ}$ e $135^{\circ}$ ), homogeneidade (ângulos de $45^{\circ}$ e $135^{\circ}$ ) e valor absoluto (ângulos de $0^{\circ} \mathrm{e}$ $\left.90^{\circ}\right)$.

Os resultados de identificação por RNA (via leave-one-out) estão presentes na Tabela 8.11. As matrizes de co-ocorrência apresentaram a melhor performance em comparação com os demais métodos empregados para extração de assinaturas do parênquima paliçádico, com uma taxa de acertos de $63,75 \%$, em média.

\begin{tabular}{|l|c|c|c|c|c|c|c|c|}
\hline B. intermedia & $80 \%$ & $10 \%$ & 0 & 0 & 0 & 0 & $10 \%$ & 0 \\
\hline .. albicans & 0 & $50 \%$ & $10 \%$ & 0 & $30 \%$ & 0 & $10 \%$ & 0 \\
\hline T. stenocarpa & $10 \%$ & $10 \%$ & $60 \%$ & $20 \%$ & 0 & 0 & 0 & 0 \\
\hline V. tucanotum & 0 & 0 & $20 \%$ & $80 \%$ & 0 & 0 & 0 & 0 \\
\hline X. aromatica & 0 & 0 & $10 \%$ & 0 & $70 \%$ & $20 \%$ & 0 & 0 \\
\hline G. polymorpha & 0 & $10 \%$ & 0 & 0 & $20 \%$ & $50 \%$ & $10 \%$ & $10 \%$ \\
\hline M. chamissois & 0 & $20 \%$ & 0 & 0 & 0 & 0 & $40 \%$ & $40 \%$ \\
\hline J. caroba & $10 \%$ & 0 & 0 & 0 & 0 & 0 & $10 \%$ & $80 \%$ \\
\hline & B. intermedia & M. albicans & T. stenocarpa & V. tucanotum & X. aromatica & G. polymorpha & M. chamissois & J. caroba \\
\hline
\end{tabular}

Tabela 8.11: Matriz de confusão média obtida por RNA via leave-one-out $(m=80)$ das matrizes de co-ocorrência do parênquima paliçádico.

\section{BoxCounting 3D}

A busca exaustiva em busca da máxima distância de Jeffrey-Matusita resultou na escolha dos seguintes parâmetros: cubos com incremento de uma unidade, $\sigma=5,4$ e vetor de características com 38 atributos (vetor com tamanho original de 56 atributos). A maior distância encontrada foi $J M=0,85482$. 
Os resultados de identificação obtido por RNA (via leave-one-out) estão presentes na Tabela 8.12. A taxa média de acertos foi de $38,75 \%$.

\begin{tabular}{|l|c|c|c|c|c|c|c|c|}
\hline B. intermedia & $50 \%$ & $10 \%$ & $10 \%$ & 0 & $10 \%$ & 0 & $20 \%$ & 0 \\
\hline M. albicans & 0 & $50 \%$ & 0 & 0 & $10 \%$ & $40 \%$ & 0 & 0 \\
\hline T. stenocarpa & $10 \%$ & $30 \%$ & $30 \%$ & $10 \%$ & 0 & 0 & $10 \%$ & $10 \%$ \\
\hline V. tucanotum & 0 & 0 & $10 \%$ & $40 \%$ & 0 & 0 & $10 \%$ & $40 \%$ \\
\hline X. aromatica & $40 \%$ & $10 \%$ & 0 & 0 & $50 \%$ & 0 & 0 & 0 \\
\hline G. polymorpha & $20 \%$ & $20 \%$ & $10 \%$ & $10 \%$ & $10 \%$ & $10 \%$ & $20 \%$ & 0 \\
\hline M. chamissois & $20 \%$ & 0 & $20 \%$ & $30 \%$ & $10 \%$ & 0 & $10 \%$ & $10 \%$ \\
\hline J. caroba & 0 & 0 & 0 & $20 \%$ & 0 & $10 \%$ & $0 \%$ & $70 \%$ \\
\hline & B. intermedia & M. albicans & T. stenocarpa & V. tucanotum & X. aromatica & G. polymorpha & M. chamissois & J. caroba \\
\hline
\end{tabular}

Tabela 8.12: Matriz de confusão média obtida por RNA via leave-one-out $(m=80)$ do método BoxCounting 3D no parênquima paliçádico.

\section{Caminhada Determinística do Turista}

Os resultados constantes na Tabela 8.13 confirmam que os vetores de características não foram eficientes. A performance de acertos foi de $8,75 \%$, resultado próximo ao que seria esperado caso as amostras fossem classificadas aleatoriamente.

\begin{tabular}{|l|c|c|c|c|c|c|c|c|}
\hline B. intermedia & 0 & $10 \%$ & $10 \%$ & 0 & $40 \%$ & $10 \%$ & $10 \%$ & $20 \%$ \\
\hline M. albicans & $30 \%$ & $10 \%$ & $10 \%$ & 0 & $20 \%$ & $20 \%$ & $10 \%$ & 0 \\
\hline T. stenocarpa & $20 \%$ & $20 \%$ & 0 & $10 \%$ & $10 \%$ & $30 \%$ & $10 \%$ & 0 \\
\hline V. tucanotum & 0 & 0 & 0 & 0 & $40 \%$ & $40 \%$ & $20 \%$ & 0 \\
\hline X. aromatica & $20 \%$ & $10 \%$ & $30 \%$ & 0 & $10 \%$ & 0 & $10 \%$ & $20 \%$ \\
\hline G. polymorpha & $10 \%$ & $20 \%$ & $20 \%$ & $10 \%$ & 0 & $20 \%$ & $20 \%$ & 0 \\
\hline M. chamissois & $10 \%$ & 0 & 0 & 0 & $20 \%$ & $20 \%$ & $20 \%$ & $30 \%$ \\
\hline J. caroba & $40 \%$ & $10 \%$ & 0 & $10 \%$ & 0 & $10 \%$ & $20 \%$ & $10 \%$ \\
\hline & B. intermedia & M. albicans & T. stenocarpa & V. tucanotum & X. aromatica & G. polymorpha & M. chamissois & J. caroba \\
\hline
\end{tabular}

Tabela 8.13: Matriz de confusão média obtida por validação cruzada leave-one-out $(m=80)$ da caminhada determinística do turista no parênquima paliçádico.

\subsubsection{Resultados Experimentais do Parênquima Lacunoso}

\section{Estatísticas de Primeira Ordem}

Pela busca exaustiva realizada com critério de distância de Jeffrey-Matusita, as seguintes medidas foram selecionadas: média, energia e entropia. A maior distância encontrada foi $J M=0,95284$.

A Tabela 8.14 expressa a matriz de confusão obtida na identificação dos vetores de características. A taxa média de acertos foi de $57,50 \%$.

\begin{tabular}{|l|c|c|c|c|c|c|c|c|}
\hline B. intermedia & $60 \%$ & 0 & $10 \%$ & $20 \%$ & $10 \%$ & 0 & 0 & 0 \\
\hline M. albicans & 0 & $60 \%$ & 0 & 0 & 0 & $30 \%$ & 0 & $10 \%$ \\
\hline T. stenocarpa & $20 \%$ & 0 & $40 \%$ & 0 & $40 \%$ & 0 & 0 & 0 \\
\hline V. tucanotum & $40 \%$ & 0 & 0 & $60 \%$ & 0 & 0 & 0 & 0 \\
\hline X. aromatica & 0 & $10 \%$ & $50 \%$ & 0 & $30 \%$ & 0 & $10 \%$ & 0 \\
\hline G. polymorpha & 0 & $10 \%$ & 0 & $10 \%$ & 0 & $80 \%$ & 0 & 0 \\
\hline M. chamissois & 0 & 0 & $10 \%$ & $10 \%$ & $20 \%$ & 0 & $50 \%$ & $10 \%$ \\
\hline J. caroba & 0 & $10 \%$ & 0 & 0 & 0 & 0 & $10 \%$ & $80 \%$ \\
\hline & B. intermedia & M. albicans & T. stenocarpa & V. tucanotum & X. aromatica & G. polymorpha & M. chamissois & J. caroba \\
\hline
\end{tabular}

Tabela 8.14: Matriz de confusão média obtida por RNA via leave-one-out $(m=80)$ das estatísticas de primeira ordem aplicadas no parênquima lacunoso. 


\section{Matrizes de Co-ocorrência}

A busca exaustiva com critério de distância de Jeffrey-Matusita encontrou como máxima distância $J M$ o valor 0,98917 para matrizes de distância $d=3$. As medidas selecionadas e respectivas matrizes foram as seguintes: energia (ângulos de $0^{\circ}, 90^{\circ}, 45^{\circ}$ e $135^{\circ}$ ), entropia (ângulos de $0^{\circ}, 90^{\circ}, 45^{\circ}$ e $135^{\circ}$ ), correlação (ângulos de $0^{\circ}$ e $90^{\circ}$ ), homogeneidade (ângulos de $45^{\circ}$ e $135^{\circ}$ ) e valor absoluto (ângulos de $0^{\circ}$ e $90^{\circ}$ ).

A Tabela 8.15 obtidos por RNA via leave-one-out expõe os resultados obtidos por esse classificador. A taxa de acertos foi de $82,50 \%$, em média.

\begin{tabular}{|l|c|c|c|c|c|c|c|c|}
\hline B. intermedia & $80 \%$ & 0 & 0 & 0 & $10 \%$ & 0 & $10 \%$ & 0 \\
\hline M. albicans & 0 & $90 \%$ & 0 & 0 & 0 & 0 & 0 & $10 \%$ \\
\hline T. stenocarpa & 0 & 0 & $80 \%$ & 0 & 0 & 0 & $10 \%$ & 0 \\
\hline V. tucanotum & $10 \%$ & 0 & 0 & $90 \%$ & 0 & 0 & 0 & 0 \\
\hline X. aromatica & 0 & 0 & $10 \%$ & $10 \%$ & $70 \%$ & 0 & $10 \%$ & 0 \\
\hline G. polymorpha & 0 & 0 & 0 & 0 & 0 & $90 \%$ & 0 & $10 \%$ \\
\hline M. chamissois & 0 & 0 & $10 \%$ & 0 & 0 & $10 \%$ & $80 \%$ & 0 \\
\hline J. caroba & 0 & $10 \%$ & 0 & 0 & 0 & 0 & $10 \%$ & $80 \%$ \\
\hline & B. intermedia & M. albicans & T. stenocarpa & V. tucanotum & X. aromatica & G. polymorpha & M. chamissois & J. caroba \\
\hline
\end{tabular}

Tabela 8.15: Matriz de confusão média obtida por RNA via leave-one-out $(m=80)$ das matrizes de co-ocorrência aplicadas no parênquima lacunoso.

\section{BoxCounting 3D}

A busca exaustiva em busca da máxima distância de Jeffrey-Matusita resultou na escolha dos seguintes parâmetros: cubos com incremento de uma unidade, $\sigma=2,0$ e vetor de características com 66 atributos (vetor com tamanho original de 76 atributos). A maior distância encontrada foi $J M=0,92006$.

A Tabela 8.16 expressa os resultados encontrados por RNA via leave-one-out. Por esse classificador a performance de acertos foi de $47,50 \%$, em média.

\begin{tabular}{|c|c|c|c|c|c|c|c|c|}
\hline B. intermedia & $30 \%$ & 0 & $10 \%$ & $10 \%$ & $30 \%$ & 0 & $10 \%$ & $10 \%$ \\
\hline M. albicans & $10 \%$ & $30 \%$ & $10 \%$ & $10 \%$ & $20 \%$ & $10 \%$ & $10 \%$ & 0 \\
\hline T. stenocarpa & 0 & 0 & $60 \%$ & $10 \%$ & $20 \%$ & $10 \%$ & 0 & 0 \\
\hline V. tucanotum & $30 \%$ & 0 & $20 \%$ & $10 \%$ & $20 \%$ & 0 & 0 & $20 \%$ \\
\hline$X$. aromatica & 0 & $10 \%$ & $40 \%$ & $10 \%$ & $30 \%$ & 0 & $10 \%$ & 0 \\
\hline G. polymorpha & 0 & 0 & 0 & 0 & 0 & $100 \%$ & 0 & 0 \\
\hline M. chamissois & $10 \%$ & 0 & 0 & $10 \%$ & 0 & 0 & $60 \%$ & $20 \%$ \\
\hline J. caroba & 0 & $20 \%$ & 0 & 0 & 0 & 0 & $20 \%$ & $60 \%$ \\
\hline & B. intermedia & M. albicans & T. stenocarpa & V. tucanotum & $X$. aromatica & G. polymorpha & M. chamissois & J. caroba \\
\hline
\end{tabular}

Tabela 8.16: Matriz de confusão média obtida por RNA via leave-one-out $(m=80)$ do método BoxCounting 3D aplicado no parênquima lacunoso.

\section{Caminhada Determínistica do Turista}

Pelos resultados alcançados, presentes na Tabela 8.17, a identificação das espécies conseguiu uma performance um pouco melhor do que seria esperado de um classificador randômico. A taxa média de acertos foi de $20,00 \%$, sendo que a probabilidade de que uma amostra seja designada ao acaso à sua verdadeira classe (espécie) é de 12,50\%. 


\begin{tabular}{|l|c|c|c|c|c|c|c|c|}
\hline B. intermedia & $20 \%$ & $10 \%$ & 0 & $20 \%$ & $10 \%$ & $30 \%$ & 0 & $10 \%$ \\
\hline M. albicans & $10 \%$ & $30 \%$ & $20 \%$ & $10 \%$ & $20 \%$ & 0 & 0 & $10 \%$ \\
\hline T. stenocarpa & $20 \%$ & $20 \%$ & 0 & 0 & $10 \%$ & 0 & $10 \%$ & $40 \%$ \\
\hline V. tucanotum & $20 \%$ & 0 & 0 & $50 \%$ & 0 & $10 \%$ & $20 \%$ & 0 \\
\hline X. aromatica & $20 \%$ & $10 \%$ & $10 \%$ & 0 & $20 \%$ & $20 \%$ & $10 \%$ & $10 \%$ \\
\hline G. polymorpha & 0 & 0 & $20 \%$ & $10 \%$ & $10 \%$ & $10 \%$ & $20 \%$ & $30 \%$ \\
\hline M. chamissois & 0 & 0 & $20 \%$ & $40 \%$ & 0 & $10 \%$ & $20 \%$ & $10 \%$ \\
\hline J. caroba & $10 \%$ & $10 \%$ & 0 & 0 & $20 \%$ & $20 \%$ & $30 \%$ & $10 \%$ \\
\hline & B. intermedia & M. albicans & T. stenocarpa & V. tucanotum & X. aromatica & G. polymorpha & M. chamissois & J. caroba \\
\hline
\end{tabular}

Tabela 8.17: Matriz de confusão média obtida por RNA via leave-one-out $(m=80)$ da caminhada determinística do turista no parênquima lacunoso.

\subsubsection{Medida de Espessura do Corte Transversal}

Na Tabela 8.18 constam as médias e os desvios padrão das espessuras dos cortes transversais de todas as espécies.

\begin{tabular}{|l|c|c|c|c|c|c|c|c|}
\hline & B. intermedia & M. albicans & T. stenocarpa & V. tucanotum & X. aromatica & G. polymorpha & M. chamissois & J. caroba \\
\hline Média (pixels) & 435,4 & 263,9 & 340,1 & 612,4 & 392,8 & 429,6 & 444,9 & 200,9 \\
\hline Desvio Padrão (pixels) & 59,68 & 35,55 & 32,69 & 58,82 & 15,91 & 56,32 & 26,24 & 43,80 \\
\hline
\end{tabular}

Tabela 8.18: Médias e desvios padrão das espessuras de corte transversal de todas as espécies.

A Tabela 8.19 demonstra o desempenho de identificação com redes neurais via método leave-one-out. As boas taxas de acertos das espécies Vochysia tucanorum e Jacaranda caroba são explicadas pelo fato de estas possuírem as maiores e menores espessuras de corte transversal, respectivamente, conforme demonstra a Tabela 8.18. Vale enfatizar também as taxas de acertos das espécies Miconia chamissois e Tibouchina stenocarpa. Nesse experimento, a percentagem média de identificação correta foi de 40,00\%.

\begin{tabular}{|l|c|c|c|c|c|c|c|c|}
\hline B. intermedia & $30 \%$ & 0 & $10 \%$ & 0 & $10 \%$ & $20 \%$ & $30 \%$ & 0 \\
\hline M. albicans & 0 & $30 \%$ & $40 \%$ & 0 & 0 & 0 & 0 & $30 \%$ \\
\hline T. stenocarpa & $10 \%$ & $20 \%$ & $50 \%$ & 0 & $10 \%$ & $10 \%$ & 0 & 0 \\
\hline V. tucanotum & 0 & 0 & 0 & $100 \%$ & 0 & 0 & 0 & 0 \\
\hline X. aromatica & $30 \%$ & 0 & $20 \%$ & 0 & $10 \%$ & $10 \%$ & $30 \%$ & 0 \\
\hline G. polymorpha & $10 \%$ & 0 & $20 \%$ & $10 \%$ & $10 \%$ & 0 & $50 \%$ & 0 \\
\hline M. chamissois & 0 & 0 & 0 & $10 \%$ & $40 \%$ & 0 & $50 \%$ & 0 \\
\hline J. caroba & $10 \%$ & $40 \%$ & 0 & 0 & 0 & 0 & 0 & $50 \%$ \\
\hline & B. intermedia & M. albicans & T. stenocarpa & V. tucanotum & X. aromatica & G. polymorpha & M. chamissois & J. caroba \\
\hline
\end{tabular}

Tabela 8.19: Matriz de confusão média obtida por validação cruzada leave-one-out $(m=80)$ das medidas de espessura dos cortes transversais.

\subsubsection{Montagem do Vetor de Características}

Pelos critérios estabelecidos na Seção 7.8, os vetores obtidos pelo método da caminhada determinística do turista no parênquima paliçádico e no parênquima lacunoso foram desconsiderados.

No primeiro experimento, que utiliza simples concatenação dos vetores, a Figura 8.2 demonstra a composição do vetor final, que tem um total de 179 atributos. Conforme explicado na Seção 7.8, os valores numéricos na figura indicam a quantidade de atributos do método. 


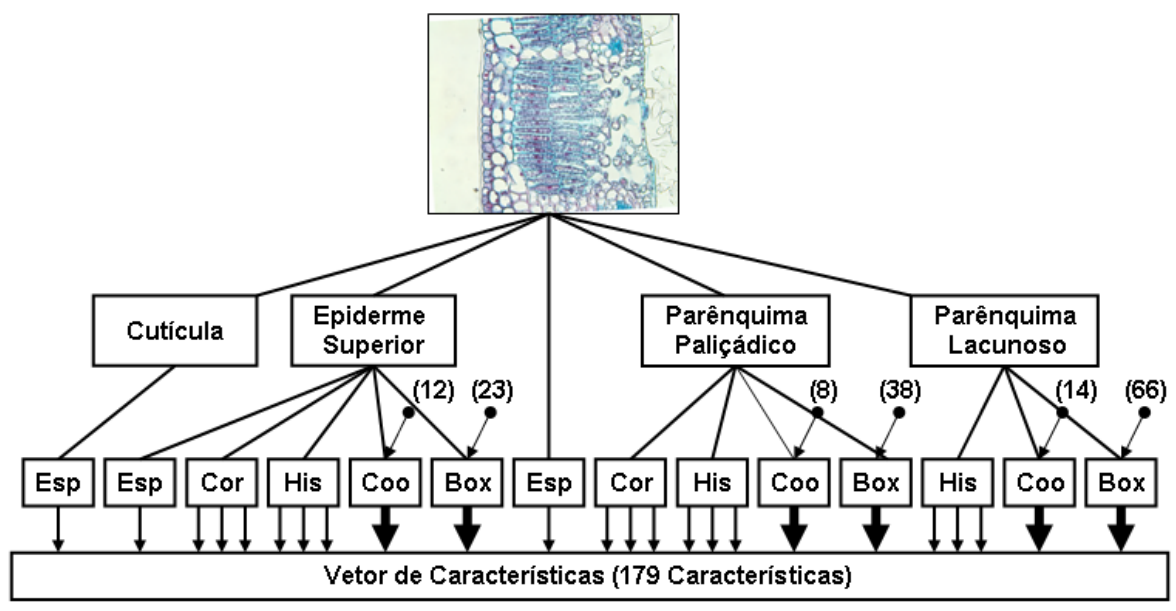

Figura 8.2: Esquema da montagem do vetor de características por concatenação simples. Siglas: Esp - espessura; His - estatística de $1^{a}$ ordem; Cor - coeficientes tricromáticos; Coo matrizes de co-ocorrência; Box - BoxCounting 3D.

A Figura 8.3 demonstra a composição do vetor final com o acréscimo do método PCA para redução de dimensionalidade. Esse vetor obteve um total de 36 características, ou seja, 20, $11 \%$ da dimensionalidade do vetor formado por concatenação simples. A Figura 8.3 demonstra a formação do vetor de características por essa segunda abordagem.

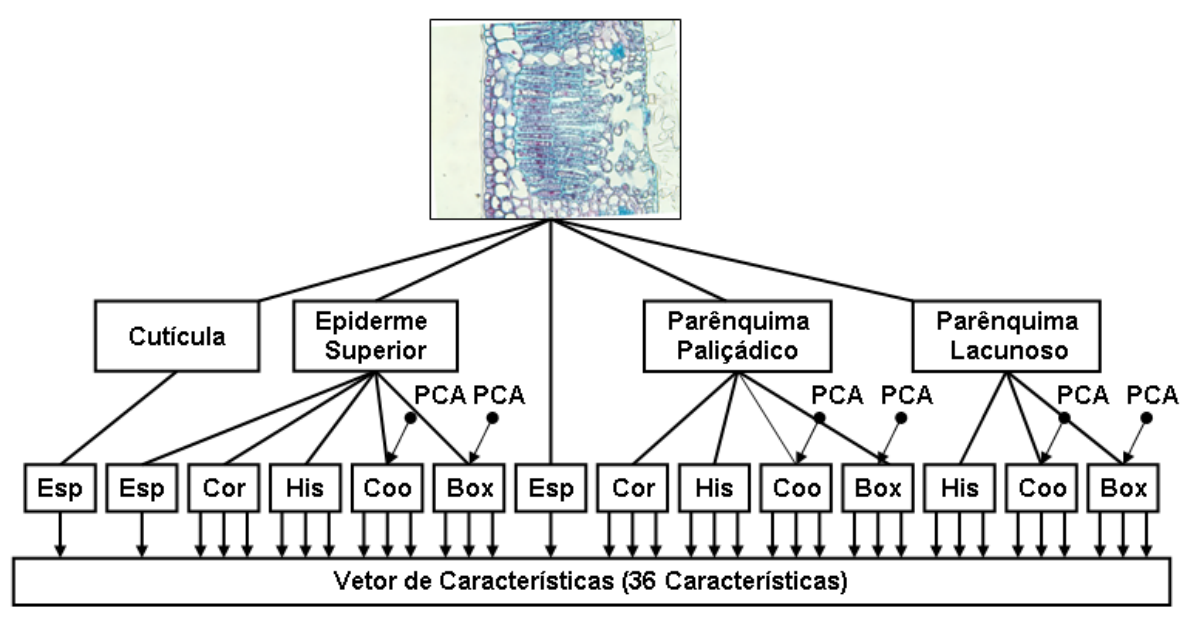

Figura 8.3: Esquema da montagem do vetor de características com o auxílio do método PCA. Siglas: Esp - espessura; His - estatística de $1^{a}$ ordem; Cor - coeficientes tricromáticos; Coo matrizes de co-ocorrência; Box - BoxCounting 3D.

\subsubsection{Resultados e Discussão}

Para a verificação de quão bem as amostras foram identificadas, ambos os métodos que reúnem as informações do vetores de características das diferentes regiões do corte transversal foliar foram testados com a rede neural descrita na Seção 7.2 pelo método leave-one-out. 
No primeiro teste, cujos vetores de características são simplesmente concatenados, a plotagem dos dois componentes principais obtidos pelo método PCA pode ser vista na Figura 8.4.

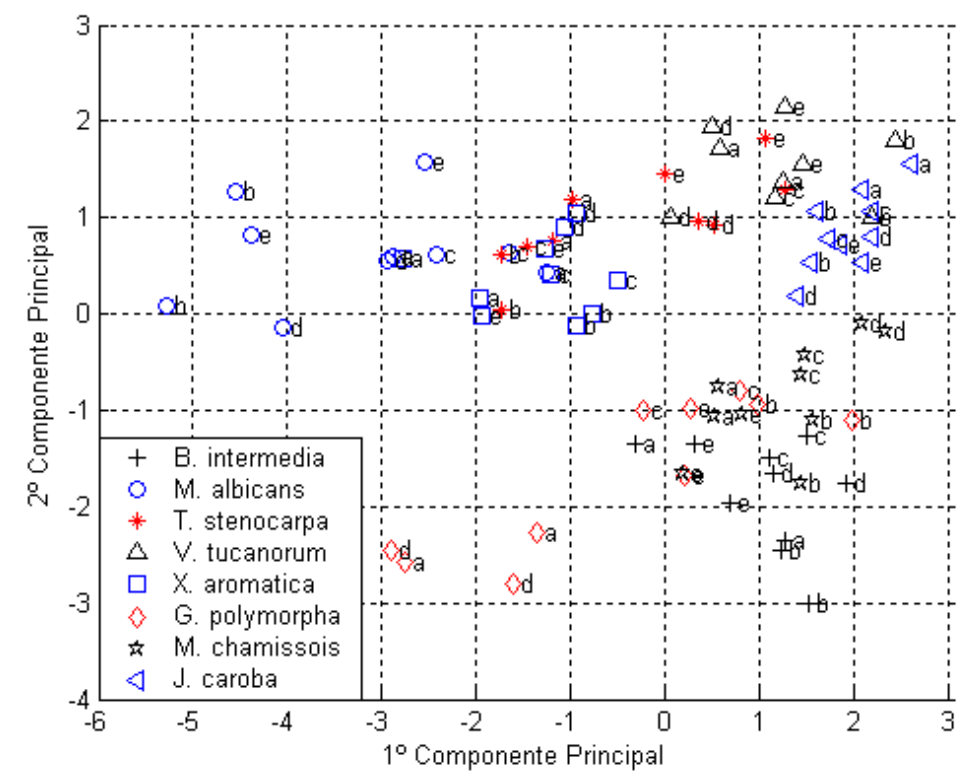

Figura 8.4: Visualização 2D (PCA - dois primeiros componentes principais) do vetor final obtido por concatenação simples (com seleção por distância de Jeffrey-Matusita) dos vetores componentes.

$\mathrm{Na}$ Figura 8.4 é possível perceber o sinergismo dos vetores integrantes. As amostras de $\mathrm{Ja}$ caranda caroba, por terem se destacado em muitos dos vetores de características componentes (por exemplo, medida de espessura da epiderme superior e do corte transversal, matrizes de coocorrência no parênquima paliçádico etc.) estão muito bem separadas das demais espécies. $\mathrm{O}$ mesmo pode ser dito das amostras de Byrsonima intermedia, que apresentou um agrupamento de dados coeso. Vale destacar ainda as amostras de Vochysia tucanorum e Miconia albicans, que, pela imagem, também se destacam, embora não totalmente.

Os resultados dos testes com leave-one-out estão presentes na Tabela 8.20. Pelas taxas de acertos alcançadas, as assinaturas obtidas por concatenação simples conseguiram alcançar uma excelente performance, não obstante o fato da alta dimensionalidade e do número diferente de dimensões entre os vetores fornecidos pelos diferentes métodos utilizados. A performance média de acertos, no presente caso, foi de $90,00 \%$.

Para comprovar a eficiência da verificação da distância de Jeffrey-Matusita para a seleção das características mais relevantes, um experimento extra foi realizado. Nele, a composição do vetor final segue basicamente o mesmo esquema presente na Figura 8.2, mas com a exceção de que os métodos de estatísticas de primeira ordem, matrizes de co-ocorrência e BoxCounting 3D não tiveram suas quantidades de características reduzidas. A seguir, são descritos os parâmetros desses métodos nas regiões foliares nas quais foram aplicados: 


\begin{tabular}{|l|c|c|c|c|c|c|c|c|}
\hline B. intermedia & $80 \%$ & 0 & 0 & 0 & 0 & $10 \%$ & $10 \%$ & 0 \\
\hline M. albicans & 0 & $80 \%$ & 0 & 0 & $10 \%$ & $10 \%$ & 0 & 0 \\
\hline T. stenocarpa & 0 & 0 & $90 \%$ & $10 \%$ & 0 & 0 & 0 & 0 \\
\hline V. tucanotum & 0 & 0 & 0 & $100 \%$ & 0 & 0 & 0 & 0 \\
\hline X. aromatica & 0 & 0 & 0 & 0 & $100 \%$ & 0 & 0 & 0 \\
\hline G. polymorpha & 0 & 0 & 0 & 0 & 0 & $100 \%$ & 0 & 0 \\
\hline M. chamissois & 0 & 0 & 0 & 0 & 0 & 0 & $90 \%$ & $10 \%$ \\
\hline J. caroba & 0 & 0 & 0 & $10 \%$ & 0 & $10 \%$ & 0 & $80 \%$ \\
\hline & B. intermedia & M. albicans & T. stenocarpa & V. tucanotum & X. aromatica & G. polymorpha & M. chamissois & J. caroba \\
\hline
\end{tabular}

Tabela 8.20: Matriz de confusão média obtida por validação cruzada leave-one-out $(m=80)$ do vetor final obtido por simples concatenação (com seleção por distância de Jeffrey-Matusita) dos vetores componentes.

- Estatísticas de primeira ordem: os vetores de características obtidos da epiderme superior, parênquima paliçádico e parênquima lacunoso ficaram com seis medidas - média, variância, obliqüidade, curtose, energia e entropia.

- Matrizes de co-ocorrência: a distância $d$ entre pares de pixels selecionada pela métrica de Jeffrey-Matusita foi mantida $-d=5, d=3$ e $d=3$ para a epiderme superior, parênquima paliçádico e parênquima lacunoso, respectivamente. As medidas utilizadas foram energia, entropia, correlação, homogeneidade, contraste e valor absoluto, cada qual com 4 matrizes de co-ocorrência, ou seja, 24 atributos por vetor de característica.

- BoxCounting 3D: Os valores de $\sigma$ e os incrementos de tamanho dos cubos selecionados pela distância de Jeffrey-Matusita não foram alterados. Os vetores obtidos por Dimensão Fractal MultiEscala, entretanto, foram usados na sua forma original, sem a averiguação de qual percentagem inicial do mesmo tinha maior relevância. Desse modo, os vetores de características ficam com 28, 56 e 76 para a epiderme superior, parênquima paliçádico e parênquima lacunoso, respectivamente.

Com essas alterações, o vetor final, que, pela concatenação com os vetores selecionados pela distância de Jeffrey-Matusita, obteve um total de 179 atributos, neste experimento obteve um total de 259 atributos. Esses vetores foram avaliados pela rede neural com os mesmos parâmetros utilizados no decorrer dos demais experimentos. Os resultados estão presentes na Tabela 8.21, cuja taxa média de acertos é $82,50 \%$.

\begin{tabular}{|l|c|c|c|c|c|c|c|c|}
\hline B. intermedia & $70 \%$ & 0 & 0 & 0 & 0 & $10 \%$ & $20 \%$ & 0 \\
\hline M. albicans & 0 & $90 \%$ & 0 & 0 & $10 \%$ & 0 & 0 & 0 \\
\hline T. stenocarpa & 0 & 0 & $50 \%$ & $10 \%$ & $30 \%$ & 0 & $10 \%$ & 0 \\
\hline V. tucanotum & 0 & 0 & $10 \%$ & $70 \%$ & 0 & 0 & $10 \%$ & $10 \%$ \\
\hline X. aromatica & 0 & 0 & 0 & 0 & $90 \%$ & 0 & $10 \%$ & 0 \\
\hline G. polymorpha & 0 & 0 & 0 & 0 & 0 & $100 \%$ & 0 & 0 \\
\hline M. chamissois & 0 & 0 & 0 & 0 & 0 & 0 & $100 \%$ & 0 \\
\hline J. caroba & $10 \%$ & 0 & 0 & 0 & 0 & 0 & 0 & $90 \%$ \\
\hline & B. intermedia & M. albicans & T. stenocarpa & V. tucanotum & X. aromatica & G. polymorpha & M. chamissois & J. caroba \\
\hline
\end{tabular}

Tabela 8.21: Matriz de confusão média obtida por validação cruzada leave-one-out $(m=80)$ do vetor final obtido por simples contatenação (sem seleção de características) dos vetores componentes.

Pelos resultados alcançados, ficou comprovado que a seleção de características realmente foi importante para melhorar a performance de identificação das espécies. É importante salientar que a diferença na taxa de acertos não foi tão acentuada em virtude de que alguns parâmetros 
selecionados pela distância de Jeffrey-Matusita foram mantidos - distâncias $d$ nas matrizes de co-ocorrência e $\sigma$ na Dimensão Fractal MultiEscala obtida por BoxCounting 3D. Se tais parâmetros também fossem modificados, seguramente a taxa de acertos de identificação seriam ainda menores.

No caso da abordagem que aplica o método PCA nos vetores de características com número de dimensões maior que três, a plotagem dos dois primeiros componentes principais do vetor final obtido está presente na Figura 8.5. Nessa imagem é possível perceber mais claramente a separação dos clusters, com especial destaque para a espécie Miconia albicans, que mantém uma separação acentuada das demais espécies. Também é possível perceber a coesão das amostras de Jacaranda caroba, Byrsonima intermedia, Gochnatia polymorpha e Miconia chamissois.

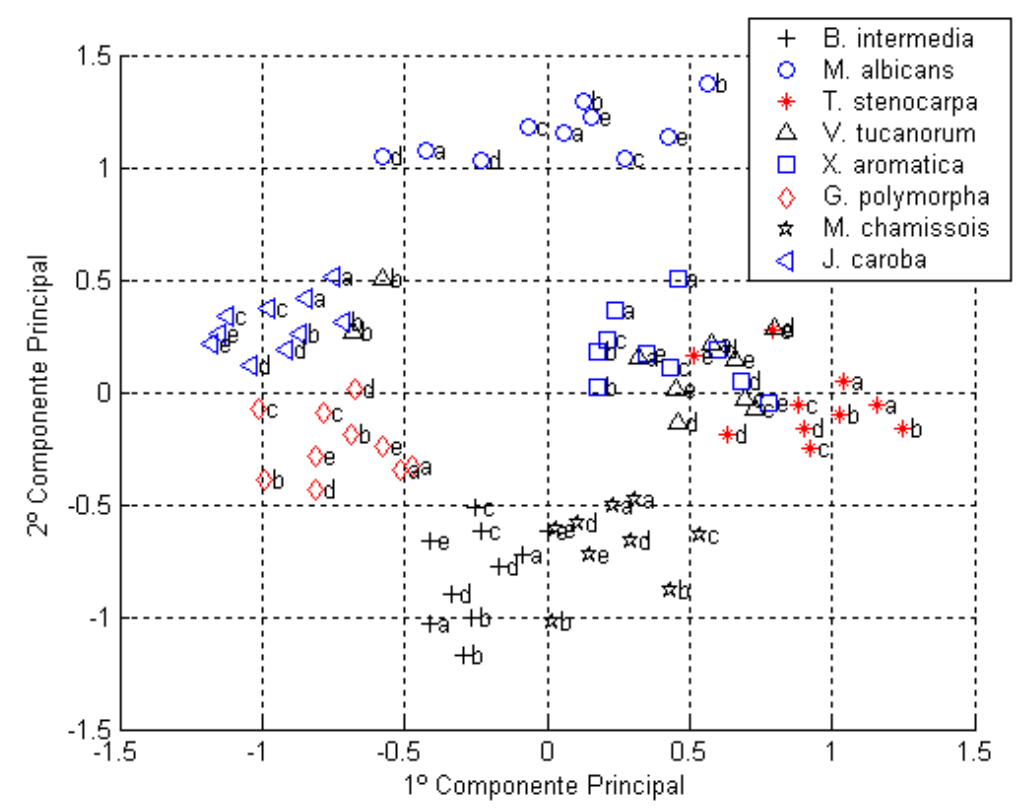

Figura 8.5: Visualização 2D (PCA - dois primeiros componentes principais) do vetor final obtido por aplicação do método PCA nos vetores componentes cujas dimensionalidades são maiores que três

Pela comparação da Figura 8.4 com a Figura 8.5, é possível perceber que esta mostra a separação entre as espécies de forma muito mais evidente do que aquela. Isso se deve ao fato de que, como explicado anteriormente, o vetor de características final é composto por contribuições iguais (exceto pelas medidas de espessura) dos vetores componentes. Dessa forma, características importantes, mas que resultam em vetores de dados de poucas dimensões, puderam dar sua contribuição de forma eficaz, permitindo um sinergismo muito mais equânime.

Os vetores finais obtidos pela abordagem PCA também foram avaliados por rede neural via método leave-one-out. Os resultados de identificação estão presentes na Tabela 8.22.

Pelos resultados alcançados, o vetor final obtido pelo método PCA concentra a essência das informações necessárias para caracterizar uma espécie. Todas as amostras tiveram uma alta 


\begin{tabular}{|l|c|c|c|c|c|c|c|c|}
\hline B. intermedia & $80 \%$ & 0 & 0 & 0 & 0 & 0 & $20 \%$ & 0 \\
\hline M. albicans & 0 & $90 \%$ & 0 & 0 & $10 \%$ & 0 & 0 \\
\hline T. stenocarpa & 0 & $10 \%$ & $90 \%$ & 0 & 0 & 0 & 0 & 0 \\
\hline V. tucanotum & 0 & 0 & 0 & $90 \%$ & 0 & $10 \%$ & 0 & 0 \\
\hline X. aromatica & 0 & 0 & 0 & 0 & $90 \%$ & 0 & $10 \%$ & 0 \\
\hline G. polymorpha & 0 & 0 & 0 & 0 & 0 & $100 \%$ & 0 & 0 \\
\hline M. chamissois & $10 \%$ & 0 & 0 & 0 & 0 & 0 & $90 \%$ & 0 \\
\hline J. caroba & 0 & 0 & 0 & 0 & $10 \%$ & 0 & 0 & $90 \%$ \\
\hline & B. intermedia & M. albicans & T. stenocarpa & V. tucanotum & X. aromatica & G. polymorpha & M. chamissois & J. caroba \\
\hline
\end{tabular}

Tabela 8.22: Matriz de confusão média obtida por validação cruzada leave-one-out $(m=80)$ do vetor final obtido por aplicação do método PCA nos vetores componentes cujas dimensionalidades são maiores que três.

taxa de identificação correta e a performance geral do sistema foi igual a do experimento por concatenação simples, ou seja, $90,00 \%$ de acertos.

Embora ambos os experimentos tenham conseguido taxas iguais de acertos, aquele que utiliza PCA se mostrou superior por dois motivos. O primeiro e mais óbvio foi a redução drástica da dimensionalidade do vetor representativo das amostras, o que, em se tratando de reconhecimentos de padrões, é algo muito importante. O segundo foi que a medida da distância de Jeffrey-Matusita do vetor final por PCA foi de 0,9847, enquanto que no experimento por concatenação simples foi de 0,9707 , fato este que está expresso na excelente separação dos clusters na Figura 8.5.

Pela comparação das imagens nas Figuras 8.4 e 8.5, também é possível perceber que as imagens retiradas de uma única folha quase sempre não tendem a ficar mais próximas entre si do que as imagens provenientes de folhas diferentes, demonstrando que as variações dentro de uma pequena região da folha podem ser tão grandes quanto àquelas presentes em folhas de indivíduos diferentes. Desse modo, a forma de aquisição das imagens empregada neste trabalho (ver Figura 7.1) sugere uma equivalência ao experimento no qual houvesse dez folhas distintas por espécie com a retirada de uma única imagem de cada uma. 


\subsection{Espécie Gochnatia polymorpha (Cerrado e Mata Ci-} liar)
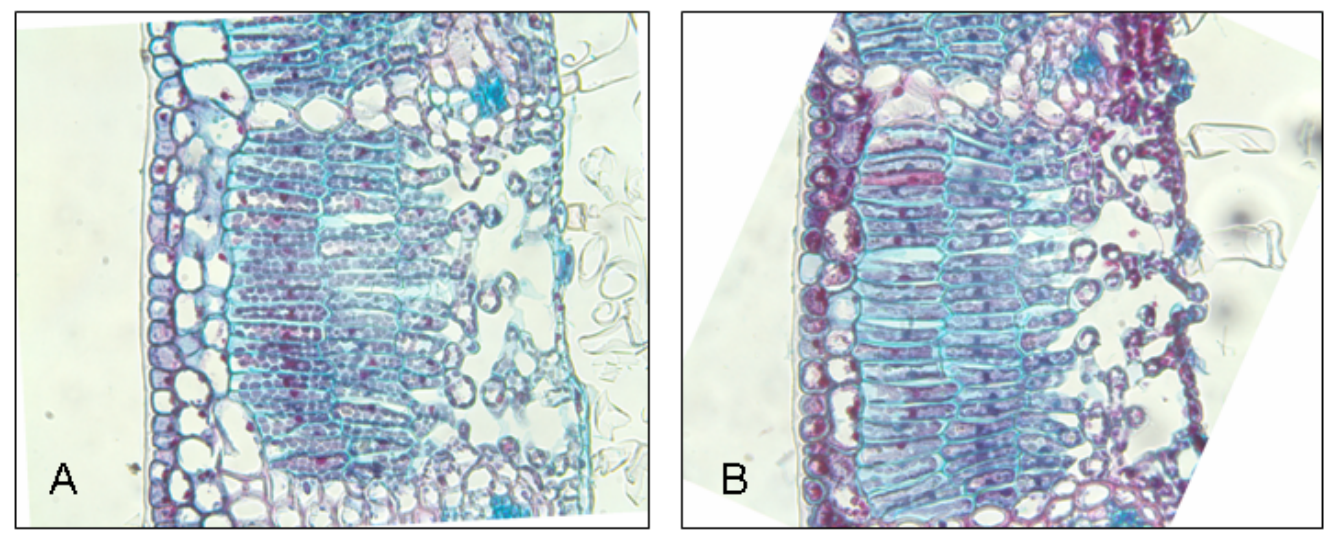

Figura 8.6: Cortes transversais das folhas da espécie Gochnatia polymorpha nos ambientes:

A - Cerrado, B - Mata Ciliar.

\subsubsection{Medida de Espessura da Cutícula}

Na Tabela 8.23 constam as médias e os desvios padrão das espessuras de cutícula de todas as amostras. As informações expostas demonstram que os espécimes do ambiente Cerrado possuem uma média de espessura mais elevada.

\begin{tabular}{|l|c|c|}
\hline & G. polymorpha (Cerrado) & G. polymorpha (Mata Ciliar) \\
\hline Média (pixels) & 15,730 & 12,280 \\
\hline Desvio Padrão (pixels) & 1,679 & 1,866 \\
\hline
\end{tabular}

Tabela 8.23: Médias e desvios padrão das espessuras de cutícula das amostras de Gochnatia polymorpha nos ambientes Cerrado e Mata Ciliar.

Na Tabela 8.24 constam as percentagens de acertos na identificação das medidas de espessura de cutícula. A taxa média de acertos foi de $76,666 \%$.

\begin{tabular}{|l|c|c|}
\hline G. polymorpha (Cerrado) & $80 \%$ & $20 \%$ \\
\hline G. polymorpha (Mata Ciliar) & $26,666 \%$ & $73,333 \%$ \\
\hline & G. polymorpha (Cerrado) & G. polymorpha (Mata Ciliar) \\
\hline
\end{tabular}

Tabela 8.24: Performance de identificação por RNA via leave-one-out ( $m=30)$ das medidas de espessura de cutícula das amostras de Gochnatia polymorpha nos ambientes Cerrado e Mata Ciliar.

\subsubsection{Medida de Espessura da Epiderme Superior}

A Tabela 8.25 expressa as médias e os desvios padrão das espessuras de epiderme superior de todas as amostras. As médias de ambos os ambientes apresentaram uma acentuada diferença 
de 26, 3 (pixels). Os desvios padrão, entretanto, mostraram-se extremamente próximos um do outro.

\begin{tabular}{|l|c|c|}
\hline & G. polymorpha (Cerrado) & G. polymorpha (Mata Ciliar) \\
\hline Média (pixels) & 152,00 & 125,70 \\
\hline Desvio Padrão (pixels) & 14,310 & 14,420 \\
\hline
\end{tabular}

Tabela 8.25: Médias e desvios padrão das espessuras de epiderme superior das amostras de Gochnatia polymorpha nos ambientes Cerrado e Mata Ciliar.

A Tabela 8.26 expressa a taxa de acertos das amostras de ambos os ambientes. A taxa média de acertos é $66,666 \%$.

\begin{tabular}{|l|c|c|}
\hline G. polymorpha (Cerrado) & $66,666 \%$ & $33,333 \%$ \\
\hline G. polymorpha (Mata Ciliar) & $33,333 \%$ & $66,666 \%$ \\
\hline & G. polymorpha (Cerrado) & G. polymorpha (Mata Ciliar) \\
\hline
\end{tabular}

Tabela 8.26: Performance de identificação por RNA via leave-one-out ( $m=30)$ das medidas de espessura de epiderme superior das amostras de Gochnatia polymorpha nos ambientes Cerrado e Mata Ciliar.

\subsubsection{Resultados Experimentais do Parênquima Paliçádico}

\section{Coeficientes Tricromáticos}

A Tabela 8.27 expressa os resultados por redes neurais via método leave-one-out nos coeficientes tricromáticos do parênquima paliçádico. A taxa média de acertos foi de $56,666 \%$.

\begin{tabular}{|l|c|c|}
\hline G. polymorpha (Cerrado) & $66,666 \%$ & $33,333 \%$ \\
\hline G. polymorpha (Mata Ciliar) & $53,333 \%$ & $46,666 \%$ \\
\hline & G. polymorpha (Cerrado) & G. polymorpha (Mata Ciliar) \\
\hline
\end{tabular}

Tabela 8.27: Performance de identificação por RNA via leave-one-out $(m=30)$ dos coeficientes tricromáticos das amostras de Gochnatia polymorpha nos ambientes Cerrado e Mata Ciliar.

\section{Matrizes de Co-ocorrência}

Pela busca exaustiva com critério de distância de Jeffrey-Matusita, a máxima distância $J M$ encontrada foi de 0,88493 para matrizes de distância $d=5$. As medidas selecionadas e respectivas matrizes foram as seguintes: energia (ângulos de $0^{\circ}, 90^{\circ}, 45^{\circ}$ e $135^{\circ}$ ) e entropia (ângulos de $0^{\circ}, 90^{\circ}, 45^{\circ}$ e $135^{\circ}$ ).

A Tabela 8.28 expressa os resultados por redes neurais via método leave-one-out. A taxa média de acertos foi de $83,333 \%$. 


\begin{tabular}{|l|c|c|}
\hline G. polymorpha (Cerrado) & $80 \%$ & $20 \%$ \\
\hline G. polymorpha (Mata Ciliar) & $13,333 \%$ & $86,666 \%$ \\
\hline & G. polymorpha (Cerrado) & G. polymorpha (Mata Ciliar) \\
\hline
\end{tabular}

Tabela 8.28: Performance de identificação por RNA via leave-one-out ( $m=30)$ das matrizes de co-ocorrência das amostras de Gochnatia polymorpha nos ambientes Cerrado e Mata

Ciliar.

\subsubsection{Resultados Experimentais do Parênquima Lacunoso}

\section{Estatísticas de Primeira Ordem}

Pela busca exaustiva realizada com critério de distância de Jeffrey-Matusita, as seguintes medidas foram selecionadas: média, variância e obliqüidade. A maior distância encontrada foi $J M=0,48872$.

A Tabela 8.29 expressa os resultados por redes neurais via método leave-one-out. A taxa média de acertos foi de $50,00 \%$.

\begin{tabular}{|l|c|c|}
\hline G. polymorpha (Cerrado) & $53,333 \%$ & $46,666 \%$ \\
\hline G. polymorpha (Mata Ciliar) & $53,333 \%$ & $46,666 \%$ \\
\hline & G. polymorpha (Cerrado) & G. polymorpha (Mata Ciliar) \\
\hline
\end{tabular}

Tabela 8.29: Performance de identificação por RNA via leave-one-out ( $m=30)$ de estatísticas de primeira ordem no parênquima lacunoso das amostras de Gochnatia polymorpha nos ambientes Cerrado e Mata Ciliar.

\section{Matrizes de Co-ocorrência}

Pela busca exaustiva com critério de distância de Jeffrey-Matusita, a máxima distância $J M$ encontrada foi de 0,51357 para matrizes de distância $d=5$. As medidas selecionadas e respectivas matrizes foram as seguintes: energia (ângulos de $0^{\circ}$ e $90^{\circ}$ ) e correlação (ângulos de $0^{\circ}$, $90^{\circ}, 45^{\circ}$ e $135^{\circ}$ ).

A Tabela 8.30 expressa os resultados por redes neurais via método leave-one-out. A taxa média de acertos foi de $40,00 \%$.

\begin{tabular}{|l|c|c|}
\hline G. polymorpha (Cerrado) & $33,333 \%$ & $66,666 \%$ \\
\hline G. polymorpha (Mata Ciliar) & $53,333 \%$ & $46,666 \%$ \\
\hline & G. polymorpha (Cerrado) & G. polymorpha (Mata Ciliar) \\
\hline
\end{tabular}

Tabela 8.30: Performance de identificação por RNA via leave-one-out $(m=30)$ das matrizes de co-ocorrência no parênquima lacunoso das amostras de Gochnatia polymorpha nos ambientes Cerrado e Mata Ciliar.

\subsubsection{Medida de Espessura do Corte Transversal}

Na Tabela 8.31 constam as médias e os desvios padrão (em pixels) das espessuras coletadas. Nos resultados, os espécimes do ambiente Mata Ciliar apresentam uma média 49, 7 (pixels) 
mais elevada que os pertencentes ao Cerrado. O desvio padrão, entretanto, apresentou-se muito parecido em ambos os ambientes, com uma diferença de 16,61 (pixels).

\begin{tabular}{|l|c|c|}
\hline & G. polymorpha (Cerrado) & G. polymorpha (Mata Ciliar) \\
\hline Média (pixels) & 831,5 & 881,2 \\
\hline Desvio Padrão (pixels) & 44,530 & 61,140 \\
\hline
\end{tabular}

Tabela 8.31: Médias e desvios padrão das espessuras do corte transversal das amostras de Gochnatia polymorpha nos ambientes Cerrado e Mata Ciliar.

Na Tabela 8.32 consta as percentagens de acertos de identificação das medidas de espessura do corte transversal de todas as amostras de Gochnatia polymorpha nos ambientes Cerrado e Mata Ciliar. A taxa média de acertos foi de $60,00 \%$.

\begin{tabular}{|l|c|c|}
\hline G. polymorpha (Cerrado) & $66,666 \%$ & $33,333 \%$ \\
\hline G. polymorpha (Mata Ciliar) & $46,666 \%$ & $53,333 \%$ \\
\hline & G. polymorpha (Cerrado) & G. polymorpha (Mata Ciliar) \\
\hline
\end{tabular}

Tabela 8.32: Performance de identificação por RNA via leave-one-out $(m=30)$ das medidas de espessura dos cortes transversais das amostras de Gochnatia polymorpha nos ambientes

Cerrado e Mata Ciliar.

\subsubsection{Montagem do Vetor de Características}

Conforme as regras estabelecidas na Seção 7.8, o vetor obtido por concatenação simples apresenta a forma descrita pela Figura 8.7.

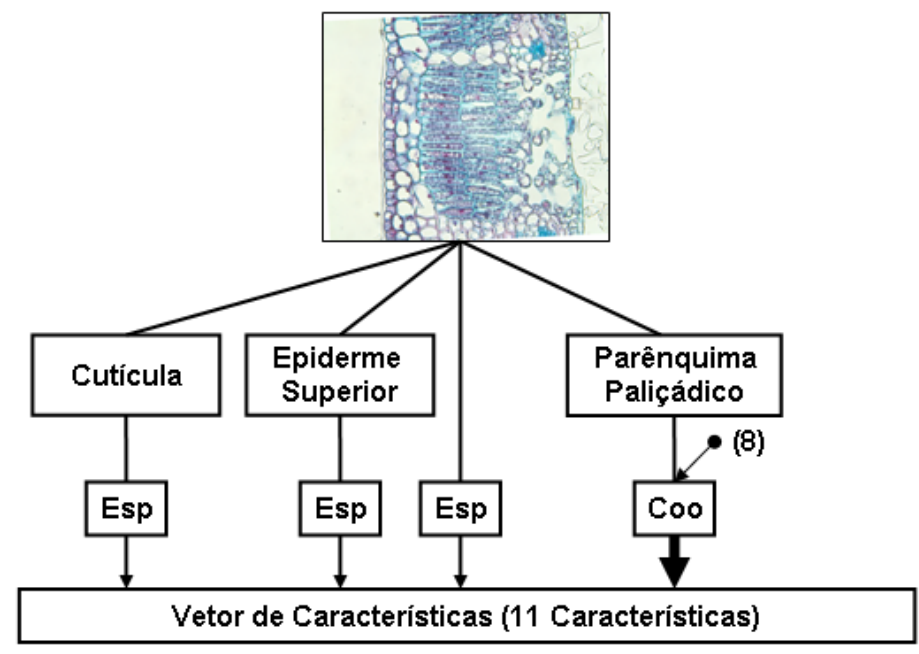

Figura 8.7: Esquema da montagem do vetor de características por concatenação simples. Siglas: Esp - espessura; Coo - matrizes de co-ocorrência.

A Figura 8.8 demonstra a configuração do vetor de características final com a redução de dimensionalidade pelo método PCA de alguns dos vetores componentes. Por essa abordagem, o vetor final ficou com $54,54 \%$ da dimensionalidade do vetor obtido por concatenação simples. 


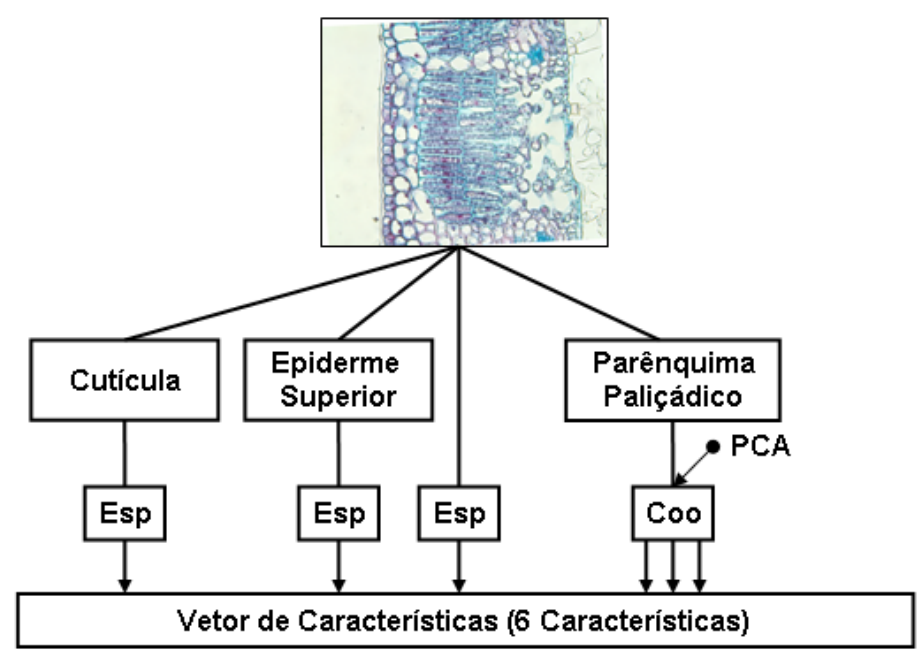

Figura 8.8: Esquema da montagem do vetor de características com o auxílio do método PCA. Siglas: Esp - espessura; Coo - matrizes de co-ocorrência.

\subsubsection{Resultados e Discussão}

De modo similar aos experimentos com espécies diversas, os vetores descritos na Seção 8.2.6 foram testados com a rede neural apresentada na Seção 7.2 pelo método leave-one-out.

A plotagem dos dois principais componentes do método PCA no vetor de concatenação simples pode ser visualizada na Figura 8.9. A imagem demonstra claramente a separação das amostras de ambos os ambientes. Também é possível perceber uma coesão maior do cluster do ambiente Cerrado, o que indica que os espécimes que cresceram nesse ambiente são mais parecidos entre si do que aqueles que se desenvolveram em Mata Ciliar.

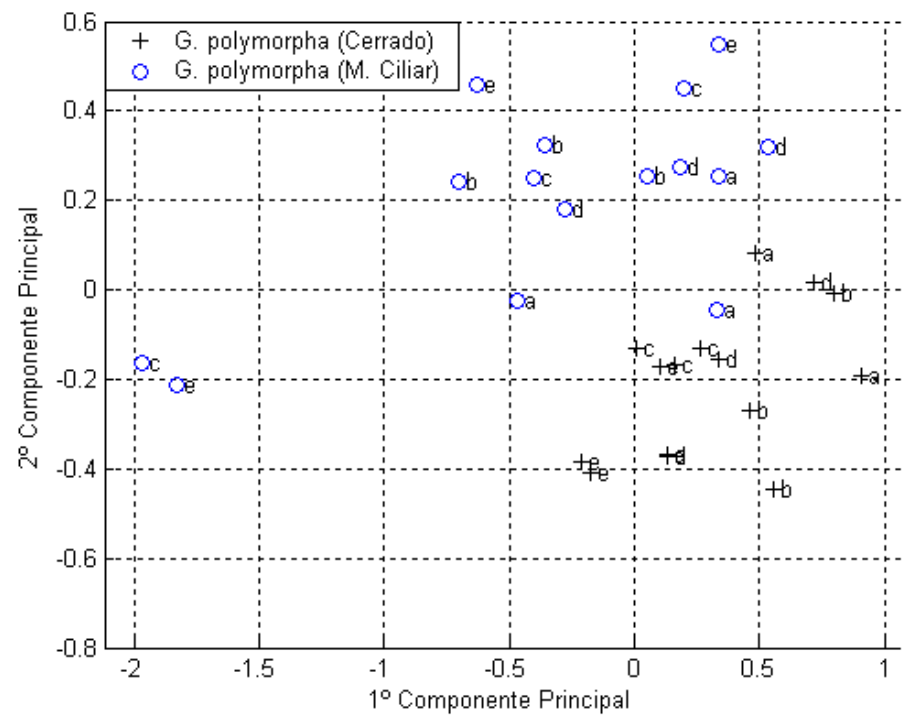

Figura 8.9: Visualização 2D (PCA - dois primeiros componentes principais) do vetor final obtido por concatenação simples (com seleção por distância de Jeffrey-Matusita) dos vetores componentes. 
A Tabela 8.33 demonstra os resultados de identificação alcançados. Embora a simples concatenção não seja a forma ideal de combinar informações de diferentes técnicas de extração de características, a taxa de acertos obtida foi muito boa, com 93, 333\% de acertos.

\begin{tabular}{|l|c|c|}
\hline G. polymorpha (Cerrado) & $93,333 \%$ & $6,666 \%$ \\
\hline G. polymorpha (Mata Ciliar) & $6,666 \%$ & $93,333 \%$ \\
\hline & G. polymorpha (Cerrado) & G. polymorpha (Mata Ciliar) \\
\hline
\end{tabular}

Tabela 8.33: Performance de identificação média obtida por validação cruzada leave-one-out $(m=30)$ do vetor final obtido por simples concatenação (com seleção por distância de Jeffrey-Matusita) dos vetores componentes.

A Figura 8.10 exibe a plotagem 2D (dois principais componentes do método PCA) dos vetores de características obtidos com o auxílio do método PCA na redução de dimensionalidade (ver Figura 8.8). Assim como aconteceu nos experimentos com diferentes espécies, essa abordagem apresentou uma separação entre os clusters bem mais acentuada.

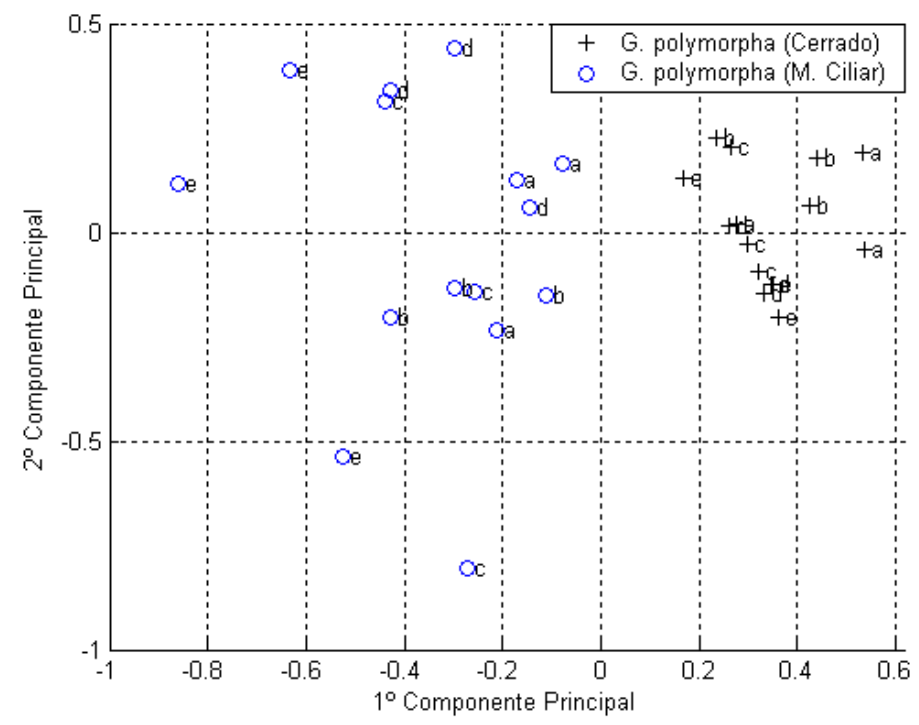

Figura 8.10: Visualização 2D (PCA - dois primeiros componentes principais) do vetor final obtido por aplicação do método PCA nos vetores componentes cujas dimensionalidades são maiores que três

A Tabela 8.34 apresenta os resultados de identificação obtidos pela abordagem com PCA. Conforme a figura acima permite antever, a taxa de acertos alcançada foi excelente, com 96, $666 \%$ de acertos, ou seja, apenas uma amostra foi identificada erroneamente.

\begin{tabular}{|l|c|c|}
\hline G. polymorpha (Cerrado) & $100 \%$ & $0 \%$ \\
\hline G. polymorpha (Mata Ciliar) & $6,666 \%$ & $93,333 \%$ \\
\hline & G. polymorpha (Cerrado) & G. polymorpha (Mata Ciliar) \\
\hline
\end{tabular}

Tabela 8.34: Performance de identificação obtida por validação cruzada leave-one-out $(m=30)$ do vetor final obtido por aplicação do método PCA nos vetores componentes cujas dimensionalidades são maiores que três. 
Os resultados alcançados confirmam que as alterações morfológicas dessa espécie em ambos os ambientes são acentuadas. Pelos experimentos, foi possível identificar quais regiões da folha apresentaram maior plasticidade anatômica. A análise de textura por matrizes de coocorrência no parênquima paliçádico forneceu a assinatura que mais precisamente identificou o ambiente dos espécimes. A seguir, as medidas de espessura de cutícula e epiderme superior se apresentaram maiores nas amostras do ambiente Cerrado, o que resultou nas taxas de acertos de $76,666 \%$ e $66,666 \%$ com essas assinaturas, respectivamente. As demais medidas, como medida de espessura do corte transversal e análise de textura do parênquima lacunoso não ofereceram resultados significativos.

Assim como no experimento com espécies diferentes, foi possível analisar a variação entre indivíduos diferentes e também a variação dentro de uma pequena região da folha. Pelas Figuras 8.9 e 8.10 foi possível perceber que as imagens retiradas de uma mesma folha não tenderam a ficar mais próximas entre si do que as imagens de folhas diferentes. 


\subsection{Espécie Gochnatia polymorpha (Chuva e Seca)}
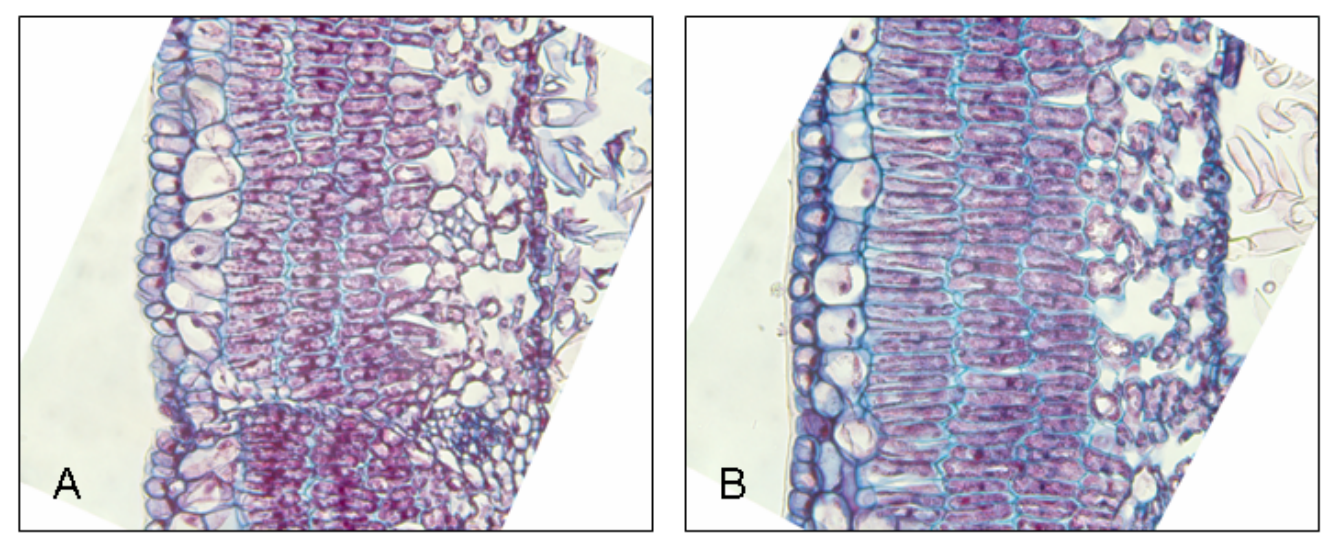

Figura 8.11: Cortes transversais das folhas da espécie Gochnatia polymorpha nas estações: A - Chuvosa, B - Seca

\subsubsection{Medida de Espessura da Cutícula}

Na Tabela 8.35 constam as médias e os desvios padrão das espessuras de cutícula de todas as amostras. Pelos dados coletados, os espécimes da estação Seca possuem uma média de espessura 3,72 (pixels) maior. A diferença entre ambos os desvios padrão é irrelevante.

\begin{tabular}{|l|c|c|}
\hline & G. polymorpha (Chuvosa) & G. polymorpha (Seca) \\
\hline Média (em pixels) & 12,55 & 16,27 \\
\hline Desvio Padrão (em pixels) & 2,147 & 2,268 \\
\hline
\end{tabular}

Tabela 8.35: Médias e desvios padrão das espessuras de cutícula das amostras de Gochnatia polymorpha nas estações Chuvosa e Seca.

Na Tabela 8.36 constam as percentagens de acertos na identificação das medidas de espessura de cutícula. A taxa média de acertos foi de $76,666 \%$.

\begin{tabular}{|l|c|c|}
\hline G. polymorpha (Chuvosa) & $80 \%$ & $20 \%$ \\
\hline G. polymorpha (Seca) & $26,666 \%$ & $73,333 \%$ \\
\hline & G. polymorpha (Chuvosa) & G. polymorpha (Seca) \\
\hline
\end{tabular}

Tabela 8.36: Performance de identificação por RNA via leave-one-out ( $m=30$ ) das medidas de espessura de cutícula das amostras de Gochnatia polymorpha nas estações Chuvosa e Seca.

\subsubsection{Medida de Espessura da Epiderme Superior}

A Tabela 8.37 expressa as médias e os desvios padrão das espessuras de epiderme superior de todas as amostras. As médias de ambas as estações se apresentaram praticamente iguais. $\mathrm{O}$ desvio padrão, entretanto, dos espécimes da estação Seca apresentou-se elevado. 


\begin{tabular}{|l|c|c|}
\hline & G. polymorpha (Chuvosa) & G. polymorpha (Seca) \\
\hline Média (pixels) & 133,90 & 133,80 \\
\hline Desvio Padrão (pixels) & 21,51 & 45,20 \\
\hline
\end{tabular}

Tabela 8.37: Médias e desvios padrão das espessuras de epiderme superior das amostras de Gochnatia polymorpha nas estações Chuvosa e Seca.

A Tabela 8.38 expressa a taxa de acertos das amostras de ambas as estações. A taxa média de acertos é $56,666 \%$.

\begin{tabular}{|l|c|c|}
\hline G. polymorpha (Chuvosa) & $53,333 \%$ & $46,666 \%$ \\
\hline G. polymorpha (Seca) & $40 \%$ & $60 \%$ \\
\hline & G. polymorpha (Chuvosa) & G. polymorpha (Seca) \\
\hline
\end{tabular}

Tabela 8.38: Performance de identificação por RNA via leave-one-out ( $m=30)$ das medidas de espessura de epiderme superior das amostras de Gochnatia polymorpha nas estações

Chuvosa e Seca.

\subsubsection{Resultados Experimentais do Parênquima Paliçádico}

\section{Coeficientes Tricromáticos}

A Tabela 8.39 expressa os resultados por redes neurais via método leave-one-out nos coeficientes tricromáticos do parênquima paliçádico. A taxa média de acertos foi de $73,333 \%$.

\begin{tabular}{|l|c|c|}
\hline G. polymorpha (Chuvosa) & $80 \%$ & $20 \%$ \\
\hline G. polymorpha (Seca) & $33,333 \%$ & $66,666 \%$ \\
\hline & G. polymorpha (Chuvosa) & G. polymorpha (Seca) \\
\hline
\end{tabular}

Tabela 8.39: Performance de identificação por RNA via leave-one-out ( $m=30)$ dos coeficientes tricromáticos das amostras de Gochnatia polymorpha nas estações Chuvosa e Seca.

\section{Matrizes de Co-ocorrência}

A busca exaustiva encontrou como máxima distância $J M$ o valor de 0,92762 para matrizes de distância $d=1$. As medidas selecionadas e respectivas matrizes foram as seguintes: energia (ângulos de $0^{\circ}$ e $90^{\circ}$ ) e entropia (ângulos de $0^{\circ}, 90^{\circ}, 45^{\circ}$ e $135^{\circ}$ ).

A Tabela 8.40 expressa a taxa de acertos alcançada por redes neurais via método leave-oneout. A performance média de acertos foi de $76,666 \%$.

\begin{tabular}{|l|c|c|}
\hline G. polymorpha (Chuvosa) & $80 \%$ & $20 \%$ \\
\hline G. polymorpha (Seca) & $26,666 \%$ & $73,333 \%$ \\
\hline & G. polymorpha (Chuvosa) & G. polymorpha (Seca) \\
\hline
\end{tabular}

Tabela 8.40: Performance de identificação por RNA via leave-one-out $(m=30)$ das matrizes de co-ocorrência das amostras de Gochnatia polymorpha nas estações Chuvosa e Seca. 


\subsubsection{Resultados Experimentais do Parênquima Lacunoso}

\section{Estatísticas de Primeira Ordem}

A busca exaustiva encontrou como máxima distância $J M$ o valor 0,67466 com as seguintes medidas: média, variância, obliqüidade e curtose.

A Tabela 8.41 expressa os resultados por redes neurais via método leave-one-out. A taxa média de acertos foi de $73,333 \%$.

\begin{tabular}{|l|c|c|}
\hline G. polymorpha (Chuvosa) & $80 \%$ & $20 \%$ \\
\hline G. polymorpha (Seca) & $33,333 \%$ & $66,666 \%$ \\
\hline & G. polymorpha (Chuvosa) & G. polymorpha (Seca) \\
\hline
\end{tabular}

Tabela 8.41: Performance de identificação por RNA via leave-one-out ( $m=30)$ de estatísticas de primeira ordem no parênquima lacunoso das amostras de Gochnatia polymorpha nas estações Chuvosa e Seca.

\section{Matrizes de Co-ocorrência}

Pela busca exaustiva com critério de distância de Jeffrey-Matusita, a máxima distância $J M$ encontrada foi de 0,8453 para matrizes de distância $d=5$. As medidas selecionadas e respectivas matrizes foram as seguintes: contraste (ângulos de $0^{\circ}, 90^{\circ}, 45^{\circ}$ e $135^{\circ}$ ) e valor absoluto (ângulos de $0^{\circ}$ e $90^{\circ}$ ).

A Tabela 8.42 expressa os resultados por redes neurais via método leave-one-out. A taxa média de acertos foi de $83,333 \%$.

\begin{tabular}{|l|c|c|}
\hline G. polymorpha (Chuvosa) & $86,666 \%$ & $13,333 \%$ \\
\hline G. polymorpha (Seca) & $20 \%$ & $80 \%$ \\
\hline & G. polymorpha (Chuvosa) & G. polymorpha (Seca) \\
\hline
\end{tabular}

Tabela 8.42: Performance de identificação por RNA via leave-one-out $(m=30)$ das matrizes de co-ocorrência no parênquima lacunoso das amostras de Gochnatia polymorpha nas estações Chuvosa e Seca.

\subsubsection{Medida de Espessura do Corte Transversal}

Na Tabela 8.43 constam as médias e os desvios padrão (em pixels) das espessuras coletadas. Os dados demonstram que o desvio padrão das amostras da estação Seca é bem elevado. Sua média também é mais alta que as dos exemplares da estação Chuvosa, mas a diferença, 17, 5 (pixels), não é muito expressiva.

A Tabela 8.44 demonstra os resultados de identificação pela medida do corte transversal. Como esperado pelos resultados da Tabela 8.43, a taxa de acertos ficou muito próxima do que seria esperado caso as amostras fossem selecionadas aleatoriamente, ou seja, 50\%. A taxa média de acertos foi de 53, $333 \%$. 


\begin{tabular}{|l|c|c|}
\hline & G. polymorpha (Chuvosa) & G. polymorpha (Seca) \\
\hline Média $($ em pixels $)$ & 846,7 & 864,2 \\
\hline Desvio Padrão $($ em pixels) & 60,89 & 105 \\
\hline
\end{tabular}

Tabela 8.43: Médias e desvios padrão das espessuras do corte transversal das amostras de Gochnatia polymorpha nas estações Chuvosa e Seca.

\begin{tabular}{|l|c|c|}
\hline G. polymorpha (Chuvosa) & $53,333 \%$ & $46,666 \%$ \\
\hline G. polymorpha (Seca) & $46,666 \%$ & $53,333 \%$ \\
\hline & G. polymorpha (Chuvosa) & G. polymorpha (Seca) \\
\hline
\end{tabular}

Tabela 8.44: Performance de identificação por RNA via leave-one-out ( $m=30)$ das medidas de espessura dos cortes transversais das amostras de Gochnatia polymorpha nas estações Chuvosa e Seca.

\subsubsection{Montagem do Vetor de Características}

A Figura 8.12 expressa a configuração do vetor final obtido por simples concatenação, conforme regras estabelecidas na Seção 7.8.

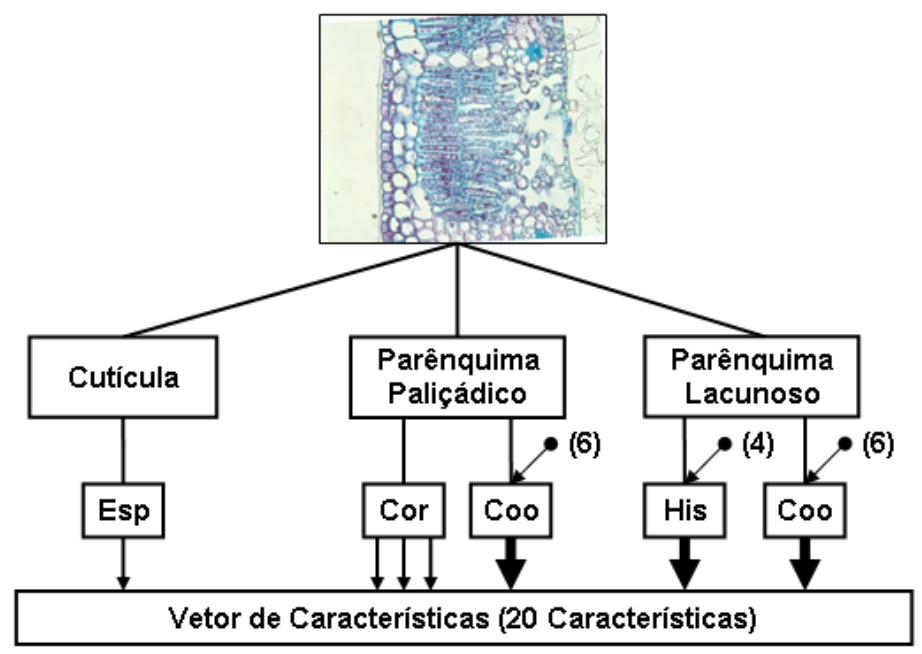

Figura 8.12: Esquema da montagem do vetor de características por concatenação simples. Siglas: Esp - espessura; Cor - coeficientes tricromáticos; His - estatística de $1^{a}$ ordem; Coo matrizes de co-ocorrência.

A abordagem com redução de dimensionalidade de algumas das assinaturas componentes para posterior concatenação está expressa na Figura 8.13. O vetor final, nesse caso, ficou com $65,00 \%$ da dimensionalidade do vetor obtido por simples concatenação. 


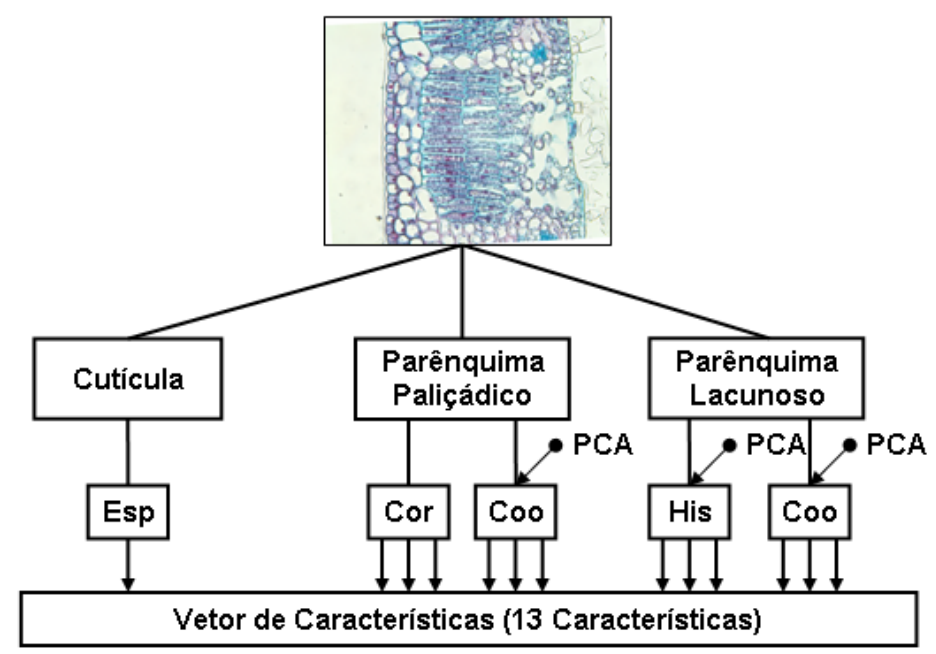

Figura 8.13: Esquema da montagem do vetor de características com o auxílio do método PCA. Siglas: Esp - espessura; Cor - coeficientes tricromáticos; His - estatística de $1^{a}$ ordem; Coo - matrizes de co-ocorrência.

\subsubsection{Resultados e Discussão}

De modo similar aos experimentos com espécies diversas, os vetores descritos na Seção 8.3.6 foram testados com a rede neural descrita na Seção 7.2 pelo método leave-one-out.

A plotagem 2D (dois principais componentes do método PCA) dos vetores obtidos com concatenação simples pode ser visualizada na Figura 8.14. Pela imagem, é possível perceber uma boa separação entre as amostras que se desenvolveram nas estações Chuvosa e Seca.

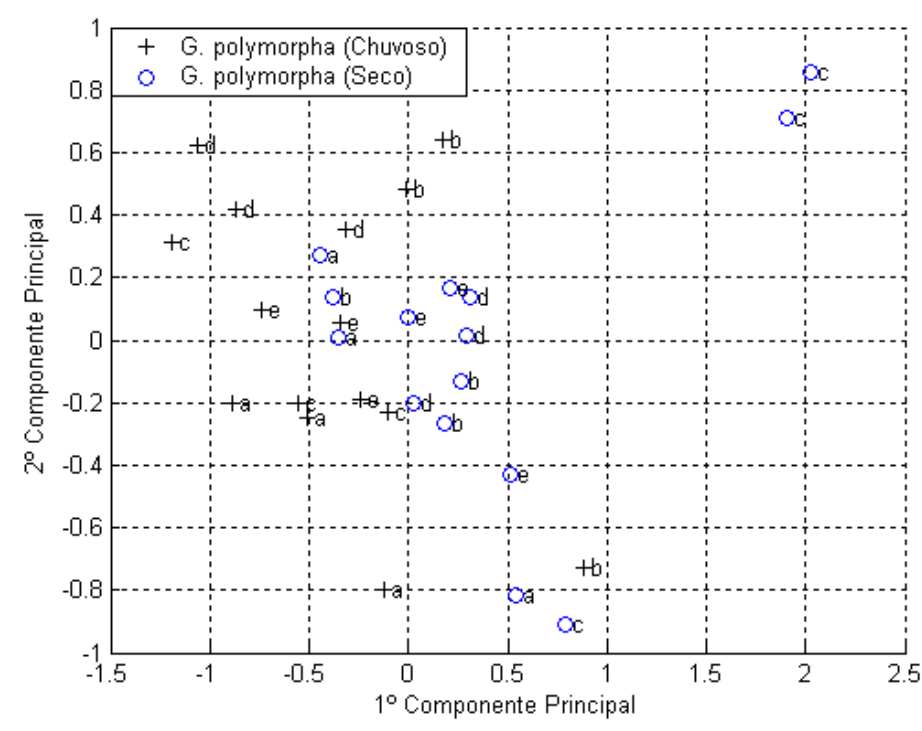

Figura 8.14: Visualização 2D (PCA - dois primeiros componentes principais) do vetor final obtido por concatenação simples (com seleção por distância de Jeffrey-Matusita) dos vetores componentes. 
A Tabela 8.45 demonstra os resultados de identificação alcançados. No presente caso, a taxa de acertos média alcançada foi de $80,00 \%$ - seis amostras foram identificadas erroneamente.

\begin{tabular}{|l|c|c|}
\hline G. polymorpha (Chuvosa) & $73,333 \%$ & $26,666 \%$ \\
\hline G. polymorpha (Seca) & $13,333 \%$ & $86,666 \%$ \\
\hline & G. polymorpha (Chuvosa) & G. polymorpha (Seca) \\
\hline
\end{tabular}

Tabela 8.45: Performance de identificação média obtida por validação cruzada leave-one-out $(m=30)$ do vetor final obtido por simples concatenação (com seleção por distância de Jeffrey-Matusita) dos vetores componentes.

A Figura 8.15 demonstra a plotagem dos dois componentes principais (método PCA) das assinaturas obtidas pela concatenação com redução de dimensionalidade. Assim como nos resultados anteriores (Gochnatia polymorpha nos ambientes Cerrado e Mata Ciliar e espécies diversas), os clusters por essa segunda abordagem se apresentaram mais separados do que a abordagem por simples concatenação.

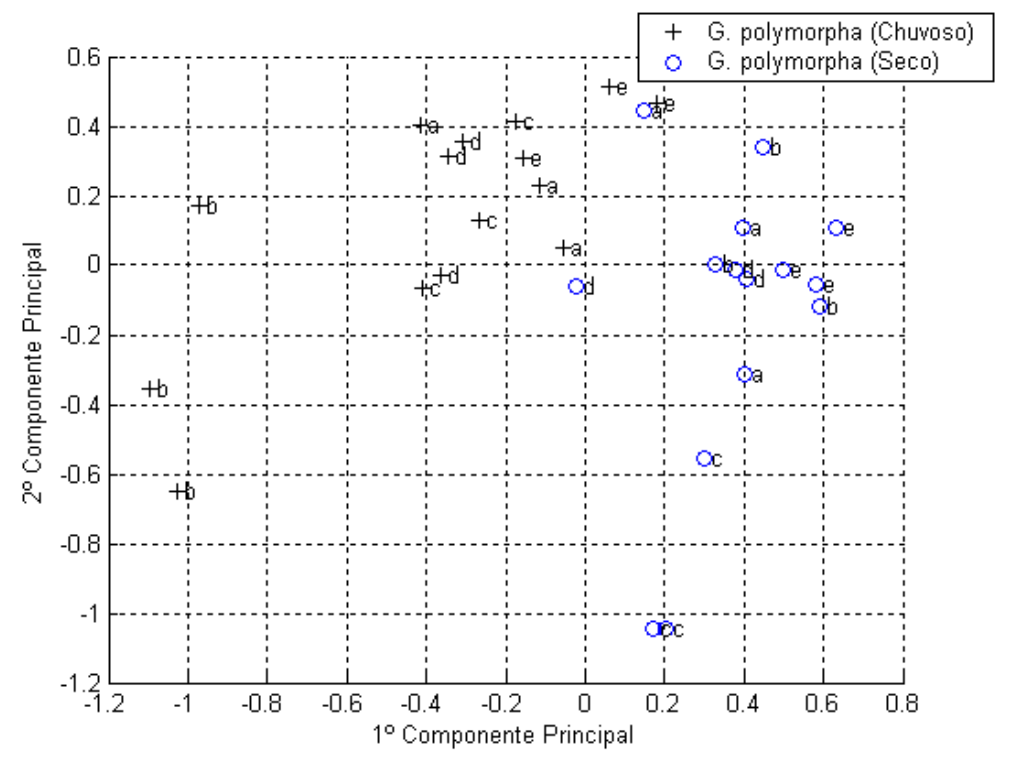

Figura 8.15: Visualização 2D (PCA - dois primeiros componentes principais) do vetor final obtido por aplicação do método PCA nos vetores componentes cujas dimensionalidades são maiores que três

A Tabela 8.46 apresenta os resultados de identificação obtidos pela abordagem com PCA. A taxa de acertos alcançada foi $90,00 \%$, ou seja, três amostras foram identificadas de forma errada.

\begin{tabular}{|l|c|c|}
\hline G. polymorpha (Chuvosa) & $86,666 \%$ & $13,333 \%$ \\
\hline G. polymorpha (Seca) & $6,666 \%$ & $93,333 \%$ \\
\hline & G. polymorpha (Chuvosa) & G. polymorpha (Seca) \\
\hline
\end{tabular}

Tabela 8.46: Performance de identificação obtida por validação cruzada leave-one-out $(m=30)$ do vetor final obtido por aplicação do método PCA nos vetores componentes cujas dimensionalidades são maiores que três. 
Os resultados alcançados indicam que as amostras que cresceram nas duas estações não apresentaram diferenças nas espessuras de epiderme superior e corte transversal. Entretanto, as demais medidas adquiridas ofereceram boas taxas de acertos, que ficaram no intervalo entre $73,333 \%$ e $83,333 \%$. Vale salientar a importância da medida de cutícula neste experimento, posto que alcançou uma performance de $76,666 \%$; e do parênquima lacunoso, que ofereceu uma taxa de acertos de 83,333\% com matrizes de co-ocorrência.

Nos resultados finais não há tendência para que as imagens extraídas de uma mesma folha estejam mais próximas entre si, exceto por um distanciamento de duas amostras $\mathbf{c}$ da estação Seca na Figura 8.14 e duas amostras $\mathbf{c}$ e três amostras b da estação Chuvosa na Figura 8.15. 


\subsection{Espécie Gochnatia polymorpha (Sol e Sombra)}
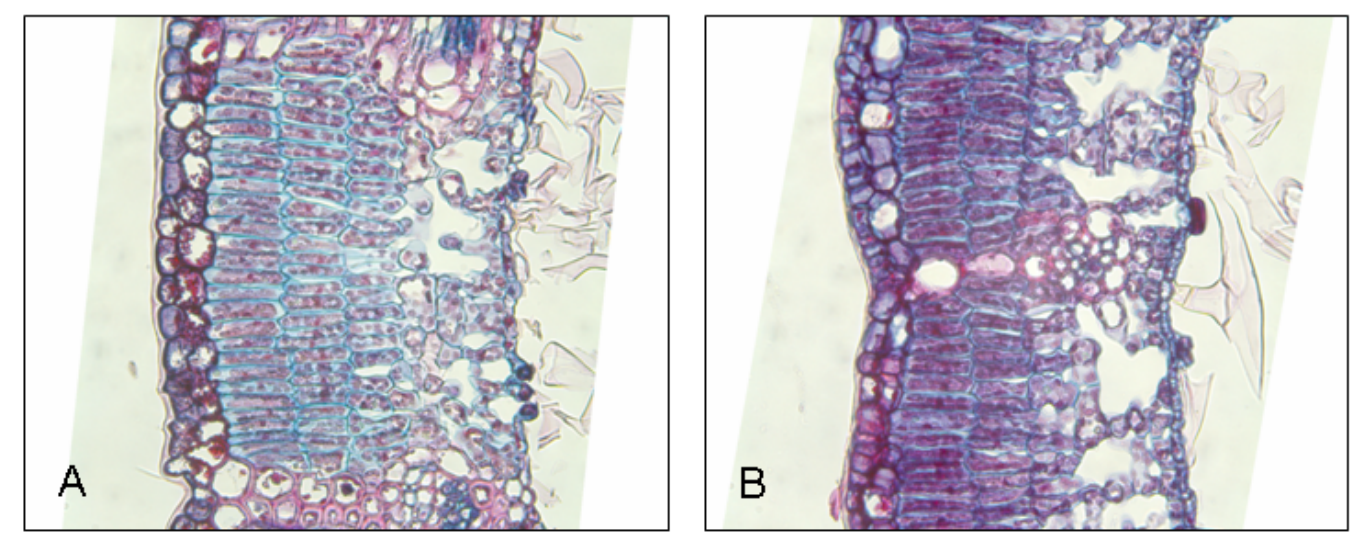

Figura 8.16: Cortes transversais das folhas da espécie Gochnatia polymorpha sob condições de: A - Sol, B - Sombra.

\subsubsection{Medida de Espessura da Cutícula}

Na Tabela 8.47 constam as médias e os desvios padrão das espessuras de cutícula de todos os espécimes. Nesse experimento, a diferença entre as espessuras em ambas as condições é muito acentuada. As amostras expostas à condição de $S o l$ possuem em média um espessura que é quase o dobro da espessura das amostras que se desenvolveram na Sombra.

\begin{tabular}{|l|c|c|}
\hline & G. polymorpha (Sol) & G. polymorpha (Sombra) \\
\hline Média $($ em pixels) & 15,74 & 8,493 \\
\hline Desvio Padrão $($ em pixels) & 3,024 & 2,972 \\
\hline
\end{tabular}

Tabela 8.47: Médias e desvios padrão das espessuras de cutícula das amostras de Gochnatia polymorpha sob condições de Sol e Sombra.

Na Tabela 8.48 constam as percentagens de acertos na identificação das medidas de espessura de cutícula. A taxa média de acertos foi de $83,333 \%$.

\begin{tabular}{|l|c|c|}
\hline G. polymorpha (Sol) & $80 \%$ & $20 \%$ \\
\hline G. polymorpha (Sombra) & $13,333 \%$ & $86,666 \%$ \\
\hline & G. polymorpha (Sol) & G. polymorpha (Sombra) \\
\hline
\end{tabular}

Tabela 8.48: Performance de identificação por RNA via leave-one-out $(m=30)$ das medidas de espessura de cutícula das amostras de Gochnatia polymorpha sob condições de Sol e Sombra.

\subsubsection{Medida de Espessura da Epiderme Superior}

A Tabela 8.49 expressa as médias e os desvios padrão das espessuras de epiderme superior de todas as amostras. 


\begin{tabular}{|l|c|c|}
\hline & G. polymorpha (Sol) & G. polymorpha (Sombra) \\
\hline Média (pixels) & 126,10 & 100,50 \\
\hline Desvio Padrão (pixels) & 16,75 & 30,67 \\
\hline
\end{tabular}

Tabela 8.49: Médias e desvios padrão das espessuras de epiderme superior das amostras de Gochnatia polymorpha sob condições de Sol e Sombra.

A Tabela 8.50 expressa a taxa de acertos das amostras em ambas as condições. A taxa média de acertos é $73,333 \%$.

\begin{tabular}{|l|c|c|}
\hline G. polymorpha (Sol) & $80 \%$ & $20 \%$ \\
\hline G. polymorpha (Sombra) & $33,333 \%$ & $66,666 \%$ \\
\hline & G. polymorpha (Sol) & G. polymorpha (Sombra) \\
\hline
\end{tabular}

Tabela 8.50: Performance de identificação por RNA via leave-one-out ( $m=30)$ das medidas de espessura de epiderme superior das amostras de Gochnatia polymorpha sob condições de Sol e Sombra.

\subsubsection{Resultados Experimentais do Parênquima Paliçádico}

\section{Coeficientes Tricromáticos}

A Tabela 8.51 expressa os resultados por redes neurais via método leave-one-out nos coeficientes tricromáticos do parênquima paliçádico. A taxa média de acertos foi de $76,666 \%$.

\begin{tabular}{|l|c|c|}
\hline G. polymorpha (Sol) & $80 \%$ & $20 \%$ \\
\hline G. polymorpha (Sombra) & $26,666 \%$ & $73,333 \%$ \\
\hline & G. polymorpha (Sol) & G. polymorpha (Sombra) \\
\hline
\end{tabular}

Tabela 8.51: Performance de identificação por RNA via leave-one-out ( $m=30)$ dos coeficientes tricromáticos das amostras de Gochnatia polymorpha sob condições de Sol e

Sombra.

\section{Matrizes de Co-ocorrência}

Pela busca exaustiva com critério de distância de Jeffrey-Matusita, a máxima distância $J M$ encontrada foi de 0,82124 para matrizes de distância $d=3$. As medidas selecionadas e respectivas matrizes foram: energia (ângulos de $0^{\circ}, 90^{\circ}, 45^{\circ}$ e $135^{\circ}$ ) e entropia (ângulos de $45^{\circ}$, $\left.135^{\circ}\right)$.

A Tabela 8.52 expressa os resultados por redes neurais via método leave-one-out. A taxa média de acertos foi de $80,00 \%$. 


\begin{tabular}{|l|c|c|}
\hline G. polymorpha (Sol) & $80 \%$ & $20 \%$ \\
\hline G. polymorpha (Sombra) & $20 \%$ & $80 \%$ \\
\hline & G. polymorpha $($ Sol) & G. polymorpha (Sombra) \\
\hline
\end{tabular}

Tabela 8.52: Performance de identificação por RNA via leave-one-out ( $m=30$ ) das matrizes de co-ocorrência das amostras de Gochnatia polymorpha sob condições de Sol e Sombra.

\subsubsection{Resultados Experimentais do Parênquima Lacunoso}

\section{Estatísticas de Primeira Ordem}

A busca exaustiva encontrou como máxima distância $J M$ o valor de 0,72493 para a seguinte combinação de medidas: média, obliqüidade e curtose.

A Tabela 8.53 expressa os resultados por redes neurais via método leave-one-out. A taxa média de acertos foi de $76,666 \%$.

\begin{tabular}{|l|c|c|}
\hline G. polymorpha (Sol) & $73,333 \%$ & $26,666 \%$ \\
\hline G. polymorpha (Sombra) & $20 \%$ & $80 \%$ \\
\hline & G. polymorpha (Sol) & G. polymorpha (Sombra) \\
\hline
\end{tabular}

Tabela 8.53: Performance de identificação por RNA via leave-one-out ( $m=30)$ de estatísticas de primeira ordem no parênquima lacunoso das amostras de Gochnatia polymorpha sob condições de Sol e Sombra.

\section{Matrizes de Co-ocorrência}

A busca exaustiva encontrou como máxima distância $J M$ o valor de 0,51357 para matrizes de distância $d=1$. As medidas selecionadas e respectivas matrizes foram as seguintes: energia (ângulos de $0^{\circ} \mathrm{e} 90^{\circ}$ ), contraste (ângulos de $0^{\circ}, 90^{\circ}$ ) e valor absoluto (ângulos de $0^{\circ}, 90^{\circ}$ ).

A Tabela 8.54 expressa os resultados por redes neurais via método leave-one-out. A taxa média de acertos foi de $73,333 \%$.

\begin{tabular}{|l|c|c|}
\hline G. polymorpha (Sol) & $66,666 \%$ & $33,333 \%$ \\
\hline G. polymorpha (Sombra) & $20 \%$ & $80 \%$ \\
\hline & G. polymorpha (Sol) & G. polymorpha (Sombra) \\
\hline
\end{tabular}

Tabela 8.54: Performance de identificação por RNA via leave-one-out ( $m=30$ ) das matrizes de co-ocorrência no parênquima lacunoso das amostras de Gochnatia polymorpha sob condições de Sol e Sombra.

\subsubsection{Medida de Espessura do Corte Transversal}

Na Tabela 8.55 constam as médias e desvios padrão das espessuras medidas. Os exemplares que se desenvolveram sob condição de Sol possuem, em média, uma espessura 160, 7 (pixels) mais elevada. As amostras que cresceram na Sombra apresentam uma variabilidade grande nas 


\begin{tabular}{|l|c|c|}
\hline & G. polymorpha (Sol) & G. polymorpha (Sombra) \\
\hline Média (em pixels) & 748,3 & 587,6 \\
\hline Desvio Padrão (em pixels) & 69,83 & 110,5 \\
\hline
\end{tabular}

Tabela 8.55: Médias e desvios padrão das espessuras do corte transversal das amostras de Gochnatia polymorpha sob condições de Sol e Sombra.

medidas coletadas, de modo que o seu desvio padrão é 40,67 (pixels) maior que os espécimes da condição Sol.

A Tabela 8.56 expressa as percentagens de acertos. Em média, a taxa de identificação correta foi de $76,666 \%$.

\begin{tabular}{|l|c|c|}
\hline G. polymorpha $($ Sol) & $73,333 \%$ & $26,666 \%$ \\
\hline G. polymorpha (Sombra) & $20 \%$ & $80 \%$ \\
\hline & G. polymorpha (Sol) & G. polymorpha (Sombra) \\
\hline
\end{tabular}

Tabela 8.56: Performance de identificação por RNA via leave-one-out ( $m=30)$ das medidas de espessura dos cortes transversais das amostras de Gochnatia polymorpha sob condições de Sol e Sombra.

\subsubsection{Montagem do Vetor de Características}

Com o método de simples concatenação dos vetores componentes, conforme explicado na Seção 7.8, o vetor final assume a forma descrita na Figura 8.17.

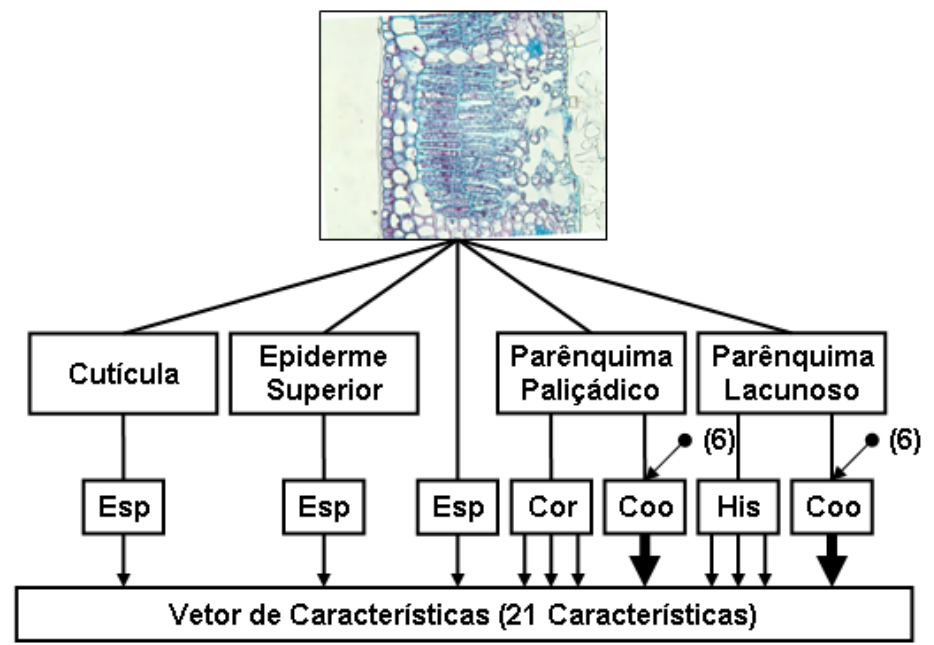

Figura 8.17: Esquema da montagem do vetor de características por concatenação simples. Siglas: Esp - espessura; Cor - coeficientes tricromáticos; His - estatística de $1^{a}$ ordem; Coo matrizes de co-ocorrência.

$\mathrm{O}$ vetor final obtido com a redução da dimensionalidade de algumas das assinaturas componentes pelo método PCA pode ser visualizado na Figura 8.18. No presente caso, essa técnica reduziu o tamanho do vetor final para $71,43 \%$ da dimensionalidade da assinatura obtida por simples concatenação. 


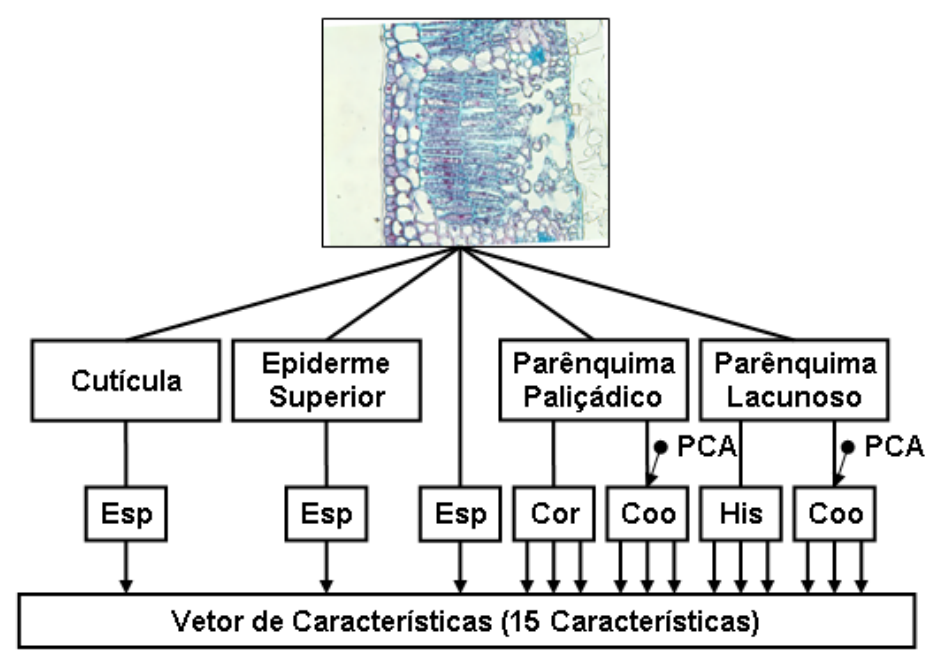

Figura 8.18: Esquema da montagem do vetor de características com o auxílio do método PCA. Siglas: Esp - espessura; Cor - coeficientes tricromáticos; His - estatística de $1^{a}$ ordem; Coo - matrizes de co-ocorrência.

\subsubsection{Resultados e Discussão}

De modo similar aos experimentos com espécies diversas, os vetores descritos na Seção 8.4.6 foram testados com a rede neural apresentada na Seção 7.2 pelo método leave-one-out.

Nos vetores finais obtidos pelo processo de concatenação simples foi aplicado novamente o método PCA para exibição das suas distribuições espaciais. O resultado pode ser visto na Figura 8.19.

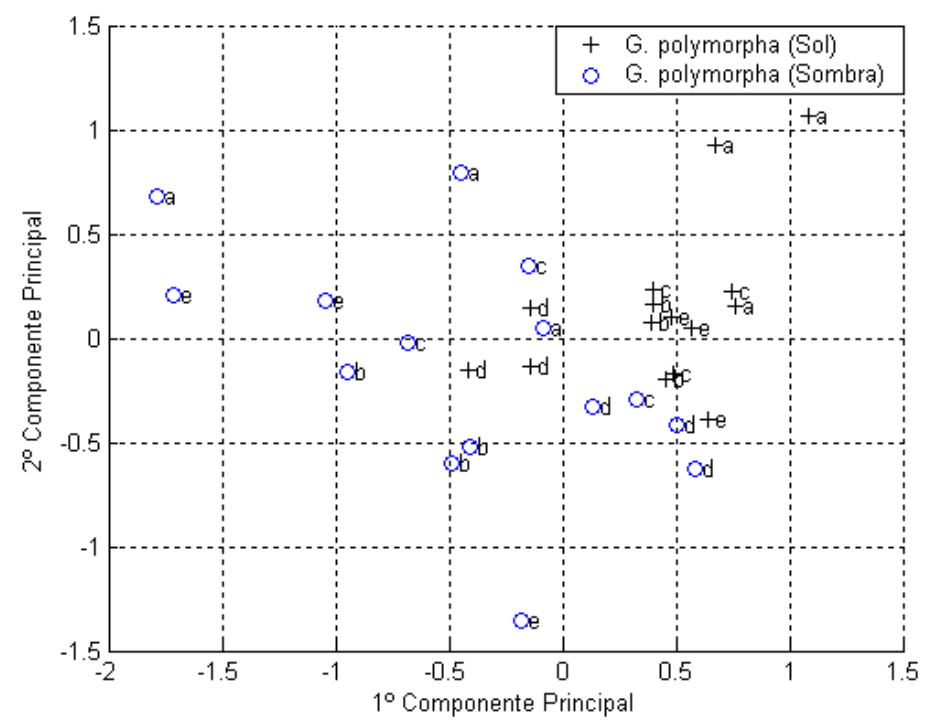

Figura 8.19: Visualização 2D (PCA - dois primeiros componentes principais) do vetor final obtido por concatenação simples (com seleção por distância de Jeffrey-Matusita) dos vetores componentes. 
A Tabela 8.57 demonstra os resultados de identificação alcançados. No presente caso, todas as amostras foram corretamente identificadas.

\begin{tabular}{|l|c|c|}
\hline G. polymorpha (Sol) & $100 \%$ & $0 \%$ \\
\hline G. polymorpha (Sombra) & $0 \%$ & $100 \%$ \\
\hline & G. polymorpha (Sol) & G. polymorpha (Sombra) \\
\hline
\end{tabular}

Tabela 8.57: Performance de identificação média obtida por validação cruzada leave-one-out ( $m=30$ ) do vetor final obtido por simples concatenação (com seleção por distância de Jeffrey-Matusita) dos vetores componentes.

A Figura 8.20 exibe a plotagem dos dois principais componentes (método PCA) dos vetores de características finais que foram obtidos com o auxílio do método PCA na redução da dimensionalidade de algumas das assinaturas componentes (ver Figura 8.18). Pela visualização, é possível perceber nitidamente a separação das amostras que se desenvolveram em ambas as condições (Sol e Sombra).

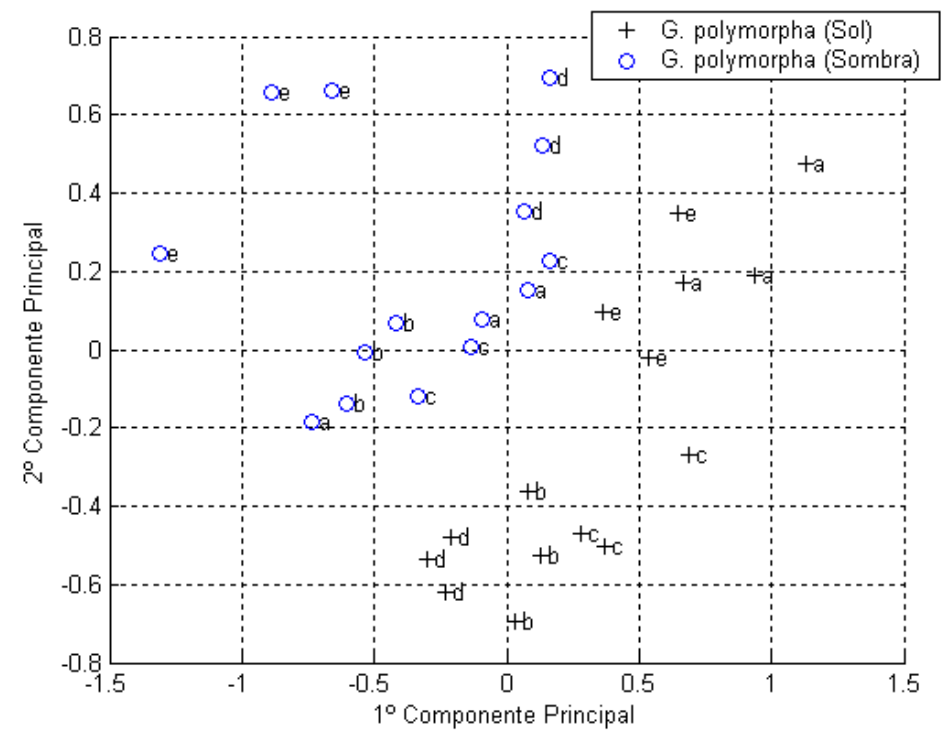

Figura 8.20: Visualização 2D (PCA - dois primeiros componentes principais) do vetor final obtido por aplicação do método PCA nos vetores componentes cujas dimensionalidades são maiores que três

A Tabela 8.58 apresenta os resultados de identificação obtidos pela abordagem com PCA. Por essa segunda abordagem, todas as amostras também foram corretamente identificadas.

\begin{tabular}{|l|c|c|}
\hline G. polymorpha (Sol) & $100 \%$ & 0 \\
\hline G. polymorpha (Sombra) & 0 & $100 \%$ \\
\hline & G. polymorpha (Sol) & G. polymorpha (Sombra) \\
\hline
\end{tabular}

Tabela 8.58: Performance de identificação obtida por validação cruzada leave-one-out $(m=30)$ do vetor final obtido por aplicação do método PCA nos vetores componentes cujas dimensionalidades são maiores que três. 
Neste experimento todas as medidas coletadas ofereceram boas taxas de acertos, o que explica o fato de todas as amostras terem sido corretamente identificadas com ambos os vetores finais descritos na Seção 8.4.6. Nesse caso, vale enfatizar a contribuição da medida de cutícula, de espessura do corte transversal e das matrizes de co-ocorrência no parênquima paliçádico, com $83,333 \%, 76,666 \%$ e $80,00 \%$ de performance, respectivamente.

Pela visualização dos vetores, foi possível perceber que algumas amostras de uma mesma folha se destacaram um pouco. Na Figura 8.19 há um pequeno distanciamento de duas amostras a e três amostras d dos espécimes que se desenvolveram sob Sol. Já na Figura 8.20, que representa as melhores assinaturas finais, há um destaque das amostras e e d da condição Sombra, além das amostras a e d da condição Sol. 


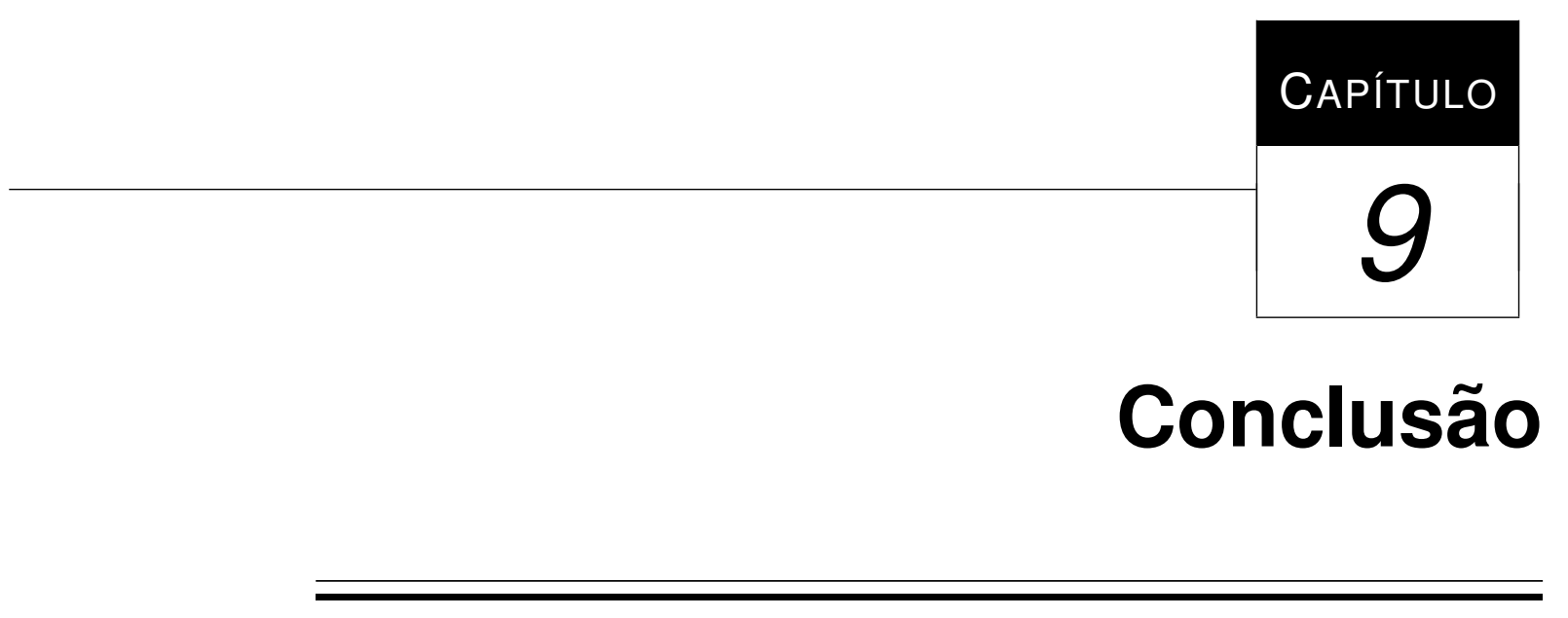

Este trabalho demonstrou que é possível identificar vegetais por meio da análise computacional do corte transversal de uma folha. Os resultados alcançados mostraram excelentes taxas de acertos, tanto na identificação de espécies diferentes como na análise de alterações morfológicas de uma mesma espécie que se desenvolveu em diferentes ambientes, estações ou condições de luminosidade.

Dentre as técnicas de extração de características aplicadas nos diferentes tecidos da folha, o método de matrizes de co-ocorrência obteve os melhores resultados. A seguir, as contribuições mais significativas foram dadas pelos métodos de estatística de primeira ordem, BoxCounting 3D, coeficientes tricromáticos e caminhada determinística do turista, em ordem decrescente de relevância. As medidas de espessura de cutícula, epiderme superior e corte transversal, embora possuam apenas um atributo cada uma, foram fundamentais, principalmente em algumas espécies (Vochysia tucanorum, por exemplo) nas quais as assinaturas de cor e textura não foram tão eficientes.

No experimento com espécies diversas, a região do corte transversal que ofereceu as melhores assinaturas foi a epiderme superior, cuja média das taxas de acertos de cada vetor obtido foi aproximadamente $62,00 \%$. Além disso, o método de estatísticas de primeira ordem aplicado nessa região resultou na máxima taxa de acertos de uma assinatura individual, ou seja, 85, 00\%. A seguir, a região do parênquima lacunoso contribuiu com uma taxa média de acertos das assinaturas de aproximadamente $51,88 \%$, sendo que as matrizes de co-ocorrência nessa região resultaram numa taxa de identificação de $82,50 \%$. O parênquima paliçádico ofereceu uma taxa média de acertos de 41,55\% e teve como taxa máxima de uma assinatura individual o valor 
de $63,75 \%$ por meio de matrizes de co-ocorrência. A cutícula, por oferecer apenas medida de espessura, contribuiu com uma taxa de identificação correta de $31,25 \%$.

Por outro lado, nos experimentos com a espécie Gochnatia polymorpha, a cutícula foi importante na separação das amostras, tanto pela qualidade das assinaturas obtidas como pelo fato de que as medidas de cor e textura nem sempre ofereceram bons resultados. A medida dessa camada ofereceu excelentes resultados nos três experimentos, com 76,666\%, 76, 666\% e 83, 333\% de acertos nos ambientes Cerrado e Mata Ciliar, nas estações Chuvosa e Seca, e sob condições de Sol e Sombra, respectivamente. O parênquima paliçádico e lacunoso, com exceção do experimento nos ambientes Cerrado e Mata Ciliar, oferereçam vetores com performances muito parecidas, no intervalo entre $73,333 \%$ e $83,333 \%$ de acertos.

Em relação às duas abordagens para concatenação das assinaturas, o método com diminuição de dimensionalidade por PCA se mostrou superior tanto por ter oferecido taxas superiores de acertos em dois experimentos (nos demais experimentos a taxa de acertos foi igual à concatenação simples), como por ter diminuído a quantidade de atributos no vetor final. Nos testes com espécies diversas, devido ao maior número de vetores adquiridos, a diminuição de dimensionalidade foi muito acentuada, reduzindo o vetor final a 36 atributos, ou seja, 20, $11 \%$ do vetor obtido por simples concatenação.

Finalmente, pela plotagem 2D dos vetores finais obtidos pelos métodos acima citados, foi possível perceber que, embora houvesse alguns agrupamentos de vetores extraídos de imagens pertencentes à uma mesma folha, a tendência geral foi que as assinaturas de folhas diferentes de uma mesma espécie permanecessem misturadas. Isso demonstrou que o modo como as imagens foram adquiridas foi válido e que não há diferença relevante entre diferentes imagens de uma mesma folha e imagens de folhas distintas.

\subsection{Contribuições}

Este trabalho trouxe contribuições importantes para a tarefa de identificação de vegetais e análise histológica de folhas. São elas:

- Comprovação de que é possível identificar espécies vegetais pela análise computacional do corte transversal de uma folha.

- Comprovação de que é possível aferir por métodos computacionais alterações morfológicas de uma mesma espécie vegetal que se desenvolveu em diferentes ambientes, estações ou condições de luminosidade.

- Descrição das regras para que o algoritmo do funcional de Mumford-Shah segmente a cutícula e a epiderme superior de forma eficiente.

- Descrição da performance de alguns métodos de extração de características aplicados nas diferentes regiões do corte transversal da folha. 
- Descrição de como combinar os vetores de características obtidos da cutícula, epiderme superior, parênquima paliçádico e parênquima lacunoso para a obtenção de um vetor final da amostra (folha) cuja performance de discriminação seja melhor do que o desempenho dos vetores componentes.

\subsection{Perspectivas}

Este trabalho pode ser expandido e há muita coisa para acrescentar. Primeiramente, ainda podem ser retirados vetores de características de regiões não exploradas da estrutura interna da folha. Um exemplo é a epiderme inferior, que não foi analisada devido à dificuldade de separá-la automaticamente do parênquima lacunoso. Outrossim, é possível analisar a proporção de área ocupada no mesofilo pelo parênquima lacunoso e parênquima paliçádico, além da definição automática de quantas camadas de células este último possui. Adicionalmente, outros métodos de extração de características podem ser aplicados, melhorando o grau de precisão do sistema.

Uma vez solucionado o problema da extração de características das regiões, o sistema pode ser melhorado pela coleta automática das janelas (janelas $60 x 60$ do parênquima paliçádico, por exemplo) que representam as diferentes regiões da folha. Pelo que já foi desenvolvido, esse problema está parcialmente resolvido. Pela segmentação do pano de fundo é possível colocar as janelas nas posições corretas para a análise da cutícula, da medida do corte transversal e da epiderme superior - no caso da cutícula, um número substancial de janelas será necessário, uma vez que ela freqüentemente se apresenta irregular ao longo da borda da folha. Com a segmentação da epiderme superior, conforme explicado na Seção 7.4, é possível coletar automaticamente janelas do parênquima paliçádico. No caso das janelas do parênquima lacunoso, a dificuldade aumenta, posto que muitas vezes é visualmente difícil definir a fronteira entre este e o parênquima paliçádico.

Com os algoritmos já descritos e as melhorias supracitadas, este projeto pode ser utilizado na resolução de outros problemas. Um deles seria a aplicação do sistema desenvolvido na identificação de táxons que apresentam um real problema na delimitação taxonômica. Outra possibilidade seria averiguar se o ataque de pragas (insetos, fungos ou viroses) já causa anomalias na estrutura interna da folha antes que atinjam estágios que, quando perceptíveis visualmente, já tenham comprometido o investimento envolvido. Uma outra vertente seria a análise de deficiências nutricionais e de que modo elas influenciam na estrutura celular da folha. Os resultados alcançados demonstram que a abordagem apresentada é promissora e que pode ser o gérmen de significativos trabalhos vindouros. 



\section{Referências Bibliográficas}

Alquini, Y.; Bona, C.; Boeger, M. R. T.; Costa, C. G.; Barros, C. F. Epiderme. In: Anatomia Vegetal, Appezzato-da-Glória, B. Z. \& Carmello-Guerreiro, S. M. (eds), Viçosa, Editora UFV, 2003, p. 87-108.

Ash, A.; Ellis, B.; Hickey, L. J.; Johnson, K.; Wilf, P.; Wing, S. Manual of leaf architecture - morphological description and categorization of dicotyledonous and net-veined monocotyledonous angiosperms by leaf architecture. http://www.peabody.yale.edu/collections/pb/mla/mla.pdf., 1999.

BACKES, A. R. Implementação e comparação de métodos de estimativa de dimensão fractal e sua aplicação à análise e processamento de imagens. Dissertação de mestrado, ICMC-USP, 2006.

Backes, A. R.; Bruno, O. M.; Campiteli, M. G.; Martinez, A. S. Deterministic tourist walks as an image analysis methodology based. In: CIARP, 2006, p. 784-793.

BALA, J. W. Combining structural and statistical features in a machine learning technique for texture classification. In: IEA/AIE, 1990, p. 175-183.

Braga, A. P.; CARValho, A. C. P. L. F.; Ludermir, T. B. Redes neurais artificiais. LTC - Livros Técnicos e Científicos Editora S.A, 2000.

BRUnO, O. M. Paralelismo em visão natural e artificial. Tese de doutorado, IFSC-USP, 2000.

Bruno, O. M.; Plotze, R. O.; Falvo, M.; De Castro, M. Fractal dimensions applied to plant identification. Information Sciences, v. (in press - março/abril de 2008), 2008.

Campiteli, M. G.; Batista, P. D.; Kinouchi, O.; Martinez, A. S. Deterministic walks as an algorithm of pattern recognition. Physical Review E, v. 74, n. 2, 2006a. 
Campiteli, M. G.; Martinez, A. S.; Bruno, O. M. An image analysis methodology based on deterministic tourist walks. In: IBERAMIA-SBIA, 2006b, p. 159-167.

CARLIN, M. Measuring the complexity of non-fractal shapes by a fractal method. PRL: Pattern Recognition Letters, v. 21, n. 11, 2000.

Carvalho, M. A. G. Análise hierárquica de imagens através da árvore dos lagos críticos. Tese de doutorado, Faculdade de Engenharia Elétrica e de Computação-UNICAMP, 2004.

CESAR, JR., R. M.; CostA, L. F. Shape analysis and classification: Theory and practice. CRC Press, 2001.

Chambolle, A. Image segmentation by variational methods: Mumford and Shah functional and the discrete approximations. SIAM J. Appl. Math., v. 55, n. 3, p. 827-863, 1995.

Chaudhuri, B. B.; SARKar, N. Texture segmentation using fractal dimension. IEEE Trans. Pattern Anal. Mach. Intell, v. 17, n. 1, p. 72-77, 1995.

CHEn, C. H.; PAU, L. F.; WAN, P. S. P. The handbook of pattern recognition and computer vision. World Scientific Publishing Co, 1998.

Duda, R. O.; Hart, P. E.; Stork, D. G. Pattern classification. 2nd ed. WileyInterscience, 2001.

FALVO, M. Identificação de espécies vegetais por meio da análise do contorno foliar - uma abordagem bio-inspirada. Dissertação de mestrado, ICMC-USP, 2005.

FIDAlgo, O.; BonONi, V. L. R. Técnicas de coleta, preservação e herborização de material botânico. Instituto de Botânica - São Paulo, 1989.

FUKUnAGA, K. Introduction to statistical pattern recognition. Academic Press, 1990.

GonZalez, R. C. Digital image processing. Addison-Wesley, 1987.

Haralick, R. M. Statistical and structural approaches to texture. Proceedings of the IEEE, v. 67, n. 5, p. 786-804, 1979.

HAYKIn, S. Neural networks. Prentice Hall, 1999.

Huber, R.; Dutra, L. Feature selection for ers 1/2 insar classification: High dimensionality case. In: Proceedings of International Geoscience and Remote Sensing Symposium, 1998, p. 1605-1607.

Jain, A. K.; DuIn, R. P. W.; MaO, J. Statistical pattern recognition: A review. IEEE Transactions on Pattern Analysis and Machine Intelligence, v. 22, n. 1, p. 4-37, 2000. 
JÄHNE, B. Practical handbook on image processing for scientific applications. CRC - Press, 1997.

Justo, C. F.; Soares, A. M.; Gavilanes, M. L.; Castro, E. M. Leaf anatomical plasticity of Xylopia brasiliensis sprengel (annonaceae). Acta Botânica Brasílica, v. 19, p. 111-123, 2005.

Materka, A.; Strzelecki, M. Texture analysis methods - a review. Technical University of Lodz, Institute of Electronics, COST B11 report, Brussels, 1998.

Mingoti, S. A. Análise de dados através de métodos de estatística multivariada. Editora UFMG, 2005.

MoreIRA, J. Uma proposta de estruturação e integração de processamento de cores em sistemas artificiais de visão. Tese de doutorado, IFSC-USP, 1999.

Mumford, D.; ShaH, J. Optimal approximations by piecewise smooth functions and associated variational problems. Comm. Pure Appl. Math., v. 42, n. 5, p. 577-685, 1989.

Nultsch, W. Botânica geral. ArtMed - Editora Artes Médicas Sul Ltda, 1996.

Oliveira, E. C. Introdução à biologia vegetal. Edusp - Editora da Universidade de São Paulo, 1996.

PAzoti, M. A.; BRUno, O. M. Aplicação da transformada Watershed no processo de separação de objetos. Relatório técnico, ICMC-USP, 2004.

Petitot, J. An introduction to the mumford shah segmentation model. Journal of Phisiology, v. 97, n. 2-3, p. 335-342, 2003.

Plotze, R. O. Identificação de espécies vegetais através da análise da forma interna de órgãos foliares. Dissertação de mestrado, ICMC-USP, 2004.

Plotze, R. O.; Falvo, M.; Pádua, J. G.; Bernacci, L. C.; Vieira, M. L. C.; OliVEIRA, G. C. X.; Bruno, O. M. Leaf shape analysis using the multiscale fractal minkowski dimension, a new morphometric method: a study with Passiflora (Passifloraceae). Canadian Journal of Botany, v. 83, n. 3.1, p. 287-315, 2005.

RôÇAS, G.; SCARANO, C. F. Leaf anatomy plasticity of Alchornea triplinervia (euphorbiaceae) under distinct light regimes in a brazilian montane atlantic rain forest. Trees, v. 11, p. 469-473, 1997.

Raven, P. H.; Evert, R. F.; Curtis, H. Biologia vegetal. Guanabara Dois, 1978. 
Roncatti, M. R.; Batista Neto, J. E. S. Avaliação do branch-and-bound para seleção de características. In: Anais do III Workshop de Visão Computacional - São José do Rio Preto - SP, 2007, p. 94-97.

Russ, J. C. The image processing handbook. 4th ed. CRC Press, 2002.

S Antos, D. P. Seleção de características: abordagem via redes neurais aplicada à segmentação de imagens. Dissertação de mestrado, ICMC-USP, 2007.

Stace, C. A. Plant taxonomy and biosystematics. 2nd ed. Cambridge: Cambridge University Press, 1989.

STERN, K. R. Introductory plant biology. WCB, 1994.

Theodoridis, S.; Koutroumbas, K. Pattern recognition. Academic Press, 1999.

WebB, A. Statistical pattern recognition. 2nd ed. Willey, 2002.

XU, S.; WEng, Y. A new approach to estimate fractal dimensions of corrosion images. Pattern Recognition Letters, v. 27, n. 16, p. 1942-1947, 2006. 